
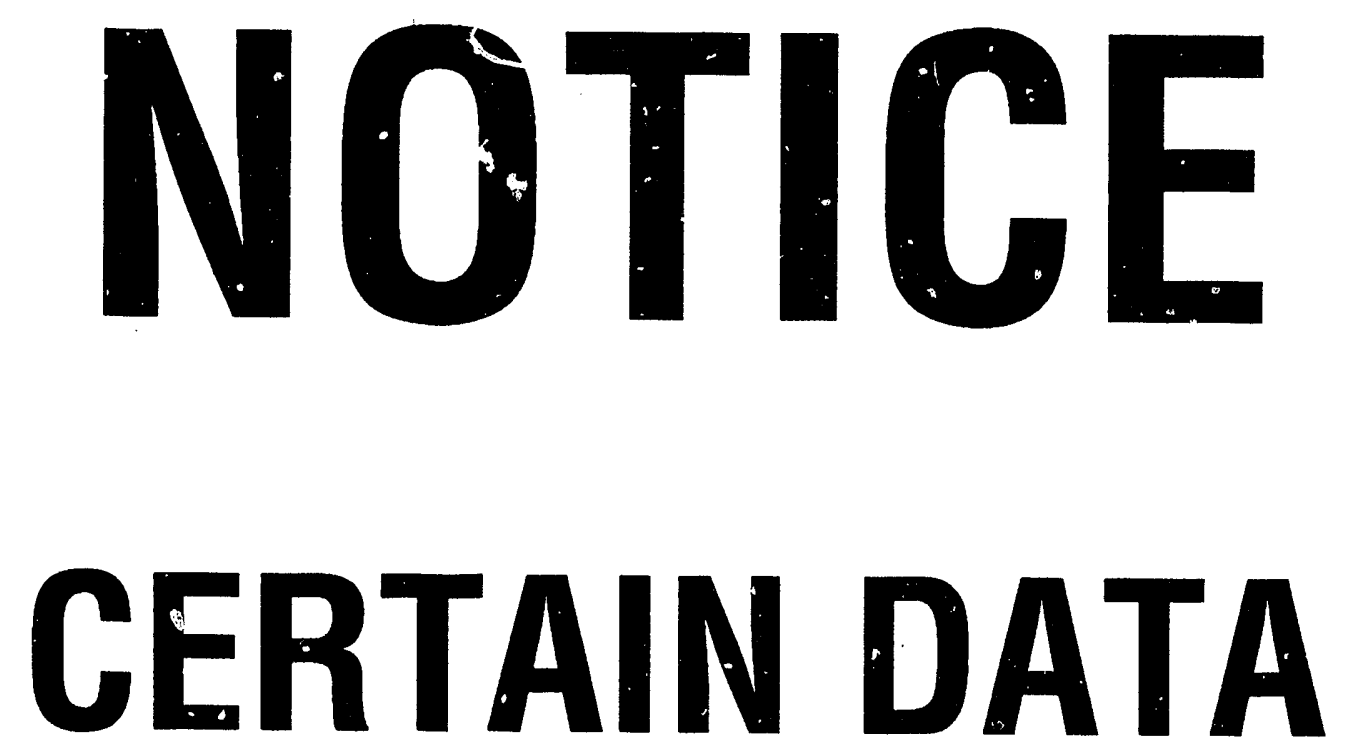

CONTAINED IN THIS

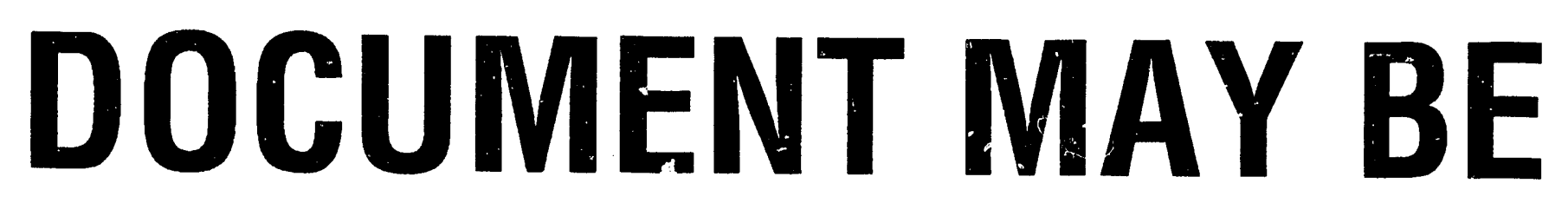

\title{
DIFFICULT TO READ
}

IN MICROFICHE

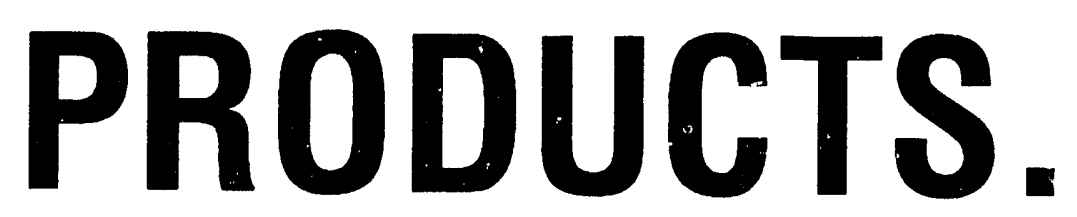


$5.9985(2)$

PPPL-2788

UC-420
PREPARED FOR THE U.S. DEPARTMENT OF ENERGY, UNDER CONTRACT DE-AC02-76-CHO-3073

PPPL-2788

FACILITIES FOR TECHNOLOGY TESTING OF ITER DIVERTOR CONCEPTS, MODELS, AND PROTOTYPES IN A PLASMA ENVIRONMENT

BY

\author{
S.A. COHEN
}

December 1991
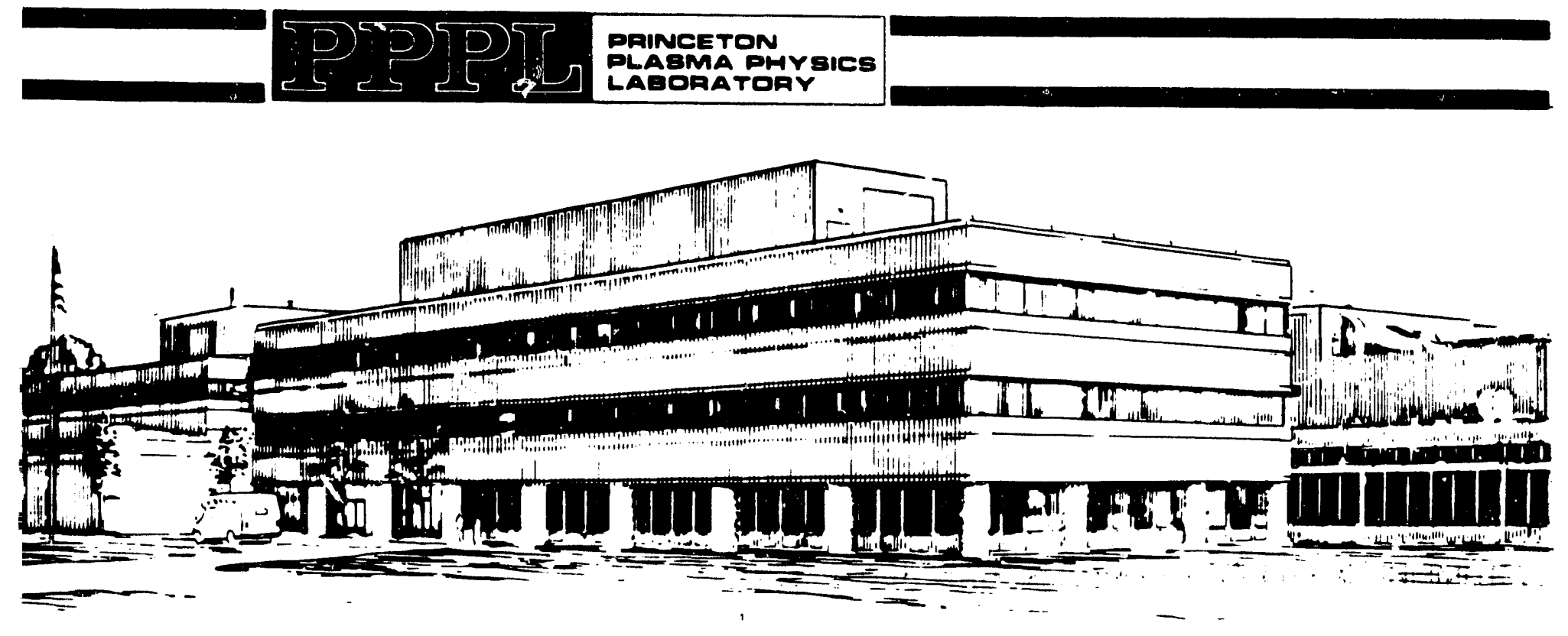


\section{NOTICE}

This report was prepared as an account of work sponsored by an agency of the United States Government. Neither the United States Government nor any agency thereof, nor any of their employees, makes any warranty, express or implied, or assumes any legal liability or responsibility for the accuracy, completeness, or usefulness of any information, apparatus, product, or process disclosed, or represents that its use would not infringe privately owned rights. Reference herein to any specific commercial produce, process, or service by trade name, trademark, manufacturer, or otherwise, does not necessarily constitute or imply its endorsement, recommendation, or favoring by the United States Government or any agency thereof. The views and opinions of authors expressed herein do not necessarily state or reflect those of the United States Government or any agency thereof.

\section{NOTICE}

This report has been reproduced directly from the best available copy.

Available to DOE and DOE contractors from the:

Office of Scientific and Technical Information

P.O. Box 62

Oak Ridge, TN 37831 ;

Prices available from (615) 576-8401.

Available to the public from the:

National Technical Information Service

U.S. Department of Commerce

5285 Port Royal Road

Springfield, Virginia 22161

703-487-4650 
Facilities for Technology Testing of ITER Divertor Concepts, Models, and Prototypes in a Plasma Environment

\author{
Prepared by \\ S. A. Cohen \\ Plasma Physics Laboratory \\ Princeton University
}

with contributions from:

P. Bonanos, J. Brooks, G. Chiu, R. Conn, N. Hershkowitz, D. Hill, Y. Hirooka, R. Mattas, P. Mioduzewski, R. Nygren, M. Peng, C.S. Pitcher, D. Smith, R. Watson, K. Wilson, T. Yang,

Prepared for the US Department of Energy under contract DE-AC02-76-CHO-3073. June 1991 


\begin{abstract}
The exhaust of power and fusion-reaction products from ITER plasma are critical physics and technology issues from performance, safety, and reliability perspectives. Because of inadequate pulse length, fluence, flux, scrape-off layer plasma temperature and density, and other parameters, the present generation of tokamaks, linear plasma devices, or energetic beam facilities are unable to perform adequate technology testing of divertor components, though they are essential contributors to many physics issues such as edge-plasma transport and disruption effects and control. This Technical Requirements Documents presents a description of the capabilities and parameters divertor test facilities should have to perform accelerated life testing on predominantly technological divertor issues such as basic divertor concepts, heat load limits, thermal fatigue, tritium inventory and erosion/redeposition. The cost effectiveness of such divertor technology testing is also discussed.
\end{abstract}




\section{Preface}

There are many classes of problems which must be addressed to make controlled thermonuclear fusion a viable option for energy production. Among the most pressing, from performance, safety, reliability, and timeliness perspectives, are issues associated with the exhaust from the plasma of power and fusion-reaction products. Components designed to accomplish these tasks for ITER can only do so marginally. Their application to a demonstration power plant is not considered probable. Serious doubts and uncertainties exist on both physics and engineering levels.

A major reason for this poor situation is the very limited attention given to these power and particle control issues in comparison with the efforts expended on core plasma confinement. Now that an extensive database for the core plasma has been established through two decades of focussed research supplemented by special task forces, e.g., the transport initiative, tokamak scientists throughout the world fusion program are expanding their interests into the edge plasma region. Extensive studies of divertors have started, highlighted by on-going ADP experiments on DIII-D and ALT-II studies on TEXTOR, and soon-to-start divertor experiments on ASDEXUpgrade, JET, JT-60U, and Alcator-Cmod. These may well answer those difficult edge physics questions raised by the ITER team and its predecessors on INTOR, Starfire, UWMAK, and other rector designs.

There remain, however, technical challenges that cannot be answered in the present generation of tokamaks because of inadequate pulse lengths, fluences, fluxes, or other parameters. Awareness of these deficiencies has led several groups of scientists to propose technology facilities to address these issues. The purpose of this Technical Requirements Documents is to present to the fusion community a coherent and complete description of the capabilities a technology test facility should have to address these divertor issues. Only through an aggressive technology test program, can adequate safety and reliability be attained.

Part of this document is tutorial in that it explains why certain parameter values must be achieved. The choice of these parameters and their values are set by the detailed design requirements for the ITER device. This document grew out of results and discussions presented in a series of DOE-sponsored ITER workshops held at Princeton University's Plasma Physics Laboratory during 1989 - 1991.

I wish to thank Dr. Marvin Cohen of the US Department of Energy for his encouragement and direction in the preparation of this report.

Samuel A. Cohen

Plasma Physics Laboratory

Princeton University

June 1991 


\section{Table of Contents}

Preface

I. Summary-

I.1. Evaluation of the ITER divertor design

I.2. Redressing the problems

II. Introduction-

III. Generals aspects of power and particle control and divertor design for ITER-

III.1. Divertor functions

III.2. Impact of divertor reliability and operation on ITER schedule and cost

III.2.1. Heat removal

III.2.2. Plasma purity

III.2.3. Helium exhaust

III.2.4. Costs and schedule

III.3. International collaboration

III.4. Time scale for contributions to ITER

III.5. Facilities

IV. Issues to be addressed-

IV.1. Technology issues

IV.2. Physics issues

V. Divertor plasma parameters-

V.1. Existing data base

V.2. Predicting ITER's divertor plasma parameters

V.2.1. Plasma temperature, density, and heat flux

V.2.2. Helium exhaust

VI. Engineering design of the divertor

VII. Technical requirements

VII.1. Cyclic heat flux capacity

VII.2. Erosion/redeprsition

VII.3. Safety issues

VII.4. Helium exhaust

VII.5. Disruption effects

VII.6. New divertor concepts

VIII. Candidate designs

VIII.1. Plasma devices

VIII.2. Linear configurations

VIII.3. Toroidal configurations

IX. Recommendations-

$X$. Appendices
A. IDEAL
B. SST
C. ATF
D. RFTF
E. CMTF 


\section{SUMMARY}

\section{I.1. Evaluation of the ITER divertor design}

The US National ITER-CDA Review Panel reached the following conclusions:

1. The present divertor design is "marginally capable of achieving the ITER objectives."

2. Added "margin of assurance for achieving the testing objectives" is necessary.

3. "Divertor-region temperature and heat loads have not been resolved [for current drive scenarios]."

4. "Understanding the heat loads to the divertor is crucial."

5. "The issues of reliability and maintainability should become high level drivers of design. Design should explore the development of advanced divertor concepts."

6. "Tests [of high- $Z$ metals] in a diverted tokamak are essential."

7. "Development of active disruption control techniques is a high priority."

8. "An aggressive mandated physics/technology R\&D effort to address these issues should be given the top priority."

9. "The cost of [an advanced materials test facility] is probably much higher than included in the R\&D plan."

Weaknesses of the present divertor design are clear. It relies on the unproven capabilities of redeposition to increase plate lifetime nearly 100-fold and of power-load sweeping to avoid burnout without thermal fatigue. In situ repair techniques are untested and plainly most difficult in an activated device. Ablation by disruptions is predicted to shorten divertor plate lifetime a factor of 10 compared to normal operation. Disruption-induced runaway electrons pose a distinct safety risk.

\section{I.2. Redressing the problems}

As recognized by the US Review Panel, physics R\&D tasks, particularly those unique to toroidal geometry, must be addressed in tokamak experiments. Included in this category are disruption issues (frequency, power loads, forces, and runaway electron impacts) and steady-state SOL conditions (SOL plasma parameters and transport coefficients, and poloidal and toroidal asymmetries).

Resolution of technology issues, especially safety and reiability, require high power plasma facilities, which have access for prototype divertor test modules and the capability of accelerated life testing in an intense plasma environment identical to that predicted for ITER. Informal proposals to build both linear and toroidal technology facilities have already been made.

This report recommends the following for the divertor technology facilities:

1. During FY 1992, financial support be given to two groups to pursue the analysis of

two generic site-blind designs, one for a linear and one for a toroidal plasma device.

2. A review of the findings and facility selection be made at the end of FY 1992.

3. Construction of the selected facilities be completed in FY 1994.

4. A consortium of universities, national laboratories, and industry - a national model for the ITER project - and international participants should contribute to the project.

Separate responsibilities might include magnet, vacuum, diagnostic, and heating systems and divertor materials and prototype divertor module fabrication.

j. Present support levels for existing D\&T technology facilities should be maintained. 


\section{INTRODUCTION}

The ITER conceptual design activity and the US National ITER CDA Review Panel have identified several critical technological issues associated with the divertor. These include: potential for fatigue or component failure during repeated thermal cycling of the divertor in its plasma environment; the accuracy of coolant tube burn-out models; the validity of erosion/redeposition models for predicting plasma-facing component (PFC) lifetimes; tritium inventory in and physical stability of co-deposited films on the divertor plates; viability of novel divertor designs, e.g., high- $Z$ materials, gaseous neutralizers, or liquid metal divertors; and helium and $D / T$ exhaust efficiencies due to the geometry and materials of the divertor plate/pump duct region.

Disruption effects and SOL plasma physics scalings are also critical. Physics aspects of these are planned be addressed by Physics R\&D tasks in existing tokamaks and are discussed only briefly in this document.

Tests of divertor configurations date back to the C-Stellarator. More recent experience has been gained on ASDEX, DIII-D, JET, JT-60, and PBX-m. New results should be available this year on Alcator-Cmod, ASLEX-Upgrade, and JT-60U. Results from JET's impurity control divertor are scheduled to arrive in 1992-1993. But present tokamaks (and ones scheduled to operate during this decade) are deficient for testing most technology questions on divertor prototypes, models, and concepts because of inadequacies in pulse length, fluence, peak power load, cyclic power load, peak density, peak flux, diagnostic access, geometry, and size. Present tokamaks can only provide a small fraction $\left(10^{-4}\right)$ of the lifetime ITER particle fluence on the divertor, less than $10 \%$ for each of the recycling rate, peak particle flux, or divertor opacity to neutrals, less than $20 \%$ of the divertor depth, and less than $50 \%$ of the peak power load. From the viewpoint of technology testing, other aspects of ITER divertor simulation on present tokamaks are highly questionable. In stark contrast, present tokamaks could be efficiently used for critical studies of disruptions, vertical displacement events, toroidal/poloidal asymmetries, scaling of edge plasma transport relitions, and other physics issues which are essentially unique to toroidal configurations.

Earlier proposals to build continuously operating divertor simulators have been made at ANL, University of Wisconsin, University of Toronto, and elsewhere. The focus of each these earlier proposals was generally on one aspect of divertor operation, such as erosion/redeposition or tritium reprocessing. The ITER team recognized, in its 198990 Technology R\&D document, the need for a divertor test facility. This, too, had one major goal, namely erosion/redeposition. Now th the final ITER Conceptual Design Report has been produced and analyzed by numerous national (US and foreign) review committees, the crucial need for a more ambitious divertor technology test program has become clear. We emphasize the necessity of this test program to ensure divertor reliability.

One purpose of this Technical Requirements Document is to examine what devices can provide divertor component, prototype, and model testing for ITER. We shall briefly address whether the technical requirements mandate plasma or charged-particle beam facilities or a single or multiple devices. Later assessments ivill evaluate which is most cost effective. Final decisions on these questions await more detailed design studies of the candidate devices. 
Facility parameters must be set for proper engineering, cost, and schedule analysis. These parameters include magnetic field strength, device size and shape, power input, and plasma parameters. Heating methods to achieve the plasma parameters, e.g., ICRF, LH, EC, and EB waves or NBI, must be appraised.

Specialized skills are required for designing, constructing, and operating each of the systems which comprise the divertor test facility. The best input will come through fully integrated activities within the D\&T, APP and Confinement System communities, i.e., tasks should be shared amongst the laboratories expert in materials development, thermal hydraulics, magnetics, diagnostics, plasma heating, and so-forth.

We propose for FY 1992 a combined engineering and physics assessment of designs and design concepts for plasma devices that would enable an accelerated life testing program for prototype divertor structures on technology issues. The selected design would be called the ITER Divertor Experiment and Laboratory (IDEAL). Included in this task are considerations of the use of existing devices and of proposed new toroidal and linear plasma devices. A final engineering design would be produced in 1993; construction and c peration of the IDEAL device would follow (1993-1994).

Section III describes the importance of divertor design and power and particle control to ITER and how international collaboration may aid in resolving these issues. In Section IV are listed technology and physics issues to be addressed. The divertor plasma parameters expected for ITER are discussed in Section V. Present engineering design considerations are presented in Section VI, and what must be attained in the divertor technology facilities is in Section VII. In section VII we discuss what technical requirements must be met by these facilities and consider whether all issues should/could be addressed in one facility or whether several facilities are the appropriate choice. Section VIII describes two generic types of facilities that could be used for these testing and R\&D programs. Section IX gives recommendations on how to proceed. The appendices contain more detailed descriptions of some candidate designs. 


\section{GENERAL ASPECTS OF POWER AND PARTICLE CONTROL AND DIVERTOR DESIGN FOR ITER}

\section{III.1. Divertor functions}

Operation of the ITER device will require the exhaust of power deposited in the plasma by the energetic fusion alphas generated in fusion reactions and the subsequent removal of the thermalized helium ash. The component chosen to meet these requirements is a high-recycling divertor. Its advantage for helium ash removal is clear in that it concentrates the helium atoms in a relatively small volume appropriate for exhaust by conventional vacuum pumps. Its appropriateness for power exhaust is open to question because divertors, of virtually any design, only subtend a small fraction of the available surface area of the vacuum vessel and hence are likely to have higher peak power loads than ideally possible. However, several other requirements for the power and particle control system also favor high-recycling divertors. These are low impurity generation and long component lifetime. High-recycling divertors are predicted to reduce core impurity content by the formation of cold dense plasmas $\left(T_{e}<50 \mathrm{eV}\right)$ near material surfaces, thus reducing sputtering, and by cneir ability to ionize impurity atoms from the walls ard divertor plates, thus preventing these impurities from promptly crossing the separatrix into the plasma core. Both promote long plasma-facing component lifetimes and eased helium-exhaust requirements.

For the reference ITER design, calculations were made to test the adequacy of a high-recycling divertor for achieving the favorable divertor plasma conditions just described. These calculations were performed for a wide range of proposed ITER operating conditions and for a variety of "conventional" solid-plate divertor designs. Uncertainties in the physics input parameters and simplifications in the physics models were seen to make plausible severe divertor conditions, particularly during steadystate operation.

From engineering considerations of detailed divertor designs (see Section VI), including material thermal conductivities and sublimation temperatures, and safety margin for coolant channel burnout, it was found that the peak steady-state surface power load tolerable was about $15 \mathrm{MW} / \mathrm{m}^{2}$. This value, a factor of two lower than that predicted for reference ITER ignition scenario, necessitated the inclusion of heat load sweeping in the divertor design to reduce the time-average power load. Indeed, presently operating tokamaks have experienced divertor and limiter power loads exceeding their capabilities; occasional divertor tile failures or rapid impurity releases, e.g., carbon blooms, have occurred in most tokamaks. As described later, even with sweeping included, several, but not all, ITER operating scenarios would have sufficiently low divertor power loads and erosion rates. It is not coincidental that those scenarios with adequately low peak power loads and erosion rates are also predicted to have adequate helium exhaust.

The divertor must also withstand off-normal operation, the prime example of which is the disruption. Predictions of disruption frequency and associated divertor erosion show that disruptions are likely to be the major divertor lifetime limiting factor and hence merit extensive R\&D. Disruptions also impact the safety of the ITER design in a crucial way because of their potential to produce energetic runaway electrons which may penetrate through divertor plate tiles and rupture the coolant tubes in the 
structures below. Studies of disruption frequency, severity, and control are scheduled to be carried out on existing tokamaks under the voluntary Physics R\&D plan.

Part of the ITER Conceptual Design mission was to select components that would be suitable for commercial reactors. A DEMO is expected to have about a 3 -fold higher fusion power (density) than ITER. Thus, the divertor conditions will be even more severe in DEMO. Testing the ITER divertor design to accommodate DEMIO's heat exhaust has been named as an ultimate goal of ITER operation.

\section{III.2. Impact of divertor reliability and operation on ITER schedule and cost}

If the divertor were to fail occasionally in its functions of heat removal, impurity control, and helium exhaust, or require frequent maintenance due to sputter erosion or damage due to disruptions, how would this impact the ability of ITER to achieve its goals? A related question is how would an improvement in divertor lifetime and operation affect ITER's goals, cost, and schedule?

\section{III.2.1. Heat removal}

The failure of the divertor to remove heat adequately during high power operation would occur in a characteristic time of 2-10 seconds. The lower end of this range is about twice the thermal conduction time of the divertor structure; the upper end is about twice the plasma's energy confinement time. Three categories for failure should be considered. The first is typified by lowe:-than-expected material thermal conductivity, as might occur due to neutron irradiation. The divertor plate surface temperature would rise. RES would increase and plasma contamination would occur. The plasma operation would degrade ir. $~ 40$ seconds, about twice the characteristic particle transport time; the exact level of degradation would depend on the increase in plasma contamination. (These processes are roughly quadratic in behavior, thus small changes could quench ignition or terminate steady-state operation.)

Coolant-tube burnout, the second category of failure, could be due to a higher than expected heat load (possibly caused by lack of burn control, prolonged up/down asymmetry, or loss of sweeping) or a loss-of-coolant or loss-of-flow accident. A timeaveraged divertor heat load greater than the specified value of $15 \mathrm{MW} / \mathrm{m}^{2}$ is predicted to cause burnout of coolant tubes in the divertor structure within $0.5-7$. seconds. Release of the water coolant into the hot vacuum vessel has been considered by the safety group. In the ITER design, extreme care has been made to allow only small portions of the vessel to be sufficiently hot to catalyze the decomposition of steam into hydrogen and oxygen. At the predicted low hydrogen/oxygen concentrations, explosions are considered virtually impossible. The main impact on ITER is considered to be the loss of time for repairs. (Processing of the tritium contaminated water will be an important safety concern.) Three to six months is estimated to be required to replace the entire divertor. No estimate has been given in the ITER Assembly and Maintenance Report (ITER-IL-MA-1-0-105) for replacement of a single module; we assume here that about one month is necessary because of overhead involved in opening and closing the vacuum system. It is likely that more than one module would be damaged by excessively high steady-state heat loads, hence each failure would cost 3-6 months of operation. 
The third category is fatigue due to thermal-cycle induced stresses. As described later, sweeping will result in $\sim 2 \times 10^{7}$ strain reversals in the technology phase. Earlier divertor designs could tolerate less than $5 \times 10^{4}$ strain reversals before failure. Hence frequent module replacement appears required.

The frequency of burnout events depends largely on plasma control. Lack of plasma burn control could cause coolant-tube burnout in the first few seconds of the first truly ignited discharge. Loss of heat load sweeping could cause burnout in any high power discharge. No passively safe method has been devised to avoid either situation, though efforts have been made. Nor has an estimate been made of the frequency of these events. As readily seen from the above numbers, fewer than two such failures per year are tolerable in light of the required ITER duty factor.

The ability of ITER to contribute directly, without scaling, to DEMO divertor designs would require that ITER operate at $\sim 3 \mathrm{GW}$. Even if the divertor heat load problem were to be resolved, it is likely that these tests could only be performed in a transient fashion, e.g., typically 100 soconds, because of constraints on other ITER systems, specifically TF coil cooling and the breeding blanket.

Disruption damage should be evaluated from the same perspective as coolantchannel burr. ut, i.e., replacement of divertor modules is necessary. Erosion due to disruption heat loads, expected to be equally severe on all modules, would necessitate annual divertor maintenance in the technology phase, and triannual maintenance in the physics phase. The latter is incompatible with the experimental program in the physics phase. Damage due to runaway electron impacts on tiles or into cooling tubes could be a worse problem, requiring maintenance on individual modules dozens of times each year. Maintenance required by sputter erosion is $1 / 10$ as frequent in both (ignited) physics and (long-pulse) technology phases. However, excessive (RES) ercsion is predicted in the steady-state scenarios of the technology phase.

\section{III.2.2. Plasma purity}

Impurity influx generally grows with power load on the divertor. An increase in impurity influx will increase radiated power and lower the divertor heat load. It is conceivabie that quasi-steady state conditions will develop. If a favorable balance is not obtained, then termination of plasma burn or shortening of the pulse length, the latter due to increased resistive volt-sec consumption, would occur in $\sim 40 \mathrm{sec}$ (two particle transport times), unacceptable to ITER operation in both the physics and technology phases.

If the divertor provided better impurity shielding than anticipated and the core plasma $Z_{\text {eff }}$ dropped, the puise length could be increased by up to $100 \mathrm{sec}$ in the physics phase and the energy confinement time enhancement factor reduced $\sim 10 \%$. However, a cleaner plasma is expected to cause higher power loads on the divertor and increased divertor power loads would occur. Thus, we conclude that improvements in plasma purity from the specified conditions may not be beneficial.

\section{III.2.3. Helium exhaust}

Lack of adequate helium exhaust would compromise the ability of ITER to sustain ignition beyond $\sim 100$ seconds. That is, even with no helium exhaust, ignition at $1 \mathrm{GW}$ 
would persist for about $100 \mathrm{sec}$ until the helium concentration rose to $\sim 15-20 \%$. This duration of pulse is not acceptable under the ITER terms of reference. In contrast, a reduction of the helium concentration to $5 \%$ would allow operation at lower plasma current, 10-17 MA, thus reducing the risk of damage due to disruptions. It would also increase the credibility of the ITER design by reducing the required energy confinement $\mathrm{H}$ factor for ignition from 2.0 to 1.7 .

Operation under driven conditions (auxiliary heated with $Q \sim 10$ ) gives more latitude in the allowed He concentration. Under these conditions, a He concentration of $20 \%$ would compromise ITER's ability to perform technology testing by reducing both the neutron wall load and the pulse length by factors of two.

\section{III.2.4. Costs and schedule}

Clearly, reliability of the divertor influences the entire ITER program, from the ability to produce a single sustained ignited discharge to completing of the technology mission. Improvements in divertor operation and reliability - specifically reduced needs for module maintenance or replacement - would shorten the length of the long-pulse technology phase by 5 years, resulting in a savings of $\sim 1 \mathrm{~B} \$$ in operating costs.

Development of a steady-state scenario for the technology phase would improve the credibility of ITER for producing DEMO-relevant data. It is likely to improve the operation of the PF system by reducing (cyclic) fatigue. A higher duty factor would also result, further reducing operating costs.

Another cost savings would accrue if convincing pronf existed that a less deep divertor were adequate for low erosion. The present divertor is $1.5 \mathrm{~m}$ deep from the $x$ point to the strike point; the previous design was $0.6 \mathrm{~m}$. This change was made to reduce the electron temperature at the sheath and hence the erosion rate. The total height of the vacuum vessel and surrounding structures grew about $3 \mathrm{~m}$ to accommodate the increased divertor depth. Poloidal field coils moved further away from the plasma; increased currents were required. Based on a volume-to-volume comparison, this $25 \%$ increase in machine volume is expected to increase costs of the central device by $\sim 200 \mathrm{M} \$$.

\section{III.3. International collaboration}

A natural question is whether international collaboration can be relied upon to support the construction and operation of a divertor technology test facility. Within the ITER five-year R\&D plan, divertor physics issues are to addressed in a voluntary physics R\&D program on existing tokamaks and divertor technology issues are restricted to studies of erosion/redeposition in a new $\sim 5 \mathrm{MS}$ divertor simulator. Such optional and restricted roles are not deemed adequate for the difficult and crucial set of divertor problems. ITER support for divertor issues may strengthen as a result of national reviews of the CDA or decisions by the new director. One possible change would be to have mandated divertor experimental programs in the major tokamaks. Also, the scope and financial support for technology testing could grow to a size that would support the full breadth of the divertor technology programs deemed necessary.

It is likely that other international support will be found for divertor technology issues outside of ITER. Three likely sources are Canada, the UK, and Germany. Scientists (P.C. Stangeby and C.S. Pitcher) from the Canadian Fusion Fuels Technology 
Program and the University of Toronto have expressed interest in a divertor test facility, particularly one that could be applied to tritium reprocessing questions. They presented a proposal to CFFTP in 1990 for a very large linear device. Culham scientists (G.M. MCCracken and D. Sweetman) are considering a linear plasma device for plasma materials interaction studies. Culham, on i:s Compass tokamak, has $2 \mathrm{MW}$ of $60 \mathrm{GHz}$ gyrotrons capable for 5 second pulses. These are suitable for ECH heating of marjnetized plasmas of TTER-like divertor plasma densities. KFA Jülich scientists, notably $\mathrm{H}$. Conrads and $\mathrm{J}$. Winter, have recently stated that they are considering building, in 1997, a linear plasma device to replace TEXTOR. Conrads has expressed support for a US-built facility, particularly as it might provide data for to enhance the capabilities of the Jülich device.

\section{III.4. Time scale for contributions to ITER}

Completion of the engineering design for ITER is scheduled for 1997. It is possible that minor changes in the divertor design could occur beyond that point. Such "minor" changes might include changing the boron content of CFC, or a variation of the braze

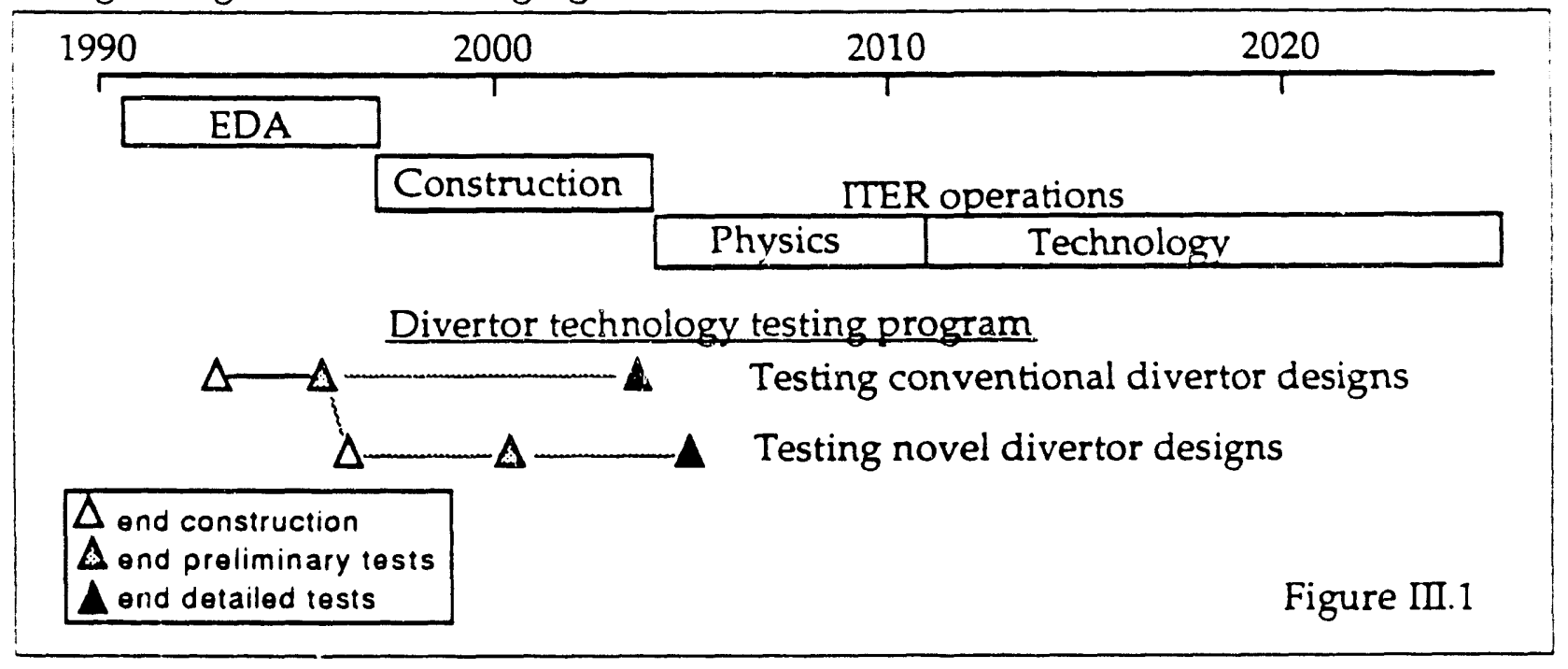

material for attaching CFCs or $\mathrm{W}$ to $\mathrm{Nb}$ or $\mathrm{Cu}$ alloys. However, the main divertor concept, e.g., solid plates versus gaseous neutra'izer versus liquid metal, must be set before 1995 to allow integration into the design of the entire machine. If a conventional stationary solid target - design is chosen based on adequate accelerated-life technology test results, detailed studies of a variety of prototype modules and candidate materials could be made through the first several years of construction, $c a 2003$. Based on these estimates and the assumption that $\sim 5$ prototype modules/materials need undergo full life cycle testing, a technology testbed should be able to carry out the equivalent of 10 years of ITER exposure in $\sim 1$ year of device operation.

If divertors of conventional design are not adequate because, for example, redeposition was not as efficient as predicted, a lead time of $\sim 5$ years would be required to develop an alternate concept. This is indicatea in Figure III.I where a decision to test novel concepts was made in $\sim 1995$. If redeposition were shown to be marginally acceptable, then several years would be devoted to learning what regions of operating space improved the redeposition process and what methods would allow 
operating ITER there. As shown in the figure, nearly simultaneous testing of the mainline and novel concepts should be possible in a technology testbed suitably
designed to allow rapid replacement of modules.

\section{III.5. Facilities}

Just as for confinement experiments, there are two classes of plasma devices to be considered for divertor testing. These are linear and toroidal. Each has benefits arid drawbacks, as indicated in Table III.1.

\section{Table III.1}

\section{Toroidal devices}

Advantages

1. Proper to study the interplay of core and edge physics

2. Proper geometry for SOL physics issues

3. Potential to study disruptions and runaway electrons

4. Appropriate to test certain novel divertor concepts, e.g., biased plate
5. Compact

Disadvantages

1. Toroidal plasma systems and diagnostics required

2. Disruptions

3. Poor access

4. Pulsed operation (possible steady state at reduced parameters)

5 . Remote operation required due to $X$ rays and neutrons from hot core

6. Complete (and lengthy) toroidal module changeovers required

\section{Linear devices}

Advantages

1. Good access for diagnostics

2. Local operation possible because of no neutrons or $X$ rays in the test cell

3. Better ascess for change of modules; only one or two modules need to be changed

4. Ease to test certain novel divertor concepts, e.g., liquid metal

5. Ease to study effects of geometry changes

6. Easier steady-state operation

\section{Disadvantages}

1. No toroidal physics possible

2. Long

In Table III. 2 are listed some characteristics and parameters of plasma devices which could contribute to the divertor testing program. These devices are at institutions presently involved in MFE research. We have omitted from this list most presently operating tokamaks because they already have missions defined for the next 5 years. The only exception is DIII-D; its management is contemplating whether to redirect the GA research efforts fully into technology development. (Again, it is the 
recommendation of this report that existing tokamaks devote their attention to divertor physics issues unique to toroidal geometry, e.g., disruptions, plasma transport, and toroidal/poloidal asymmetries.) Additionally, the ATF device is included, both because of its unique magnetic configuration, but also because of a change in goals.

\section{Table Wl.2}

Existing linear plasma edge/divertor simulator facilities

\begin{tabular}{|c|c|c|c|c|c|c|c|c|}
\hline & & $\underline{r(\mathrm{~cm})}$ & $L(m)$ & $\mathrm{P}(\mathrm{MW})$ & $I(\mathrm{eV})$ & $T_{(\mathrm{eV})}$ & $\mathrm{n}_{9}\left(\mathrm{~cm}^{-3}\right)$ & $\underline{B(T)}$ \\
\hline a. PENNING & Maryland & 2 & 1 & .001 & 10 & 3 & le 12 & 0.2 \\
\hline TPX & SNLL & 2 & $i$ & .001 & 10 & 3 & le 12 & 0.1 \\
\hline c. PISCES-A & UCLA & 1 & 1 & .002 & $20 *$ & 5 & le 13 & 0.1 \\
\hline d. PISCES-B & UCLA & 2 & 1 & .005 & $40^{*}$ & 5 & $5 e 13$ & 0.2 \\
\hline e. NASA & PPPL & 2 & 0.3 & .002 & $15^{*}$ & 5 & $5 e 13$ & 0.3 \\
\hline f. PHAEDRUS(B) & Wisconsin & 10 & 2 & 0.4 & 30 & 500 & $5 e 12$ & 0.1 \\
\hline g. CMPPX & MIT & 36 & 3.2 & 0.8 & 10 & 1000 & le & 2.0 \\
\hline h. RFTF & ORNL & 30 & 2 & 0.8 & 50 & 100 & le13 & 0.1 \\
\hline PSI-1 & CIEP & 3 & 2 & 0.005 & 40 & 3 & e 13 & 0.1 \\
\hline
\end{tabular}

\section{Proposed plasma edge/divertor simulator facilities}

\section{Linear}

$\begin{array}{llrrrrrrr}\text { j. ICTF } & \text { ANL } & 10 & 2 & 0.8 & 50 & 100 & 3 \mathrm{e} ! 3 & 4 . \\ \text { k. NEUTRON } & \text { LLL } & 8 & 40 & 50 & 2.50 & 500 & 1 \mathrm{e} 15 & 12 \\ \text { 1. CFFTPTX } & \text { Toronto } & 20 & 20 & 50 & 100 & 400 & 1 \mathrm{e} 13 & 1 . \\ \text { m. IDS } & \text { PPPL } & 5 & 20 & 5 & 100 & 200 & 5 \mathrm{e} 13 & 3\end{array}$

\section{Toroidal}

n. TST

o. DIII-D

p. SST

q. ATF

\begin{tabular}{|c|c|c|c|c|}
\hline \multicolumn{5}{|c|}{$2 \pi \mathrm{R}(\mathrm{m})$} \\
\hline ORN & 40 & 3 & 5.8 & 200 \\
\hline $\mathrm{G}$ & 50 & 8 & 23 & 200 \\
\hline GA & 50 & 15 & 8 & 200 \\
\hline ORNL & 27 & 13 & 2 & $1000 *$ \\
\hline
\end{tabular}

$200 \quad$ le 13

$2003 \mathrm{e} 13$

$200 \quad 5 e 13$

$1000^{*}$ le 14

1.

2.

3.

* Not attained at maximum density 


\section{ISSUES TO BE ADDRESSED}

\section{IV.1. Technology issues}

The ultimate goal of a divertor test facility is to qualify full-scale prototype divertor modules for use in ITER. Scale models made of the reference materials and structures would receive the first and most intensive investigations. These smaller modules would have to have dimensions characteristic of the processes important for ITER. As discussed in Section VII, a likely size is $>0.1 \mathrm{~m}^{2}$. Later experiments would focus on alternate divertor materials, then alternate cooling structures, and, if necessary, novel divertor concepts. Finally, full-scale prototypes would be tested. Reliability testing for each of the five major issues requires a full-life/accelerated-life test program.

1. Heat flux capacity

A. Full peak power load in long-pulse operation

B. Thermal fatigue resistance under cyclic loads

C. Burn-out limits on coolant channels

D. LOCA/LOFA response

E. Corrosion in cooling channels

F. Fabrication technology

G. Alternate materials

2. Lifetime with respect to sputter and RES erosion

A. Alternate materials: $\mathrm{SiC}, \mathrm{Be}, .$.

B. Physics phase plasma parameters

C. Technology phase plasma parameters

D. Eftect of divertor depth on erosion rate

E. Thermo-mechanical properties of redeposited materials

F. In situ repair capability

3. Safety issues

A.Tritium inventory

i) Hydrogen inventory in redeposited films: spatial distribution

ii) Hydrogen inventory in dust

iii)Methods to reduce inventory

B. Low activation materials

C. Steam/air reactions

4. Helium exhaust efficiency of divertor

A. Ratio of He to D pumped: reference design

B. Effects of divertor plate/pump duct geometry

C. Methods to improve He to D ratio in exhaust

i) ICRF assisted

ii) Helium burial

iii) Permeable membranes

5. Disruption effects

A. Response to heat loads of the thermal quench

i) Ablation

ii) Codeposition

iii) Dust formation 
B. Response to forces of the current quench and VDE's

C. Response to runaway electron impacts

6. Tests of new divertor concepts: liquid metal, gaseous, ponderomotive, $\mathrm{W}$ plates, radiative divertor, thermionic emitting, biased,...
A. Heat flux capacity
B. Erosion lifetime
C. Tritium inventory
D. He exhaust efficiency
E. Compatibility with core plasma operation

As will be discussed in section $V$, proper performance of these tests will require very specific plasma parameters and geometry. For example, the inclination angle of the total magnetic field to the plate is critically important because of its predicted influence on erosion/redeposition and hydrogen fluxes.

\section{IV.2. Physics issues}

Physics issues are critically important to the design of the ITER divertor. It is arguable that they be resolved in a toroidal device. But no proof has been given that the SOL region of a tokamak "knows" that it is part of a closed torus. (Similar field curvature to a torus and/or similar intrinsic local plasma parameters may be adequate to explain/cause identical transport processes and rates.) Nevertheless, and because edge physics R\&D tasks have already been established for the tokamaks in the ITER five-year Physics R\&D program, we do not require the ITER divertor technology facility to address the physics issues.

In this section we list the critical physics issues to provide guidance to tokamak (or other interested) scientists.

1. Cross-field transport
A. Heat : $\chi$ vs $n, T, \nabla Q \nabla T, \nabla B, \nabla n, R_{c}$
B. Charged particles: $D$ and $v_{\text {convection }} v s, T, \nabla Q, \nabla T, \nabla B, \nabla n$
C. Imputity transport
D. Neutral transport
E. Suprathermal transport

i) electrons

ii) fusion products

F. Turbulence/ergodic transport for remediation of too small $\lambda_{P}$

G. Effects of electric fields, poloidal currents, and drifts

H. ELMs and other MHD effects

I. Dependence of $n_{s}$ on $<n>$

2. Field-parallel transport
A. Heat flux limit factors on electrons and ions
B. Effect of $\nabla T$, drag, and magnetic sheath on impurity flows
C. Sheath heat transmission coefficient
D. Sheath potential vs plasma parameters and geometry 
E. Effect of intense SOL impurity radiation on plasma flows

3. Dependence of divertor plasma parameters on geometry

A. Depth of divertor

B. Plate tilt

C. Toroidal/poloidal (in/out and up/down) symmetry

D. Locked mode avoidance/control

4. Helium flows
A. Impact profile on divertor plate
B. Effects of ELMs on He exhaust
C. Effects of other impurities on He flows
D. He exhaust from gaseous divertors

5. Disruptions and VDE's
A. Power, energy and particle fluxes
B. Frequencies
C. Control and avoidance
D. Runaway electron generation 


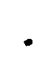

- 


\section{DIVERTOR PLASMA PARAMETERS}

\section{V.1. Existing data base}

An examination of the edge plasma data base was made for ITER and is presented in Physics section of the Final CDA Report. Only a small tokamak data base exists for the main physics issues listed in Section IV.2. For example, a total of 10 discharges (from DEL-D, JET, TFTR, TEXTOR ASDEX, and JT-60) have been analyzed with the 2-d fluid models to yield cross field $\chi_{\perp}$ and $D$ values. The measured values of $\chi_{\perp}$ vary by about a factor of 10 . In contrast, an accuracy of $\sim 20 \%$ is needed for ITER. No scaling of $\chi_{\perp}$ and D to ITER or against $\mathrm{n}$ and $\mathrm{T}$ has been made. A similar situation exists for the dependence of $n_{s}$ on $<n>$. It is difficult to locate the exact position of the separatrix, hence to measure $n_{s}$. The ratio $n_{s} /<n>$ was seen to vary from $1 / 5$ to $1 / 2$. Again an accuracy of $\sim 20 \%$ is needed. Studies of turbulence and induced ergodic transport have been made on several machines, notably, Tore Supra and TEXT. Regrettably, results for the edge and SOL regions are minimal.

Data on the other physics issues listed in Section IV.2 is even weaker than the sparse database on cross-field transport.

\section{V.2. Predicting ITER's divertor plasma parameters}

V.2.1. Plasma temperature, density and heat flux

Three divertor plasma parameters, the peak electron temperature at the divertor sheath, the peak ion flux through the sheath, and the peak power load onto the divertor plate, set the requirements for the engineering design and materials suitable for the divertor plate and are used to predict its operation. These thiee plasma parameters are largely determined by the power flow into the scrape-off layer $(\nabla Q)$, the plasma density at the separatrix $\left(n_{s}\right)$, the plasma recycling at the divertor plate, the plasma cross-field thermal conductivity in the SOL $\left(\chi_{-}\right)$, the divertor plate and magnetic field geometry, and the radiation energy losses in the SOL. The divertor plate lifetime with respect to sputter erosion is particularly sensitive to the peak sheath electron temperature, $\hat{T}_{e}$. Radiation-enhanced sublimation (RES) is sensitive to both $\hat{\mathrm{T}}_{e}$ and the material temperature.

For ITER, the divertor plasma parameters are predicted by use of 2-d numerical fluid plasma codes (mainly the B2 code). The above-named sources, transport properties, and boundary conditions, which are used as inputs to the codes, come from the small aforementioned data base collected from tokamaks. Extrapolations of these data to ITER result in an uncertainty due to experimental measurements, incomplete understanding of the physical processes, and the paucity of data.

Additionally, the 2-d fluid codes are "ideal" in the sense that they do not include: toroidal and poloidal (up/down) asymmetries known to exist; a realistic impurity radiation model; and power variation due to lack of perfect burn-rate control. Estimated corrections are applied after the "ideal" 2-d predictions are made. The net correction, termed a "physics safety factor," consists of both the omitted physics and the 
uncertainties. To calculate the "real" peak power load on the divertor tiles, an engineering safety factor (of order 1.5) must be applied in addition, to accommodate inaccuracies in tile installation and gaps between the tiles.

Separate safety factors are calculated for $\hat{T}_{\mathbf{e}}$ and peak power load $\hat{P}$ for both the inner and outer divertor plates and tor each different operating scenarios. Though $\hat{\mathrm{T}}_{\mathrm{e}}$ is more sensitive than $\hat{P}$ to small changes in $n_{s}$ or $\chi_{\perp}$, both are bounded by the constraint of energy conservation. If $\chi_{\perp}$ is different than assumed, the power load profile width, typically $0.08-0.1 \mathrm{~m}$ on the divertor plate, changes inversely as $\hat{P}$. A safety factor of 3 is recommended fo $\cdot \hat{T}_{e}$. If $\hat{T}_{e}$ is higher, $\hat{\Gamma}$ is lower.

In Table V.1 are listed $\hat{T}_{e}, \hat{P}, \hat{n}_{d}$ (the peak electron density at the divertor sheath) and $\hat{\Gamma}$ (the peak ion flux) for the outer divertor plate calculated for three operating scenarios: A1, B1 and B6. These scenarios correspond to ignited, hybrid long-pulse, and pure non-inductive steady-state operation. The physics safety factor for $\hat{P}$ has been applied in the sixth line and the engineering in the seventh. The values for these parameters are averages of those predicted by five similar, 2-d fluid codes. Parameters predicted at the inner divertor plate are generally comparable to those at the outer, when safety factors have been included. Other parameters that are listed in the table are: the peak power flow in the $\theta$ direction onto the divertor plate, $\hat{P}_{\theta}$; the peak power flow in the toroidal direction, measured just above the divertor sheath, $\hat{\mathrm{P}}_{\phi}$; the fullwidth at half height of the power load profile on the tilted divertor plate, $\Delta_{p}$ (FWHH), the particle throughput per meter of ITER circumference; the $\Omega_{1} \mathrm{ux}$ amplification factor (essentially the ratio of particles hiting the divertor plate to the throughput); and the frequency, $f$, and amplitude, A, of the sweeping across the divertor plate.

From the perspective of divertor plate erosion due to physical sputtering, a sheath electron temperature below $\sim 50 \mathrm{eV}$ is considered necessary. Scenarios A1 and B1 satisfy this criterion, even after the application of a safety factor to $\hat{T}_{e}$. Scenario B6, steady-state non-inductive operation, does not have an acceptable $\hat{T}_{e}$ value. This is mainly due to the low assumed separatrix density and a high applied auxiliary power, both associated with current drive requirements. Whether this will indeed be true must be tested in a physics R\&D program.

To calculate the expected divertor plate temperature, the appropriate power load profile must be used as well as the exact divertor plate design (materials and dimensions) and power load sweeping scenario (amplitude and frequency). As described in section VI, sweeping is necessary to reduce the divertor plate temperature, even for scenarios A1 and B1.

It is anticipated that improvements in the $\chi_{\perp^{\prime}} \mathrm{n}_{\mathrm{s}}$ data base will be achieved within 


\begin{tabular}{|c|c|c|c|c|}
\hline \multicolumn{5}{|l|}{ Table V.1 } \\
\hline & & $\underline{\text { A1(ignited) }}$ & $\underline{B 1}$ (long pulse) & $\underline{B 6}$ (steady state) \\
\hline$\hat{\Gamma}$ (ideal) & $10^{23} / \mathrm{m}^{2} \mathrm{~s}$ & 4.3 & 2.7 & 1.7 \\
\hline$n_{d}$ & $10^{20} / \mathrm{m}^{3}$ & 6.7 & 6.5 & 1.7 \\
\hline$\hat{\mathrm{T}}_{\mathrm{e}}$ (ideal) & $\mathrm{eV}$ & 15 & 15 & 130 \\
\hline$\hat{\mathrm{T}}_{\mathrm{e}}$ (with safety factor) & $\mathrm{eV}$ & 45 & 45 & 390 \\
\hline$\hat{\mathrm{P}}$ (ideal) & $\mathrm{MW} / \mathrm{m}^{2}$ & 6 & 4.2 & 22 \\
\hline$\hat{\mathrm{P}}$ (physics safety factor) & $\mathrm{MW} / \mathrm{m}^{2}$ & 20 & 14 & 75 \\
\hline$\hat{\mathrm{P}}$ (engin'r safety factor) & $\mathrm{MW} / \mathrm{m}^{2}$ & 30 & 21 & 105 \\
\hline$\hat{\mathrm{P}}_{\theta}$ & $\mathrm{MW} / \mathrm{m}^{2}$ & 79 & 55 & 289 \\
\hline$\hat{P}_{\phi}$ & $\mathrm{MW} / \mathrm{m}^{2}$ & 150 & 110 & 800 \\
\hline $\begin{array}{l}\text { Throughput/unit length } \\
\mathrm{F}_{\mathrm{A}}\end{array}$ & $10^{20} / \mathrm{m} \cdot \mathrm{s}$ & $\begin{array}{r}4 \\
300\end{array}$ & $\begin{array}{r}2 \\
200\end{array}$ & $\begin{array}{r}1 \\
100\end{array}$ \\
\hline$\Delta_{\mathrm{p}}(\mathrm{FWHH})$ & m & 0.1 & 0.105 & 0.075 \\
\hline $\mathrm{f}$ & $\mathrm{Hz}$ & 0.2 & 0.2 & 0.2 \\
\hline A & $\mathrm{m}$ & 0.12 & 0.12 & 0.12 \\
\hline
\end{tabular}

the next few years as a result of voluntary physics R\&D. These may - or may not result in lower predicted values for $\hat{T}_{e}$ and $\hat{P}$. They will, at least, give a more definite statement of the heat removal requirements for conventional divertor designs. Improvements in plasma control, such as the ability to rotate or avoid locked modes, would reduce the power load $\sim 50 \%$. Recent, but preliminary, assessments of SOL impurity radiation also predict substantially lower $\hat{T}_{e}$ and $\hat{P}$. This latter effect also warns of the proximity of a density limit to the selected ITER operating space.

\section{V.2.2. Helium Exhaust}

To achieve the low core helium concentration desirable for improved operation characteristics, helium transport through three regions must be adequate. These regions are the core, the SOL, and the pump duct (see Figure V.1). The transport processes are serial, hence boundary conditions must be matched at the interfaces, namely at the separatrix and at the pump duct opening. The main divertor technology aspect of helium exhaust lies in the pump duct region. The question is whether adequate helium exhaust can be obtained simultaneously with good $D / T$ recycling.

There are no experimental data on helium flows in the SOL. The B2 code predicts an outward shift of about $30 \mathrm{~cm}$ for the peak of the $\mathrm{He}^{++}$impact profile on the divertor plate. Having helium closer to the pump duct opening would naturally aid helium exhaust. The causes of this outward shift include plate tilt, atomic physics (higher $\mathrm{He}^{\circ}$ 
ionization potential compared to $D^{\circ}$ ) and entrapment of $\mathrm{He}^{++}$in the reversed $\mathrm{D}^{+} / \mathrm{T}^{+}$flow away from the divertor region.

The effects of pump duct/divertor plate geometry designs on helium exhaust have been calculated with Monte Carlo neutral codes. These use plasma parameters from the 2-d multifluid simulations. The required pumping speed for 3 ITER operation scenarios are shown in Table II for different assumptions on the divertor geometry and on the flux profile on the divertor : late. The cases marked "reference" include no shift to the helium flux profile and the "1990 - as drawn" divertor plate/pump duct geometry. The cases marked "improved" take credit for both geometry changes and the predicted outward shift of the helium flux profile. Changes in the separatrix plasma density

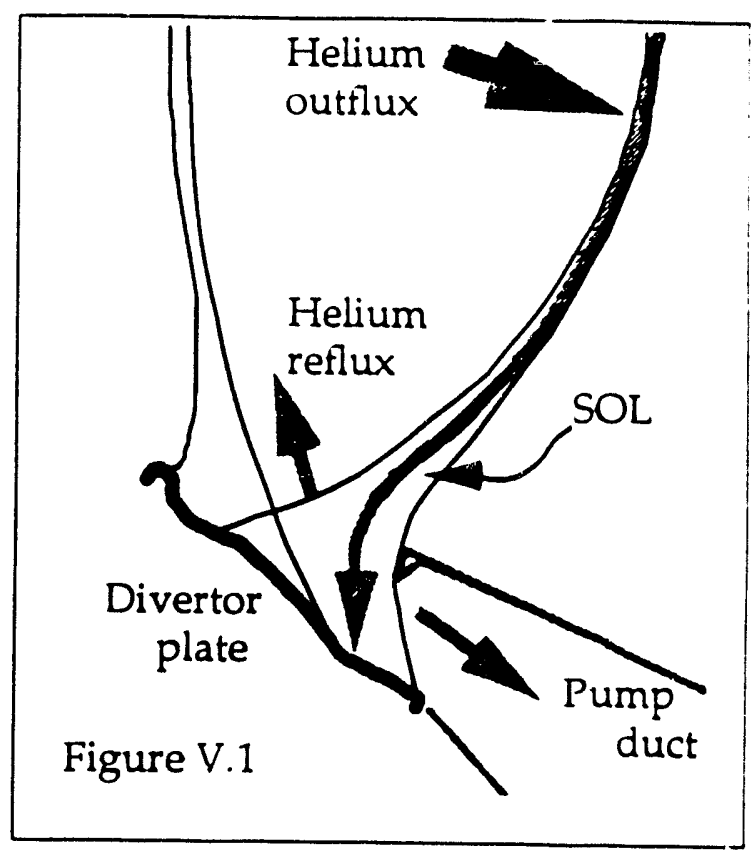

Table V.2 Pumping speed required for ITER

Reference geometry $\left(\mathrm{m}^{3} / \mathrm{s}\right)$

Improved geometry $\left(\mathrm{m}^{3} / \mathrm{s}\right)$

A1

700

310
B1

800

340
$\underline{B 6}$

1970

1060

from those values assumed are predicted to alter the required pumping $\propto \mathrm{n}_{\mathrm{s}}^{-2}$

The pumping speed available at the pump duct openings is $700 \mathrm{~m}^{3} / \mathrm{s}$. Thus scenarios A1 and B1 are likely to have more than adequate helium exhaust capability. $B 6$, however, is lacking. The reason is the low helium density at the divertor plate which arose from the low separatrix electron density required for current-drive operation. Thus low density operation is predicted to cause three problems: too high a divertor power load; too high a divertor erosion rate; and too low helium exhaust. 


\section{ENGINEERING DESIGN OF THE DIVERTOR}

The Conceptual Design Activity (CDA) led to separate divertor designs for the physics and technology phases. The major difference between the designs is the choice of the plasma-facing material. Carbon fiber composite was selected for the physics phase based upon the large amount of experience with graphite in existing machines, its capability to serve as a protective armor, and the advantage of using a low- $Z$ material for reduced impurity effects in the plasma. Tungsten was selected for the technology phase based upon predictions for extremely low rates of sputtering erosion and reduced neutron irradiation effects. The latter also contributes to longer lifetimes. For both $C$ and $W$ tiles, redeposition of eroded material is predicted to reduce the net erosion rate by a factor of 10 to 100 over the gross erosion rate, markedly extending the divertor plate lifetime. (Beryllium, with somewhat less favorable erosion properties, was conisidered a "back-up" material for both phases.)

Ir. both the physics and technology phases, active cooling of the divertor plate, using low-temperature, low-pressure water, was selected because of long-pulse operation and safety issues, particularly at high material temperatures. Since the candidate plasma-facing materials are not considered to be structural materials, they must be bonded to structural backing plates that contain the water coolast channels. Copper alloys and refractory metal alloys (e.g. $\mathrm{Nb}$ and $\mathrm{Mo}$ ) are candidates for the backing plate structure.

The divertor designs represent a compromise between performance capability (e.g. allowable heat flux), risk/reliability, and lifetime. The basic approach used in the CDA was to design a divertor plate with the maximum lifetime (based on erosion losses) that meets the other requirements of heat flux, material temperature, and safety. The peak heat flur level calculated by the physics group was multiplied by an engineering safety factor (typically 1.3 to 2.0 ) to take into account possible inaccuracies in tile installation and gaps between tiles. As noted in Table V.1, this raised the peak heat flux in scenario A1 from 20 to $30 \mathrm{MW} / \mathrm{m}^{2}$, severely affecting design options. To accommodate high heat fluxes and avoid high material surface temperature $\left(>1000^{\circ} \mathrm{C}\right)$ which promote RES, the plasma-facing material thickness was reduced to about $7 \mathrm{~mm}$. Even at this thinness, sputter erosion was predicted to require relatively few divertor replacements. The safety margin for coolant channel bumout is reduced at high heat fluxes, adding to the risk of component failure.

Using conventional designs and presently available materials, sweeping the heat deposition profile was found to be necessary to tolerate $30 \mathrm{MW} / \mathrm{m}^{2}$. The parameters of the sweeping procedure were an amplitude of $\pm 12 \mathrm{~cm}$ across the divertor plate at frequency above $0.2 \mathrm{~Hz}$. (This prescription lowers the effective time-average power load to $\sim 15 \mathrm{MW} / \mathrm{m}^{2}$ and the peak surface temperature to $1000{ }^{\circ} \mathrm{C}$.) These sweeping parameters are marginally within the capability of the existing PF system. Improvements in the burnout safety margins are likely to occur with better thermal conductivity materials, better sweeping procedures, and lower power fluxes. In the CDA, detailed examination of cyclic heat load fatigue was not performed.

The expected lifetime of the divertor plates has been estimated based upon sputtering erosion. (Note that disruption erosion is expected to be more severe.) For 
graphite, it is estimated that the divertor plates would need to be replaced less that 3 times during the physics phase. For tungsten tiles, less then one replacement would be needed during the technology phase for hybrid long pulse ( $>2500 \mathrm{sec}$ ) operation. However, steady-state operation would result in runaway erosion of either $W$ or $C$ because of the high plasma temperature. 


\section{TECHNICAL REQUIREMENTS}

An integrated test of the five major divertor technology issues listed in section IV.I is most desirable. However, as will be shown in the discussion below, one of the issues, certain aspects of heat load limits have less stringent requirements than the others. Hence, initially heat flux limits could be tested in a separate facility. We stress that reliability testing, i.e., testing to the full-life exposure, must be a principal goal of a divertor technology test program.

\section{VII.1. Heat flux capacity}

As listed in section IV.1, there are seven aspects of heat flux capacity that must be addressed. The first is the ability of the tile/braze-joint/coolant-tube structure to withstand the peak heat load for periods exceeding $\sim 20$ seconds. The surface temperature of the tiles must not exceed that specified safe for RES and steam-carbon reactions, $\sim 1000^{\circ} \mathrm{C}$. The peak heat load, including physics and engineering safety factors, is $30 \mathrm{MW} / \mathrm{m}^{2}$ in the physics phase and $105 \mathrm{MW} / \mathrm{m}^{2}$ during steady-state operation in the technology phase (see Table V.I). The engineering peaking factor includes roughly a $15 \%$ effect due to gaps between tiles. These full peak heat loads need only be tested on a small area, $\sim 1 \mathrm{~cm} \times 10 \mathrm{~cm}$, sufficient to include gaps between tiles. The heat must arrive at the surface at a grazing angle to properly test tile edge temperature distributions.

The areas of the divertor plate away from the gaps would experience only $85 \%$ of the peak power. These test areas need to be larger, $\sim 10 \mathrm{~cm} \times 10 \mathrm{~cm}$, consistent with the width of the power load on the divertor plate, $\Delta_{p}$ (FWHH). The present engineering models predict that a steady-state heat load of only $15 \mathrm{MW} / \mathrm{m}^{2}$ can be tolerated by the present divertor plate design. The applied heat load must be controllable up to values several times higher to test the engineering models for scenarios A1 and B6 Heat-load variation scenarios should encompass realistic histories for operation.

A heai stux facility capable of certifying full-size $(3 \mathrm{~m} \times 3 \mathrm{~m})$ ITER divertor modules should be considered essential late in the R\&D program.

The second aspect is the ability to withstand extended

Table VII.1 Technical requirements: heat flux facility

Facility parameters

Power $\left(\mathrm{MW} / \mathrm{m}^{2}\right)$

Pulse duration (s)

Irradiated area

Fluence (s)

Duty factor (\%)

Target orientation

Sweep frequency $(\mathrm{Hz})$

Magnetic field

Plasma parameters
Minimum Value

30

400

$1 \mathrm{~cm} \times 10 \mathrm{~cm}$

$3 \times 10^{7}$

33

$30^{\circ}$

$0.1-1.0$

NA

NA

\begin{tabular}{l} 
Preferred Value \\
\hline 100 \\
3000 \\
$10 \mathrm{~cm} \times 10 \mathrm{~cm}$ \\
$3 \times 10^{7}$ \\
$75^{\circ}$ \\
$2^{\circ}$ \\
$0.1-1.0$ \\
NA \\
NA
\end{tabular}
thermal cycling. The heat flux test facility could modulate the power load on a divertor prototype assembly by either sweeping the heat load in space or time. In either case, the required frequency of modulation should be controllable between 0.1 and $1 \mathrm{~Hz}$. The duration of the test 
would need to be about one-burn year, $3 \times 10^{7}$ seconds. A test facility should provide the full ITER life exposure in 2-3 years, at most, corresponding to a duty factor of $33 \%$ to $50 \%$.

We note that the predicted fatigue life of the DEMO divertor plate, which experience on a peak power load of $13 \mathrm{MW} / \mathrm{m}^{2}$ is $5 \times 10^{4}$ cycles, about $1 / 200$ of that required for ITER.

The third aspect is a study of burnout limits on the coolant tubes. Guided by standard engineering safety analysis, a factor of two below the heat flux burnout limit has been chosen as the operating point. Tests up to and beyond the predicted burnout limit ( $30 \mathrm{MW} / \mathrm{m}^{2}$ ) are essential. Furthermore, because of the benefit to ITER schedule, costs, and mission that would result from the ability of the divertor to withstand $3 x$ higher heat loads (comparable to DEMO), the test facility should be able to provide these loads $\left(\sim 100 \mathrm{M} \cdot V / \mathrm{m}^{2}\right)$ for periods greater than 100 seconds.

Other elements important to heat flux testing are the ability to readily change tile and coolant tube materials and structures (fabrication techniques) to assess their qualities.

A variety of techniques could produce these heat fluxes. Electron, ion, neutral and plasma beam devices should all be capable. For these tests there is a need to have the heat flux arrive at small angles to model tile-gap effects. However, an integrated test, in an intense hydrogen plasma environment must eventually be performed because of potential problems associated with hydrogen embrittlement and altered thermal conduction properties of redeposited films and eroded tiles.

\section{VII.2. Erosion/redeposition}

The technical requirements for an erosion/redeposition facility are stringent. Detailed plasma parameters must be attained as well as detailed geometry. To get the proper measure of the resistance of a particular material to sputter and RES erosion, not only must the ion and electron temperatures immediately adjacent to the sheath be the same as in ITER, but materia! temperature and the shrath potential drop, $\phi_{s^{\prime}}$ must be the same. The ITER SOL plasma is marginally collisional. Hence some hot electrons from the midplane can reach the plate (without collisions) and increase the sheath potential

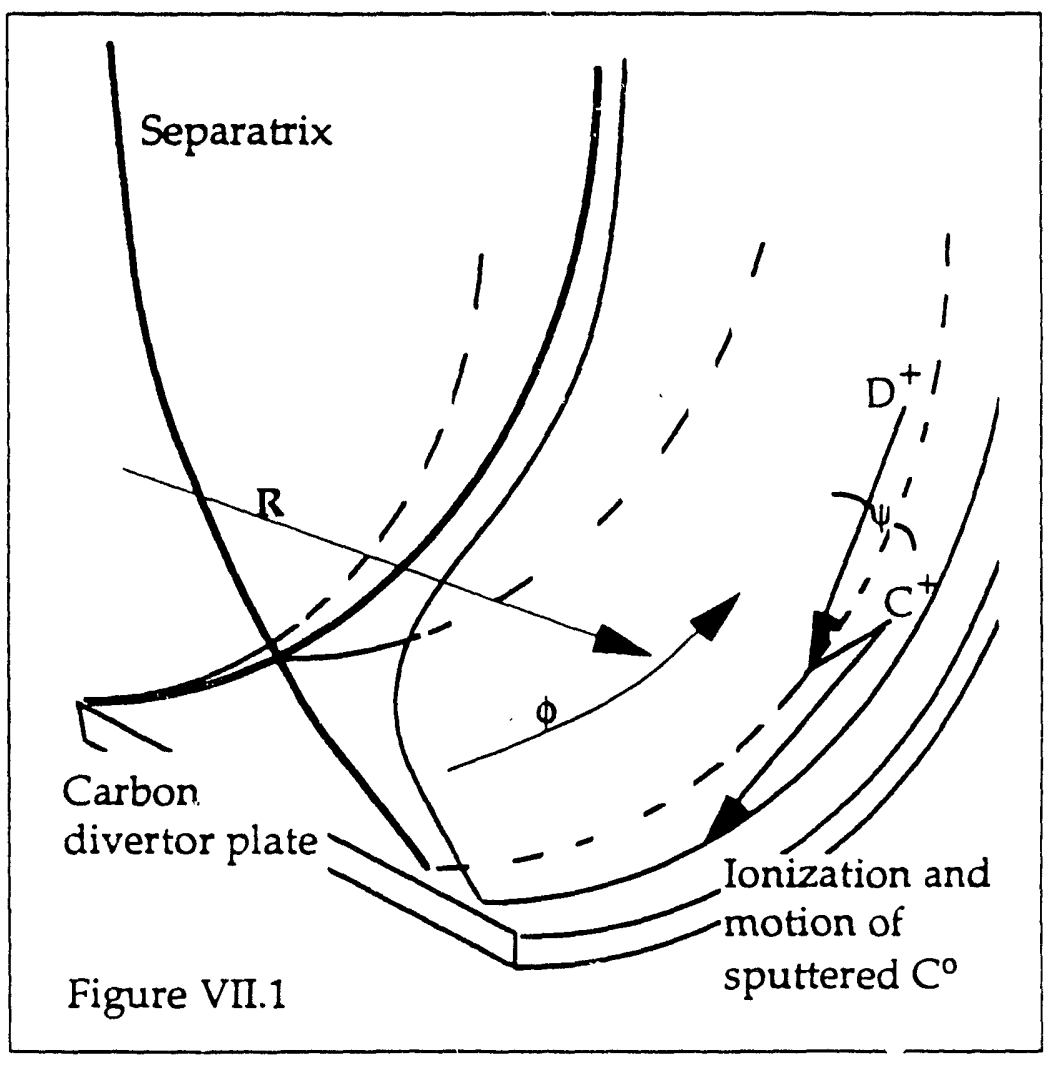


above $3 x$ the local electron temperature. This would increase the impacting ions energy and the sputter erosion. The electron density and temperature at the sheath must match ITER's for reasons to be noted in the next paragraphs. Additionally, the ion species mix must be the same, i.e. roughly $85 \% \mathrm{D}, 10 \% \mathrm{He}$, and a few percent each of $C$ and $O$, again to match the sputter rate.

Geometrical aspects of the redeposition location are shown in figure VII.1. Consider a deuterium ion positioned just outside the separatrix. It moves predominantly along the total magnetic field down towards the divertor plate. The magnetic field line intersects the divertor plate at a grazing angle of only $\Psi \sim 2^{\circ}$. When the deuterium ion impacts the divertor plate a carbon atom may be sputtered from the surface. (The predicted angle of impact is $\sim 60^{\circ}$ due to the sheath acceleration.) The carbon atom is initially neutrai, hence its trajectory may cross magnetic surfaces. The tilt of the divertor plate promotes a radially outward motion for the atom. The atom will not proceed very far from the plate before it is ionized by electron impact, the rate of which is directly proportional to the electron density and more strongly on the electron temperature. Depending on the forces on the newly created carbon ion $\mathrm{C}^{+}$, it may flow back to the plate and be redeposited, or may move up towards the midplane. In the first case, the $\mathrm{C}^{+}$will land at a position displaced both toroidally, due to its trajectory following the total magnetic field, and radially, because of $\mathrm{C}^{\bullet}$ motion across flux surfaces. The exact values of these shifts depend on the plate tilt with respect to the magnetic field and the flux surfaces, the ionization location, and the forces on the ions. The forces on the ions arise from electric and magnetic fields, drag from the $D^{+}$flow, and plasma thermal gradients. Electric fields are most strong in the sheath. In unmagnetized plasmas the sheath is very thin, but in tokamaks the thickness of the sheath may be lengthened to a size comparable to the ion gyroradius (actually $3 c_{s} / \omega_{c i}$ where $c_{s}$ is the ion sound speed and $\omega_{\mathrm{ci}}$ the ion gyrofrequency), if the magnetic field is oriented nearly parallel to the material surface. In Table VII.2 are listed characteristic lengths for this situation. The lengths include the magnetic sheath, $\lambda_{\text {Magn' }^{\prime}}$ the standard Debye sheath, $\lambda_{\text {Debye }}$ and the ionization mean-free-path for sputtered $C$ and $W$ and reflected $D$ for a plasma having parameters comparable to the ITER ignited physics phase scenario (Table V.1) and the same magnetic field as in ITER's divertor region.

Clearly, $W$ would be most affected by the magnetic sheath. If the plasma parameters were different than assumed, the ionization mean-free-paths would grow $\propto T_{e}^{-0.5}$ to +0.5 , including the effects of sputter energy, ionization rate, and plasma density. The ion gyroradius, $\lambda_{\text {Magn }} \propto T_{e}^{1 / 2}$. The Debye length would grow $\propto T_{e}$ for constant plasma pressure. Hence, the relative values of the dimensions listed in Table VII.2 would change little. 


$$
\Delta_{\mathrm{P}}(\mathrm{FWHH}) \gg \lambda_{\mathrm{D}} \gg \lambda_{\mathrm{C}}>\lambda_{\mathrm{W}} \sim \lambda_{\text {Magn }} \gg \lambda_{\text {Debye }}
$$

This ranking is only valid for $T_{e}>5 \mathrm{eV}$, otherwise the ionization rate is too low. Thus it is required that a divertor test facility be able to produce hot electrons, 10- 200 $\mathrm{eV}$, the first appropriate to ITER scenario A1, the latter to B6.

For the situation described in Table VII.2, the poioidal and toroidal displacements of the redeposited $C$ are approximately $(0.08 \mathrm{~cm} \times \sin$ (plate inclination)) $\sim 0.05 \mathrm{~cm}$ and 1.4 cm, respectively. Complicating this simple picture are omission of $\mathrm{E} \times \mathrm{B}$ drifts in the sheath, gyromotion, and the energy and spatial distributions of sputtered particles.

As readily seen from the above description, a smaller magnetic field would increase the ion gyroradius, hence the magnetic sheath thickness. This would increase for $C$, in particular, the importance of the sheath field for redeposition, but it would also increase the step size. From the above estimates, a two-fold reduction in B appears to be acceptable in a test facility for carbon erosion/redeposition. The angle of incidence of the total magnetic field B onto the divertor plate need not be as grazing as $2^{\circ}$ because of the (cos $\Psi$ ) dependence of the magnetic sheath thickness. An angle of $\sim 30^{\circ}$ would reduce the magnetic sheath thickness by a factor of two. Thus the two changes, less grazing but lower B, would tend to cancel. To far a deviance from the ITER parameters is, however, deemed ill advised.

The angle of the test divertor plate with respect to the magnetic flux surfaces must, however, remain close to that specified for ITER, $15^{\circ}$, because of the effects on hydrogen recycling and radial transport of sputtered particles. The estimated step size of $0.05 \mathrm{~cm}$ for poloidal motion, when divided into the width of the heat flux profile on the divertor plate , $10 \mathrm{~cm}, \Delta_{\mathrm{p}}$ (FWHH) $/ \lambda_{C}=200$, explains why the redeposition process extends the lifetime of the plate up to 100 times.

The spatial extent of the irradiated surface must be $10 \mathrm{~cm}$ in the poloidal direction, equal to that in ITER. The required length in the toroidal direction depends on the angle $\psi$, because that sets the number of steps before redeposited atoms exit the irradiated area. For $\psi=30^{\circ}$, the toroidal extent needs to be about four times the poloidal (because the step size is twice longer), i.e., $\sim 40 \mathrm{~cm}$. At a more grazing angle, $5^{\circ}$, the toroidal extent would have to be $-3 \mathrm{~m}$. Note that as the total compound angle of the divertor becomes more grazing, the erosion/redeposition facility must provide more power flow per unit area along the magnetic field. That power flow must remain consistent with the plasma parameters at the divertor plate sheath.

The distance between the divertor target region and the heat input (to the plasma) zone should be as close a duplication to the ITER values as necessary. It has been predicted that longer lengths reduce the sheath electron temperature, hence gross erosion. The tilt of the plates sets a lower limit for the length of the apparatus, as do the power input constraints. The values given in Table VII.3 represent geometrical lower limits based solely on the tilt of the plate. Further study is necessary to see if they are adequate to test redeposition processes which may be affected by thermai gradients along $B$, recycling conditions, or plasmas flows.

The erosion/redeposition facility must be supported by diagnostic systems capable of measuring the properties of the redeposited films, e.g., thermal conductivity, 
adhesion, hydrogen content, mechanical stability, and sputter yield. Furthermore, a system to test the suitability of in situ repair must be available for preparing targets or repairing those eroded. And, obviously, a healthy program to develop alternate materials must exist.

Table VII.3 Technical requirements: erosion/redeposition facility

Facility parameters

Power flow $\left(\mathrm{MW} / \mathrm{m}^{2}\right)$

Onto surface

Along field

Pulse duration (s)

Irradiated area

Length (m)

Module change time

Fluence (s)

Duty factor (\%)

Sweep frequency $(\mathrm{Hz})$

Magnetic field (T)

Target orientation

to toroidal field

to poloidal field

Plasma parameters

$\mathrm{T}_{\mathrm{e}}(\mathrm{eV})$
$\mathrm{n}_{\mathrm{e}}\left(10^{20} \mathrm{~m}^{-3}\right)$

Plasma species
Minimum Value

30

100

400

$10 \mathrm{~cm} \times 40 \mathrm{~cm}$

$>1$

1 week

$3 \times 10^{7}$

33

$0.1-1.0$

2

$30^{\circ}$

$15^{\circ}$

$10-50$

2-6

$4 \mathrm{~T}_{\mathrm{e}}$

D, $\mathrm{He}, \mathrm{O}$
Preferred Value

100

500

3000 - steady state

$15 \mathrm{~cm} \times 300 \mathrm{~cm}$

$>3$

1 day

$$
3 \times 10^{7}
$$

75

$0.1-1.0$

5

$5^{\circ}$

$15^{\circ}$

$\mathrm{D}, \mathrm{H}, \mathrm{He}, \mathrm{O}, \mathrm{C}, \mathrm{Fe}$

\section{VII.3. Safety issues}

Tritium inventory in carbon PFC can arise from codeposition or trapping in damage sites. Experimental studies of these are already underway in a number of plasma devices, some listed in Table III.2. These facilities are not yet able to produce the fluence and exact plasma parameters at ITER's divertor. Nor can sufficiently large samples be irradiated to examine the effects of redeposition tens of centimeters from the location of most intense irradiation.

In the ITER divertor, the largest tritium inventories are expected on the coldest divertor regions because of thermal desorption of trapped hydrogen at temperatures above $\sim 600^{\circ}$. Hence, it is necessary for a divertor test facility to simulate the temperature excursions expected from sweeping operation. Also, the irradiated divertor tiles should have the exact geometry of the ITER reference tiles, because of thermal. gradients in the gaps between tiles.

One aspect that may not be readily addressed in a linear plasma simulator is the effects of disruptions on tritium trapping. Disruptions could liberate much carbon which would codeposit on nearby surfaces. The form of the carbon may be dust 
particles. There should be efforts to diagnose the form of the ablated carbon in existing tokamaks.

Other safety issues involve LOCA and LOFA scenarios. A divertor test facility should be able to simulated these conditions and have such incorporated into its test program. Diagnostics would be needed to measure gases and particulates evolved.

Based on these arguments, the requirements for a tritium inventory facility are identical to those for an erosion redeposition facility, with two exceptions. First is it is necessary to have a tritium plasma instead of $\mathrm{D}$ or $\mathrm{H}$ ? There is one tritium plasma facility already operating at low power. We must look to it for guidance as to whether operation of the IDEAL facility with tritium is necessary. Secondly, what can be done to get sufficient information on disruptions? A separate shock tube may be necessary if tokamaks are unable to deliver the information.

\section{VII.4. Helium exhaust}

To validate the exhaust of helium from the divertor plate/pump duct region will require geometry identical to that in ITER. Each pump duct opening is keystone in shape, with a height of $\sim 1 \mathrm{~m}$ and top/bottom lengths of $\sim 0.5 / 0.25 \mathrm{~m}$ respectively. These top/bottom lengths are essentially along B. Other aspects of the geometry that are important are the nose inside the pump duct and the bend in the divertor plate near the duct opening (see Figure V.1). The pumping speed at the duct opening must be 44 $\mathrm{m}^{3} / \mathrm{s}$. The expected particle throughput is approximately half that listed in Table V.1, $2 \times 10^{20} / \mathrm{s}$.

Adequate space must be available around the pump duct to test the novel concepts for improving helium exhaust and reducing tritium throughput. Among the schemes are: helium burial in $\mathrm{Ni}$; deuterium permeation through $\mathrm{Vn}$; and ICRF-assisted implantation of $\mathrm{He}$ or $\mathrm{D}$. To test these lower fluences are required than for erosion redeposition, though surface contamination by sputtered particles may be important to all of the schemes.

Furthermore, the impact location of the helium on the test plate must be controllable to simulate the predicted behavior in ITER, i.e., an outward-shifted $(30 \mathrm{~cm})$ peak for the helium flux relative to the D/T flux.

\section{VII.5. Disruption effects}

There are two categories to disruption issues: physics and technology. Under the physics label are questions of disruption frequency, power loads, currents in the PFC structures, runaway electron Table VII.4 Disruption parameters

Thermal quench:

$\begin{array}{lll}\text { duration } & (\mathrm{ms}) & 0.1-1 \\ \text { peak divertor energy load } & \left(\mathrm{MJ} / \mathrm{m}^{2}\right) & 12\end{array}$

Current quench/VDE duration (ms) $20-200$ peak divertor energy load $\left(\mathrm{MJ} / \mathrm{m}^{2}\right)$ peak wall current $\quad$ (MA) 4

Runaway electrons

peak energy $(\mathrm{MeV}) \quad 300$ average energy $(\mathrm{MeV}) \quad 40$ maximum current (MA) $\quad 10$ peak divertor energy load $\left(\mathrm{MJ} / \mathrm{m}^{2}\right) \quad 30$ parameters, and - importantly - methods to eliminate disruptions or reduce their 
severity. Given these inputs, the technology issues are compressed to a single question: how to avoid damage to the PFC from disruptions. Thus it is first necessary to get a detailed tokamak data base and understanding to extrapolate to ITER. Until then, it may well be wasted effort to test components to $10 \mathrm{MJ} / \mathrm{m}^{2}$, for example, when the real value may only be $1 \mathrm{MJ} / \mathrm{m}^{2}$.

The ITER guidelines for disruptions are in Table VII.4. A test facility must have plasma to fully simulate the shielding/redeposition phenomena expected.

\section{VII.6. New divertor concepts}

Several new divertor concepts have been proposed. These are: liquid metals; ponderomotive forces for sweeping plasma loads across the divertor; gaseous neutralizers; biased divertor plates; and thermionically emitting divertor plates. Additionally, tests of various high- $Z$ materials are suggested by the US CDA Review Panel.

It is important that a divertor test facility be able to accommodate each of these. Because each novel divertor has different capabilities, the required testing program would be different from that planned for conventional divertor designs. In Table VII.5 are listed whether four of the technology issues are different for each of the novel designs compared with the conventional

Table VII.5 Will novel divertors have different behavior than conventional designs?

\begin{tabular}{|c|c|c|c|c|}
\hline Novel concept & Heat & Redep & Helium & Safety \\
\hline Liquid metal & yes & yes & yes & yes \\
\hline Gaseous & yes & yes & yes & yes \\
\hline Thermionic & yes & yes & yes & yes \\
\hline Ponderomotive & yes & no & no & no \\
\hline High-Z & yes & yes & yes & yes \\
\hline Biased & yes & yes & yes & yes \\
\hline
\end{tabular}
design. This table does not imply that redeposition, helium exhaust, and tritium inventory are unimportant to ponderomotive effects, but that it is likely that they would be the same whether plasma sweeping was accomplished by ponderomotive forces or PF coils. Heat removal is different because the ponderomotive technique may require input of $>10 \mathrm{MW}$ of auxiliary power.

The liquid metal divertor would have different behavior than conventional designs in all technology areas. It is expected to have heat load limits 3-10 times greater than solid carbon plates. Redeposition would be rather different too, particularly in that it is not a lifetime determining phenomenon. Depending on the liquid metal concept, i.e., showerhead design versus free-flowing surface, the helium exhaust geometry would be rather different. Tritium inventory is also quite different, Tritium reprocessing could take place when the liquid metal exited the vacuum chamber. For these reasons, a shorter test program is necessary, compared to conventional designs, to qualify liquid metal divertor. Other safety issues, too, are different, including corrosion and chemical reactivity.

Gaseous divertors also would have a rather different test program. Erosion is expected to be less important since the impact ion/neutral energies are small. Thus only a short lifetime test is required. The need to develop helium exhaust schemes may take an appreciable amount of time. 
The differences expected for biased, high-Z, and thermisnically emitting divertors are smaller than for liquid metals or gaseous neutralizers, but nevertheless significant. Heat loads could differ because of the change in sheath potential or material reflection properties. Plasma flows could be different, thus altering helium exhaust and tritium implantation. Notwithstanding, it is anticipated that the lifetesting program would likely be similar to that for conventional designs. 


\section{CANDIDATE DESIGNS}

\section{VIII.1. Plasma devices}

In section III.5, several plasma tacilities were named as candidate designs for a diverto: technology test facility. In this section we discuss the ideas behind these concepts. In the appendices are attached more detailed descriptions of some of these machines, written by their proponents.

The common denominator for all of these machines is that they are hydrogen plasma devices. Other facilities, ion or electron beams for example, exist or could be built to provide means to study erosion, RES, and thermomechanical properties without plasma irradiation. However, exposure to hydrogen plasmas must be considered as the only proper divertor plate testing environment because of the known interactions of chemical sputtering, hydrogen embrittlement, arcing, and so forth.

\section{VIII.2. Linear configurations}

The goal of linear designs is to simulate the plasma parameters in a flux tube similar to that in the ITER SOL. Linear devices could operate steady-state in a straightforward manner.

Linear designs differ from each other in magnetic configuration as well as heating method. The two main magnetic configurations are the mirror and the uniform solenoid. Mirrors are used to increase the plasma confinement, possibly increasing the plasma temperature and density. Because a reasonably large mirror ratio, $\sim 10$ or greater, is generally required, the field in the central region is limited to a few kilogauss. Mirrors suffer from well-known instabilities, e.g., the AIC, which must be stabilized. This has been achieved, in the TARA device for example, by ponderomotive forces. As listed in Table III.2, short, 2-3 m, mirror devices have achieved the $100 \mathrm{eV}$ ion and electron temperatures expected in the ITER SOL.

Simple solenoidal devices, or those with B decreasing along the length, do not have the same instability problems of the mirror, though possibly they may suffer from interchange modes. Increases in plasma parameters must be achieved by increases in the length of the devices, applied power, or other means.

Energy may be coupled into the plasma though solid surfaces, e.g., cathodes, or by volumetric processes such as wave or beam heating. The PISCES and other arc devices are members of the first class. These devices have a limited ability to produce a thermal plasma with ITER's SOL characteristics because the heat load on the surfaces would then equal that on the divertor plate under test. Since the conditions at the divertor plate are expected to be extreme, it is unlikely that the cathode surfaces could bear that load. Heating by neutral beams is unlikely to be suitable because they are not able to produce, in a practical manner, the high currents $(\sim 1000 \mathrm{~A})$ at the low voltages $(\sim 1000$ $\mathrm{V})$ necessary for most testing. Also, charge exchange losses may be a severe problem. A variety of wave heating schemes may be considered. Ion heating appears the best method, in part because of the likelihood of matching ITER SOL hot ion conditions, and also because power supplies are markedly cheaper at lower frequencies.

\section{VIII.3.Toroidal configurations}

Toroidal configurations can be used to study physics as well as technology issues. 
One important aspect of toroidal machines deserves special mention. Those tokamaks that operated 10-20 years ago had similar plasma parameters in their cores as ITER is predicted to have in its SOL. Hence, insights for ITER SOL parameters scaling is likely to come analysis of data from these old machines. However, the more complex construction of toroidal devices, as well as their historically poor uptime, makes dubious their ability to test reliability issues or to perform accelerated life testing. We do note that the TRIAM tokamak, now operating in Japan, has current drive capability and superconducting coils. With these it has achieved pulses in excess of 1 hour, albeit, at lower densities than needed for ITER divertor testing. ATF, at ORNL, similarly is a steady-state machine. The proposed STE and SST tokamaks would also have long pulse lengths.

Candidate toroidal devices differ from each other in a variety of ways. First is the magnetic configuration. As noted in the appendices, tokamaks, stellarators, or even simple tori with no applied rotational transform could be used. In all these cases, the devices are operated in their standard configurations, with closed magnetic surfaces inside the separatrix. However, one could envision a toroidal system with no closed flux surfaces, i.e., with the divertor test plates cutting fully across the device aperture. To date, this option has not yet been analyzed. 


\section{RECOMMENDATIONS}

1. DOE should mandate extensive SOL physics and disruption research on existing tokamaks. There are sufficient facilities in the US, especially at DIII-D and AlcatorCmod, to accomplish this. These machines have unique capabilities in the world. TFTR is not considered suitable for disruption studies because of the inherent competition to its $\mathrm{D} / \mathrm{T}$ program. However, it, too, has unique capabilities for divertor research in its high-beta naturally-diverted configuration.

2. DOE should continue support of the existing D\&T divertor technology programs which have provided the basic data and understanding of the severity of the divertor problem. These will lead the way to developing and selecting alternate materials and advanced concepts for testing in a technology test facility.

3. DOE should commit FY 1992 funds for detailed designs of a toroidal and a linear plasma facility for integrated tests of heat flux, erosion/redeposition, tritium inventory, and helium exhaust. Detailed cost, schedule, and test programs must be analyzed in the technical designs.

4. These design efforts should be performed by a consortium of university, industry and national laboratory personnel. Foreign support, under the ITER banner and elsewhere, should be pursued.

5. The facility designs and test programs must stress how they will improve ITER safety, reliability, and performance.

6. Separate efforts to define stand-alone heat flux (e.g., NB source or electron gun) and disruption simulation (e.g., shock tubes or e-beams) facilities shouid also be made.

7. Selection of the integrated test facility should be made at the end of FY 1992. Construction should be completed within 18 months and operations commenced. 


\section{APPENDICES}

\section{A. ITER Divertor Experiment and Laboratory (IDEAL)}

As presented at the Workshop on Edge Plasma Physics for ITER and BPX (Princeton January 1991), simple linear plasma devices should have the potential to provide the plasma parameters (density, temperature, heat load, power flow), fluence, duty factor and geometry to satisfy all the technical requirements listed in Section VII. Mirror devices are not needed and are possibly undesirable because of potential instability problems. Stability may be obtained in a linear device through the natural cusp shape of a magnetic beach, augmented by use of the quadrupole magnets or the ponderomotive force. Confinement is set by end losses. The total energy confinement time needed is only $\sim 0.1 \mathrm{~ms}$, a value readily exceeded in much shorter machines than that described here.

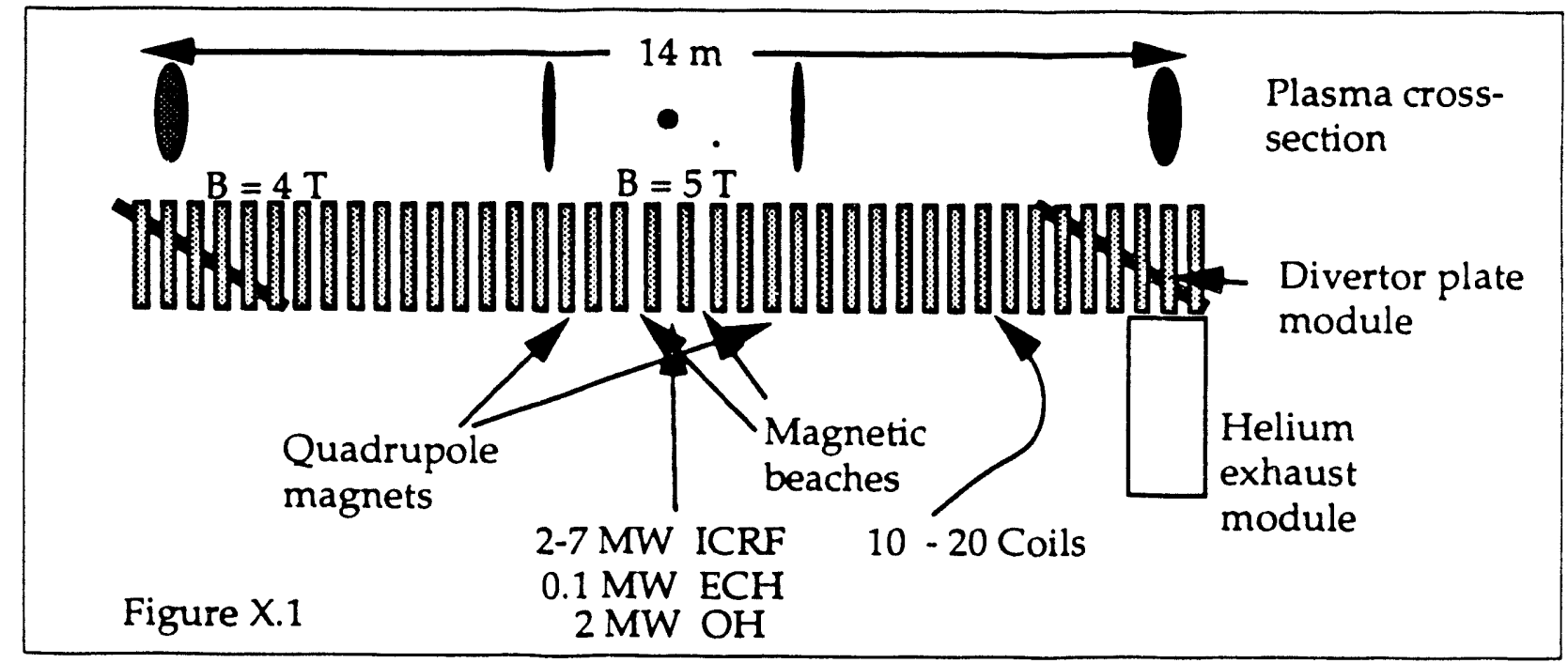

The candidate device is shown schematically in figure X.1. In a solenoidal central cell of $\sim 0.04 \mathrm{~m}$ radius and $5 \mathrm{~T}$ magnetic field, plasma heating is accomplished by 2-7 MW of ICRF waves absorbed in a magnetic beach. This technique has been used for 30 years, first at high powers, $>1 \mathrm{MW}$, on the C-Stellarator. More recent work, on the Phaedrus and Tara mirror machines repeated these experiments with virtually identical results, i.e., ion and electron temperatures of 500 and $100 \mathrm{eV}$ respectively. (Direct electron heating may be supplemented by $\mathrm{OH}$ or $\mathrm{ECH}$ at the $0.1-2.0$ MW level.)

The length for the central cell, $\sim 3 \mathrm{~m}$, is chosen to match power the minimum throughput capability of the ICRF antenna, $100 \mathrm{~W} / \mathrm{cm}^{2}$. Beyond the magnetic beaches are quadrupole magnets which flatten the cylindrical plasma into a ribbon of $3 \mathrm{~cm}$

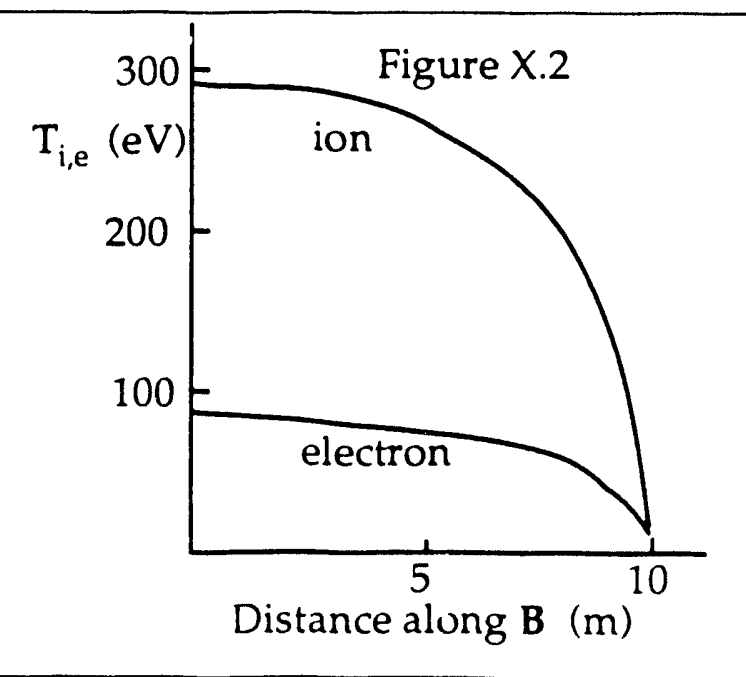


thickness and $20 \mathrm{~cm}$ breadth. The plasma drifts about $2 \mathrm{~m}$ in another solenoidal section where $B$ is about $4 \mathrm{~T}$. At the end of the drift sections the plasma impacts on tilted divertor plates. The axial (corresponding to the toroidal) tilt of the surface normal with respect to $B$ is $85^{\circ}$. This increases the length of the plasma-irradiated region from $20 \mathrm{~cm}$ to $200 \mathrm{~cm}$. The tilt in the vertical direction (corresponding to the poloidal direction) is $75^{\circ}$, which increases the irradiated region a factor of 3.9 to $12 \mathrm{~cm}$ in the poloidal direction. This last estimate is in the absence of plasma cross field transport. Transport at the Bohm rate would increase the irradiated area $\sim 30 \%$. The total irradiated area is $2500 \mathrm{~cm}^{2}$. B2 calculations show that the peak power flow along B with $2 \mathrm{MW}$ injected power is $-200 \mathrm{MW} / \mathrm{m}^{2}$, which is about $20 \%$ greater than that predicted for ITER in the physics phase. The peak power load on the plate is about $7 \mathrm{MW} / \mathrm{m}^{2}$. This excludes safety factors. (A factor of 2 loss of parallel power flow due to radiation and radial transport is predicted by B2.)

B2 code simulations of this plasma also give densities and temperatures quite similar to those predicted for the ITER divertor (see Figure X.2). Higher sheath temperatures are predicted to result at lower recycling confficients. Thus, this device is predicted to give the warm electron population, $T_{e} \sim 10-50 \mathrm{eV}$, in conjunction with a high density at the divertor plate that are necessary to test redeposition phenomenon.

In the B2 modeling, the ions are heated by ICRF only. The electrons are heated only by collisions with the ions. Direct electron heating could be accomplished by Ohmic heating to $2 \mathrm{MW}$, low enough to avoid kink modes. Such a method could duplicate nonthermal electron distributions. Using electron cyclotron resonance, lower hybrid, or electron-Bernstein waves at similar power is much more costly. Control of the divertor plate potential with respect to the plasma potential could be accomplished with dc biasing.

The cost to construct this device depends heavily on the choice of magnets and the site credits. Superconducting magnets are more expensive to purchase but inexpensive to run. Normal copper magnets are cheap to build arfd.expensive to run. At a $50 \%$ duty factor, the two options balance in about 5 years. PPPL has extensive site credits in CW ICRF power supplies and DC power supplies.

Because of the linear configuration, extensions of length and/or heating power would be easy to implement. Such upgrades may be necessary if improved divertor plate materials or designs are found which would tolerate higher heat loads than currently thought possible. In this manner, DEMO-like parameters could be tested. It would also be comparatively easy to test exotic divertor schemes, such as the liquid metal, or novel deposition methods, such as a gas feed stock. 
Appendix B

Steady-State Standard and Spherical Tokamaks as ITER Divertor Simulators

Y-K. Martin Peng 


\section{APPENDIX \\ STEADY-STATE STANDARD AND SPHERIC. IL TOKAMAKS \\ AS ITER DIVERTOR SIMULATORS \\ Y-K. Martin Peng \\ April 10, 1991}

Table of Content

I. Introduction

II. The Divertor Challenge - An Integrated Description

III. Mission and Features of Integrated Divertor Simulators

IV. Examples of Small Steady-State Tokamaks and STs

V. Physics Data Base and Accommodation of Uncertainties

VI. Conclusion and Discussion

Acknowledgement

References 


\title{
STEADY-STATE STANDARD AND SPHERICAL TOKAMAKS AS ITER DIVERTOR SIMULATORS
}

\author{
Y-K. Martin Peng \\ Draft-2, April 10, 1991
}

\begin{abstract}
Broad advances in tokamak physics have been achieved in recently years. Also, several first-generation experiments [1-5] of the spherical tokamak (ST, tokamak with aspect ratios approaching unity) are presently being designed, under construction, or in operation. These introduce the possibility of using low-cost tokamaks and STs for deoeloping fusion technologies needed by ITER. Small steady-state tokamaks and STS using auxiliary heating and current drive are estimated to be capable of producing steady-state ITER-leoel plasma edge, SOL, and divertor parameters. With demountable toroidal field coils and divertor modules, they become suitable for testing and developing innooative, integrated divertor solutions for ITER, an area in critical need of near-term $R E D$. Relative to the standard tokamak, the ST can be compact in size, modest in magnetic field, and high in plasma current and beta $[6,7]$. The small major radius, plasma volume, and surface-to-oolume ratio lead to minimal heating and current-drive powers in the ST. Assuming that the tokamak data base provides for adequate regimes of steady-state operation, the general features and parameters of such devices can be characterized by $R_{0}-0.5 \rightarrow 1.0 \mathrm{~m}, A-1.4 \rightarrow 3, \mathrm{~K}_{x}-2.5 \rightarrow 2.1, \mathrm{~B}_{10}-1.0 \rightarrow 2.5 \mathrm{~T}$, and $I_{p} \leq 1 \mathrm{MA}$. The physics data base and the approaches to accommodate its remaining uncertainties, needed to make these deoices reliable and cost-effective ITER divertor simulators, are identified. Conceptual design to clarify the potential and uncertainties of such devices jointly with the divertor deoelopers is suggested.
\end{abstract}

\section{Introduction}

A recent U.S. review of the ITER-CDA design identified the divertor as an area in critical need of development $[8,9]$. The review further mandated physics/technology R\&D efforts to address these issues and develop advanced concept divertor solutions. This echoes the conclusion of an earlier steady-state tokamak workshop [10], which identified the steady-state operation with regard to plasma-surface interactions and the development and demonstration of the capability for continuous heat and particle removal as the leading R\&D area of critical importance. In this paper we will discuss a near-term, low-cost tokamak and ST approach to carry out this critical research and develop the needed divertor solutions for ITER, jointly with the divertor developers, before installation of ITER divertors in as early as 2001.

To define the proper mission and the required features of such small steady-state devices, the nature of the divertor physics/technology issues needs to be claridied. We will describe in Section $I$ these issues in terms of the strong interactions between the 
tokamak edge physics mechanisms and the divertor technologies of plasma-material interaction (PMD) and high heat flux (HHF), and the intrinsic constraints thereof. The mission and the required features of such integrated ITER divertor simulators will then be presented in Section III.

The approximate parameters of such devices will be discussed in Section IV, estimated by using the present tokamak data base. Great progress in this area has been made worldwide through experiments on and analysis of tokamak plasmas. The tokamak has recently exhibited 1) good confinement, as in the quiescent $\mathrm{H}$-mode [11]; 2) stable high beta, with average betas above $10 \%[12]$ or $\varepsilon \beta_{p}$ of order unity $\left.[13,14] ; 3\right)$ efficient heating of the plasma by neutral beams (NBs) and if waves providing tens of megawatts of power $[15,16]$; 4) successful noninductive initiation, ramp-up and maintenance of plasma currents $\left(I_{p}\right)$ up to $2 \mathrm{MA}$ [17-20]; and 5) operation of high-recycle divertors with $\mathrm{H}$-mode plasmas for durations of up to several seconds $[21,22]$.

In addition, several first-generation ST experiments are presently being designed, under construction, or in operation. These include 1) the START experiment [1], currently in operation at Culham, U.K.; 2) the CDX-U (PPPL) [2], HIT (Univ. of Washington) and SPHEX (UMIST, U.K.) [3] currently under modification, construction, and in operation, respectively, to test helicity injection current drive in the ST configuration; 3) the proto-ETA and TBR-2E devices [4] currently being designed in Brazil; and 4) the GLOBUS device [5] currently being designed and under initial construction at the Ioffe Institute, U.S.S.R. As can be seen in Table 1, these ST experiments project $I_{\mathrm{p}} \approx 30-500 \mathrm{kA}, A \approx 1.2-1.6$, and plasma durations up to $0.5 \mathrm{~s}$. In particular, the START experiment is expected to provide, in a year's time, initial data on whether the ST plasma is basically tokamak-like [1]. Confirmation of heating and current drive of the ST plasma are expected in the next few years.

Table 1. First-Generation Spherical Tokamak Experiments

\begin{tabular}{llllllll}
\hline $\begin{array}{l}\text { Device } \\
\text { Country }\end{array}$ & $\begin{array}{l}\text { START } \\
\text { UK }\end{array}$ & $\begin{array}{l}\text { CDX-U } \\
\text { US }\end{array}$ & $\begin{array}{l}\text { HIT } \\
\text { US }\end{array}$ & $\begin{array}{l}\text { SPHEX } \\
\text { UK }\end{array}$ & $\begin{array}{l}\text { Pr-ETA } \\
\text { Brazil }\end{array}$ & $\begin{array}{l}\text { TBR-2E } \\
\text { Brazil }\end{array}$ & $\begin{array}{l}\text { GLOBUS } \\
\text { USSR }\end{array}$ \\
\hline$R_{0}(\mathrm{~m})$ & 0.23 & 0.33 & 0.3 & 0.25 & 0.27 & 0.40 & 0.50 \\
$A$ & 1.2 & 1.4 & 1.5 & 1.1 & 1.5 & 1.6 & 1.5 \\
$I_{\mathrm{p}}(\mathrm{kA})$ & 150 & 30 & 300 & 150 & 150 & 300 & 500 \\
$\mathrm{~K}^{\text {Duration (s) }}$ & 1.6 & 1.5 & 1.4 & 1.3 & 1.5 & 1.5 & 2.0 \\
Technique $^{\dagger}$ & 0.02 & 0.1 & 0.1 & 0.005 & 0.05 & 0.3 & 0.5 \\
Statust $^{\ddagger}$ & $\mathrm{I}+\mathrm{C}$ & $\mathrm{HI}+\mathrm{I}$ & $\mathrm{HI}$ & $\mathrm{HI}$ & $\mathrm{I}$ & $\mathrm{I}$ & $\mathrm{I}$ \\
& $\mathrm{O}$ & $\mathrm{O} / \mathrm{C}$ & $\mathrm{C}$ & $\mathrm{O}$ & $\mathrm{D}$ & $\mathrm{D}$ & $\mathrm{D} / \mathrm{C}$ \\
\hline
\end{tabular}

${ }^{\dagger} \mathrm{I}=$ induction; $\mathrm{C}=$ compression; $\mathrm{HI}=$ helicity injection.

to $=$ operation; $C=$ construction; $D=$ design. 
These recent and expected near-term accomplishments provide for adequate regimes of steady-state operations. The standard tokamak and the ST will be considered to clarify the trade-offs in aspect ratios.

Finally, it is important to identify the core plasma conditions that permit reliable operations in these devices. Given that some uncertainties in the data base will remain, it is of interest to see whether these devices can be designed to accommodate the uncertainties and still produce the appropriate plasma conditions. Section $V$ will present some initial considerations in this area. Conclusions and some discussion on other important applications of small steady-state STs will be presented in Section VI.

\section{The Divertor Challenge - An Integrated Description}

A comprehensive discussion of the divertor challenge in ITER can be found in recent physics considerations of the ITER conceptual design [23]. The ITER divertors are to handle the bulk of power and particle fluxes produced by the plasma $\left(P_{\alpha}-200 \mathrm{MW}\right)$, which may also receive large auxiliary drive power $\left(P_{\text {aux }}-100 \mathrm{MW}\right)$. Since the active divertor plate area in ITER can at best be $-5 \%$ of the total wall area (which is $-10^{3} \mathrm{~m}^{2}$ ), serious technical challenges should be expected. R\&D needs separately in the plasma physics and the technology areas have been clearly identified $[8,23]$. However, a recent review of the ITER CDA [9] also identified reliable steady-state divertor solutions also as an area in critical need of R\&D.

A divertor solution must account for the interactions between the tokamak plasma and the divertor components, and perform under steady-state (for 200-2000 s), H-mode, TTER-level SOL and divertor plasma conditions. These interactions are listed in Table 2 , and can be characterized as follows:

1. The divertor plate heat flux for the ignition-phase ITER plasma is estimated to be near the thermo-hydraulic and thermo-mechanical limits $\left(-15 \mathrm{MW} / \mathrm{m}^{2}\right)$ for sustained reliable operation, under a relatively conservative assumption of $\chi_{\perp}$ $\left(-2 \mathrm{~m}^{2} / \mathrm{s}\right)$ for the cross-field heat diffusivity of the SOL plasma.

2. Under the same assumption, the peak plasma temperature at the divertor sheath is estimated to be no less than $T_{\text {ed }}-45 \mathrm{eV}$ for a plasma edge density of no more than $n_{x}-3.5 \times 10^{13} \mathrm{~cm}^{-3}$ [24]. This value of $T_{\text {ed }}$ is too high to avoid excessive sputtering erosion of the graphite divertor plates, even after assuming a $99 \%$ probability of in-situ redeposition of the eroded material.

3. Sputtering of the divertor plate material introduces impurities in the SOL plasma. To prevent the impurities from excessive accumulation in the core plasma, ELMv $\mathrm{H}$-mode operation is necessary, degrading the core plasma confinement by about $30 \%$ [25] below the $\mathrm{H}$-mode [26] condition required for ignition in ITER. 


\begin{tabular}{|c|c|c|c|c|}
\hline Parameters & $\begin{array}{l}\text { Strong } \\
\text { Interactions }\end{array}$ & $\begin{array}{l}\text { Divertor } \\
\text { Constraints }\end{array}$ & $\begin{array}{l}\text { Non-divertor } \\
\text { Requirements }\end{array}$ & Uncertainties \\
\hline $\mathrm{W}_{\mathrm{div}}\left(\mathrm{MW} / \mathrm{m}^{2}\right)$ & $\Delta_{Q}, T_{\text {ed }}, \theta_{d}$ & $\leq 15$ (heat removal) & 215 (heat input) $^{\dagger}$ & $\chi_{1}, D_{1}$ \\
\hline$T_{\mathrm{ed}}(\mathrm{eV})$ & $W_{\text {divo }} n_{x}, n_{z}$ & $\Omega 25$ (erosion) & 245 (heat flux $^{\dagger}$ & $\begin{array}{l}\text { disruptions, RES, } \\
\text { redeposition }\end{array}$ \\
\hline$H_{\text {fac }}$ & $n_{\mathrm{Z}}, n_{\mathrm{He}}$ ELMs & $\begin{array}{l}\text { S1.4(impurity } \\
\text { removal) }\end{array}$ & $\geq 2.0$ (ignition) & H-mode scaling \\
\hline$n_{x}\left(10^{13} \mathrm{~cm}^{-3}\right)$ & $Q_{1}\left(W_{\text {div }}\right), T_{\text {ed }}$ & $\begin{array}{l}\geq 3.5 \text { (minimize } \\
T_{\text {div }} \text { and sputter) }\end{array}$ & $\$ 3.5$ (disruption) & $\begin{array}{l}\text { margin for } \\
\text { disruption-free } \\
\text { operation }\end{array}$ \\
\hline$n_{\mathrm{z}} / n_{\mathrm{e}}(\%)$ & $\begin{array}{l}W_{\text {divv }} T_{\text {ed }} \\
\text { disruptions }\end{array}$ & $\begin{array}{l}\text { introduce } \\
\text { impurities }\end{array}$ & $\begin{array}{l}55(\text { low-Z) } \\
50.5(\text { high-Z) }\end{array}$ & $\begin{array}{l}\chi_{z_{1}}, D_{z_{1}} \\
\text { vortex flow }\end{array}$ \\
\hline$\dot{N}_{\mathrm{He}} / \dot{N}_{\mathrm{DT}}(\%)$ & $\dot{N}_{Z}, \dot{N}_{\text {DT }}$ & $\begin{array}{l}<5(x \text {-point } \\
\text { gas-puff), }\end{array}$ & $\begin{array}{l}-5 \text { (pump } \\
\text { capability) }\end{array}$ & $\begin{array}{l}\text { plasma-flush } \\
\text { requirements }\end{array}$ \\
\hline
\end{tabular}

+ peak values after applying safety margins and strike-point sweeping.

4. Low levels of impurities cause thermal collapse of the SOL plasma when $n_{\times}$ exceeds a critical level $n_{x c}$, leading to core plasma disruption [27]. For the ignition-phase plasma of IIER, $n_{x c}$ is estimated to be $-3.5 \times 10^{13} \mathrm{~cm}^{-3}[28]$ and sets a lower bound on $T_{\text {ed }}$. In view of item 2 above, the ignition-phase plasma is expected to operate at the density limit of plasma disruption. It is also observed that this lower bound in $T_{\text {ed }}$ increases with increasing impurity content [27].

5. The above constraints apply equally to both divertor channels. Since the outboard channel in ITER is expected to receive 4-times the power as the inboard channel [23a], the disruption limit $n_{\times c}$ due to the inboard channel will force the outboard channel to operate at an $n_{x}$ substantially lower than otherwise possible. This raises $T_{\text {ed }}$ in the outboard channel, accentuating the difficulty of plate erosion. 6. A vortex flow pattern is expected in the ITER divertor and SOL plasma [29,30].
This flow pattem enhances the exhaust of helium as well as a reflux of impurities 
from the divertor to the plasma edge, which enhances the speed of impurity accumulation in the core plasma. Schemes to stem the reflux of impurities, such as the divertor gas puffing and active pumping, are being installed and tested in DIII-D [31] and JET [32]. These schemes are expected to impact essentially all the divertor plasma parameters listed in Talble 2.

The "gaseous-target" divertor [33] exemplifies the integrated nature of the divertor plasma mechanisms and PMI and HHF technologies. Successful test in a linear configuration [34] is so far limited to relatively small plasma sizes (cold neutral ionization mean-free-path $\lambda_{n c}<d_{\text {plasma }}<$ that for Frank-Condon neutral $\lambda_{\mathrm{FC}}$ ). Integration of the gaseous-target divertor into ITER will encounter the issues of: 1) the integrity of plasma-neutral interface when $\left.\lambda_{\mathrm{FC}}<d_{\mathrm{plasma}}, 2\right)$ the compatibility of the implied high $n_{x}$ with the disruption limit $n_{x c}$ [27], and 3) the compatibility of the implied high $n_{x}$ with the H-mode operation [26].

New techniques to resolve these issues of the gaseous-target divertor will most likely be required. Exploration for such techniques, and verification under steady-state conditions in a tokamak will likely be accompanied with frequent diruptions and loss of $\mathrm{H}$-mode. A near-term, low-cost, flexible, robust, and steady-state divertor tokamak or ST with ITER-level SOL and divertor conditions will therefore be needed in the effort to develop divertor solutions for ITER. Several other divertor innovations have been identified recently [35]. Most of these innovations need verification in such a tokamak divertor simulator before consideration by the STE [10], ITER and a DEMO [36], which are expected to have long turn-around times and low tolerance to divertor failure.

\section{Mission and Features of Integrated Divertor Simulator}

In view of the foregoing discussion, the mission of the integrated ITER divertor simulator is clear:

To carry out near-term, physics-technology-integrated tests and development of innooative divertor solutions under proper, steady-state conditions for future large tokamaks, such as STE, ITER, and DEMO.

The following features of the integrated divertor simulator are therefore required:

1. It must be capable of producing simultaneously ITER-level plasma edge, SOL, and divertor parameters, such as those identified in Table 2. In addition, the device should be operable somewhat beyond the constraints expected in ITER, to permit proper exploration of innovative concepts.

2. It must be flexible in configuration to accommodate readily all divertor innovations that warrant investigation [35]. A goal of -2 months down time to replace two complete test divertors and support systems appears reasonable. 
3. It must have robust construction to recover readily from disruptions and divertor component failure.

4. It must have reliable steady-state core plasma operation, by utilizing tokamak plasma conditions far removed from known limits and instabilities.

5. It must have high availability, by relying only on standard tokamak engineering and technology approaches, such as steady-state TFC of modest fields, if systems of readily available frequencies, NBI with moderate energies, etc. A goal for the overall device availability can be $-10 \%$, permitting, for example, about 10500 -s plasma pulses per day during a 4-month period of operation. Each test divertor can in principle be afforded a total plasma test time of $-10^{2}$ hours, or until divertor failure.

In addition, it is desirable for the device to require low cost ( $\$ 20 \mathrm{M}$, including the steady-state drive and the first test divertors) by making full use of existing fusion facilities; to be balanced in cost, size, and complexity between the torus and the test divertors; and to be a user facility that permit broadly based investigations of divertor innovations.

\section{Examples of Small Steady-State Tokamaks and STs}

Given the above-mentioned features, the basic configuration of such devices can be depicted in Fig. 1, which shows the elevation view of a double-null divertor tokamak or ST with the aspect ratio $(A)$ as low as 1.4.

1. Fully demountable, normal-conductor toroidal field coils (TFC) with steady-state cooling and essentially straight inner legs can be used. The joints are so located as to allow replacement of divertor and torus modules in straight vertical motion. For this not to require advanced technologies, the vacuum toroidal field $\left(B_{t 0}\right)$ at the major radius $\left(R_{0}\right)$ should not exceed $2.5 \mathrm{~T}$. The number of TFC return legs can be low (e.g., 12) to allow ample access to the divertor modules and the plasma torus.

2. A relatively simple set of steady-state poloidal field coils will be used, consisting of outer vertical field coils, divertor coils (within the divertor modules and/or external to the TFC bore), and possibly a relative small Ohmic induction solenoid (internal or external to the TFC bore) to assist initiation and ramp-up of the plasma current $\left(I_{P}\right)$.

3. For tokamaks with $R_{0} \leq 1 \mathrm{~m}$ and $A \leq 3$, it is not feasible to build a solenoid capable of initiating $I_{p}$ and maintaining it for more than a few seconds, even with auxiliary heating. Since highly intense auxiliary heating is needed to produce $\mathrm{H}$ mode plasmas with proper edge, SOL, and divertor conditions, non-inductive 
ORNL-DWG 9OM-309ORA FED

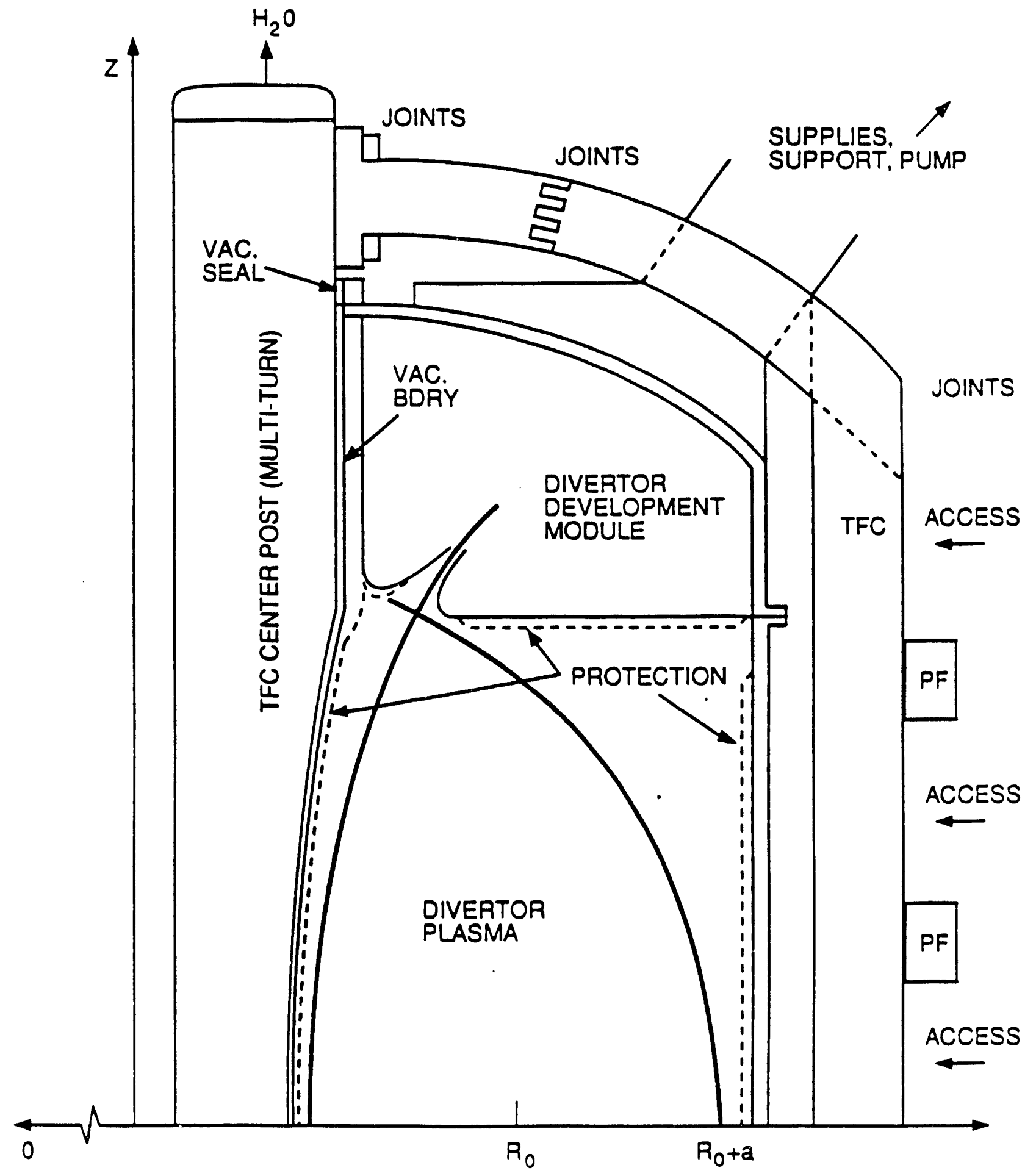

FIGURE 1. PRINCIPAL FEATURES OF A SMALL STEADY-STATE TOKAMAK OR SPHERICAL TOKAMAK 
current drive must therefore be used, as part or all of the heating power.

4. Toroidally complete divertor modules of relatively large volumes and detachable from the torus vacuum vessel are now possible. At the inner legs (or the center post) of the TFC, the modules should have detachable vacuum seals similar to those used in the START experiment [1]. The modules should have support, supply, power handling, and pumping systems separate from those for the main torus. The divertor modules should allow internal divertor coils when needed to produce the proper parameters for ITER-relevant tests.

5. A relatively standard plasma cross section of double-null divertors with elongations $k_{x}=2.0-2.5$ and triangularities $\delta_{x} \approx 0.4-0.7$ can be used. These values are somewhat dependent on $A$ and on whether the inner divertor channel is also to be scrutinized in the investigation. The tapering of the TFC inner legs toward the midplane, as permitted by the plasma cross section, can provide significant benefits for $A<2$.

The parameters of three examples are provided in Table 3: I) a standard tokamak with $A=3$ at the minimum radius of $a=0.3 \mathrm{~m}, \mathrm{I})$ an ST with $A=1.7, a=0.3 \mathrm{~m}$, and relatively high values of $B_{t 0} q$, and $L_{t}$, and Im) another ST with $A=1.4, a=0.36 \mathrm{~m}$, and somewhat lowered values of $B_{10} q$, and $L_{\gamma}$, but utilizing the potential advantages of high $I_{p}$ and $\beta$ of the ST. The plasma edge, SOL, and divertor parameters of interest are also estimated and shown in Table 4, together with the parameters projected for the ITER ignition plasma and for a DIII-D case [21].

It is seen that these examples are more conservative in assumptions than those currently used in estimating the basic parameters of the ITER conceptual design [37], and are well within the stable tokamak regimes. These include high $q_{95}$, moderate $n_{\mathrm{e}}$ and

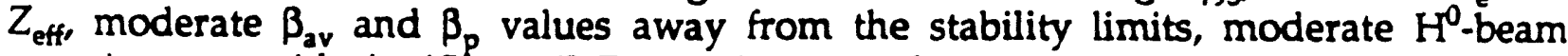
energies to avoid significant D-D reactions, moderate current drive coefficient $\gamma_{C D}$ bootstrap current fraction within the experimentally achieved range, and long $L_{4}$ and $L_{x d}$ (via high $q$ values) so that relatively collisional plasmas are obtained in the SOL. A minimum minor radius of $a=0.3 \mathrm{~m}$ is assumed to insure a plasma core relatively free of atomic effects.

A set of simplified scaling expressions $[24,27,28,38]$ are used to relate the expected plasma SOL and divertor parameters to those of ITER and DIII-D. In the case of a steady-state ST, improved estimates are introduced $[6,39]$ when the high- $A$ approximations are inaccurate or misleading. The devices are also chosen with economy as an important figure-of-merit, assuming that the installed cost is dominated by the weight and the steady-state auxiliary drive power of the device.

Some important trends in $A$ are evident from these examples. Relative to the STs, the standard tokamak $(A=3)$ requires about twice in $R_{0}, E_{\mathrm{b}}, P_{\mathrm{aux}}$ and $P_{\mathrm{tfc}}$ to achieve 
Table 3. Examples of Small Steady-State Tokamaks and STs

\begin{tabular}{|c|c|c|c|}
\hline Parameters & I & II & III \\
\hline Aspect ratio, $A$ & 3 & 1.7 & 1.4 \\
\hline Major radius, $R(\mathrm{~m})$ & 0.9 & 0.52 & 0.5 \\
\hline Safety factor, $q_{95}$ & 5.3 & 17 & 10 \\
\hline External toroidal field, $B_{10}(T)$ & 2.6 & 2.0 & 1.0 \\
\hline Plasma current, $I_{\mathrm{p}}$ (MA) & 0.81 & 0.52 & 1.0 \\
\hline Plasma volume, $V_{p}\left(\mathrm{~m}^{3}\right)$ & 3.0 & 1.9 & 2.6 \\
\hline Plasma surface area, $A_{\mathrm{p}}\left(\mathrm{m}^{2}\right)$ & 16.4 & 9.7 & 11.4 \\
\hline Avg. elec. density, $n_{e}\left(10^{20} \mathrm{~m}^{-3}\right)$ & 0.80 & 0.63 & 0.30 \\
\hline Avg. temperature, $\left\langle T_{n}(\mathrm{keV})\right.$ & 1.0 & 1.0 & 2.5 \\
\hline Poloidal beta, $\beta_{\mathrm{p}}\left(=2 \mu_{0}\langle p\rangle / \bar{B}_{\mathrm{p}}^{2}\right)$ & 1.9 & 1.7 & 0.9 \\
\hline Average beta, $\beta_{\mathrm{av}}\left(=2 \mu_{0}\langle p\rangle / B_{\mathrm{av}}^{2}\right)$ & 0.032 & 0.018 & 0.076 \\
\hline Plasma thermal energy, $W_{t h}(M)$ & 0.22 & 0.052 & 0.078 \\
\hline Required confinement time, $\tau_{E}(s)$ & 0.035 & 0.018 & 0.024 \\
\hline Conf. enhancement, $H_{\text {fac }}$ (ITER-P) & 2.0 & 2.0 & 1.9 \\
\hline Conf. enhancement, $H_{\text {fac }}$ (ITER-OL) & 1.2 & 0.9 & 0.8 \\
\hline Conf. Enhancement, $H_{\text {fac }}$ (ITER-H) & 1.8 & 2.4 & 2.2 \\
\hline Neutral $\mathrm{H}^{0}$ inj. energy, $E_{\mathrm{b}}(\mathrm{kV})$ & 80 & 30 & 35 \\
\hline NBCD power, $P_{\mathrm{b}}(\mathrm{MW})$ & 7.2 & 2.1 & 3.3 \\
\hline Additional heating power, $P_{\mathrm{h}}(\mathrm{MW})$ & 1.7 & 2.0 & 0 \\
\hline Bootstrap current fraction, $I_{b s} / I_{p}$ & 0.4 & 0.7 & 0.4 \\
\hline NBCD coefficient, $\gamma_{\mathrm{NB}}\left(10^{20} \mathrm{~A} / \mathrm{W} \mathrm{m}^{-2}\right)$ & 0.049 & 0.024 & 0.030 \\
\hline Inner TFC leg resistive power, $P_{\text {tfc }}(\mathrm{MW})$ & 37 & 19 & 10 \\
\hline
\end{tabular}

roughly the same range of plasma edge, SOL, and divertor parameters. The test divertor modules for the standard tokamak would also be about twice in size and support systems. The ST example of Case II is basically a high-q tokamak, driven primarily by the assumption that $L_{i}$ and $L_{x d}$ comparable to those in ITER is important. Case III corresponds to the case that somewhat shorter connection lengths are acceptable, permitting lowered $B_{10} q_{95}$ and $P_{\text {aux }}$ and higher $I_{\mathrm{p}}$ and $\beta$. Case II can also be operated in the ST mode if desired. These examples suggest that a wide range of such integrated ITER divertor simulators are possible. 
Table 4. Estimated SOL and Divertor Parameters

\begin{tabular}{|c|c|c|c|c|}
\hline Parameters & ITER $_{\text {ig }}$ & I & $\Pi$ & III \\
\hline Aspect ratio, $A$ & 2.8 & 3 & 1.7 & 1.4 \\
\hline Major radius, $R$ (m) & 6.0 & 0.9 & 0.52 & 0.5 \\
\hline Plasma current, $I_{p}$ (MA) & 22 & 0.81 & 0.52 & 1.0 \\
\hline Safety factor, $q_{95}$ & 3 & 5.3 & 17 & 10 \\
\hline Plasma surface area, $A_{p}\left(\mathrm{~m}^{2}\right)$ & 800 & 16.4 & 9.7 & 11.4 \\
\hline Total heating power, $P_{h}(\mathrm{MW})$ & 216 & 8.9 & 4.1 & 3.3 \\
\hline Power flux at edge, $Q_{\perp}\left(\mathrm{MW} / \mathrm{m}^{2}\right)^{a}$ & 0.19 & 0.38 & 0.30 & 0.20 \\
\hline$X$-point to midplane, $L_{t}(\mathrm{~m})$ & 45 & 12 & 29 & 10 \\
\hline$X$-point to divertor, $L_{x d}(m)$ & 28 & $\leq 12$ & $\leq 29$ & $\leq 10$ \\
\hline X-point temperature, $T_{x}(\mathrm{keV})$ & 0.18 & 0.18 & 0.25 & 0.18 \\
\hline$x$-point density, $n_{x}\left(10^{20} \mathrm{~m}^{-3}\right)$ & 0.35 & 0.27 & 0.21 & 0.25 \\
\hline$x$-point density limit, $n_{x c}\left(10^{20} \mathrm{~m}^{-j}\right)$ & 0.35 & 0.48 & 0.37 & 0.25 \\
\hline SOL electron collisionality, $L_{4} / \lambda_{\text {ex }}$ & 18 & 3.5 & 3.9 & 2.9 \\
\hline SOL ion collisionality, $L_{4} / \lambda_{1 x}$ & 18 & 3.7 & 4.1 & 2.8 \\
\hline Midplane SOL thickness, $\Delta_{Q}(\mathrm{~cm})^{b}$ & 0.5 & 0.4 & 0.6 & 0.21 \\
\hline Parallel power flux, $Q_{\mathbf{l}}\left(\mathrm{MW} / \mathrm{m}^{2}\right)$ & 200 & 230 & 170 & 150 \\
\hline Divertor temperature, $T_{\mathrm{d}}(\mathrm{eV})^{c}$ & $\geq 15$ & 12 & 16 & $\geq 10$ \\
\hline Plate-to-flux-surface angle, $\theta_{d}$ (deg) & $\geq 15$ & $\geq 15$ & $\geq 20$ & $\geq 5$ \\
\hline Deposition width on plate $(\mathrm{cm})$ & 10 & $5+10$ & $5 \cdot 10$ & $5-10$ \\
\hline Plate power flux, ${ } W_{d}\left(\mathrm{MW} / \mathrm{m}^{2}\right)^{c}$ & 6 & $5-10$ & $4-8$ & $3-6$ \\
\hline
\end{tabular}

\section{Physics Data Base and Accommodation of Uncertainties}

To be effective in developing integrated divertor solutions, the small steady-state tokamaks and STs must be reliable in operation. Our choices have emphasized parameter regimes well within the domain of reliable tokamak operation under normal conditions. Here, normal conditions refer to the presently projected ITER-level SOL and divertor parameters. However, since the mission of these devices is also to explore for innovative divertor solutions for ITER, broader operating conditions as may be demanded by the test divertors, should also be expected. This requirement, however, adds to the uncertainties in our present projections of all the cor ditions of these devices. In addition, the basic requirement of steady-state operation, and the ST operation will 
also introduce some uncertainties beyond the present data base.

It is therefore necessary to incorporate flexibility and make adjustments to the device parameters to adequately accommodate these uncertainties. The key areas of interest here include confinement, current drive, and $\mathrm{SOL}$ and divertor parameters.

\section{Confinement}

1. Relative to the ITER power-law and offset-linear scaling expressions [40], the examples shown in Table 3 require $H_{\mathrm{fac}} \sim 2$ and 1, respectively. Thus, if this turns out to be equivalent to the quiescent $\mathrm{H}$-mode, there is uncertainty in the longevity of the plasma duration as excessive accumulation of impurities is expected to develop in the impurity transport time $>$ cale [26]. Therefore, it may be advisable to increase $R_{\alpha} a$, and $I_{p}$ by about $20 \%$, and $P_{\text {aux }}$ by about $60 \%$ to permit the ELMy $\mathrm{H}$-mode operation with $H_{\mathrm{fac}}=1.4$, assuming the power-law scaling and holding $K_{x}, B_{t o}$ and $\beta$ constant.

2. Table 3 also indicates that a high " $H_{\text {fac }}$ " $(-2)$ is needed for all cases, when the more recent ITER H-mode confinement scaling [41] is assumed. This raises questions in applying the scaling expressions to small tokamaks and STs. Since these scaling expressions are based on a common tokamak data base, confinement projections in these devices still contain significant uncertainties.

3. The key confinement question for the ST plasma is whether it is tokamak-like, i.e., whether it has confinement times comparable to those predicted by the justmentioned scaling expressions. Recent achievement of plasma with $I_{p}=70 \mathrm{kA}$ and $A=1.6$ in START [1] should soon shed some light on this question. Preliminary analysis of the START plasma [42] suggests a confinement time of the order of $1 \mathrm{~ms}$, which is consistent with the tokamak confinement scaling expressions.

\section{Current drive}

1. There is a strong data base of non-inductive current drive in a variety of tokamaks. A good summary of this subject is already available [43]. This data base covers the initiation of the plasma current using LHW with or without assist from the ECH waves [17-19], achieving $I_{p}$ up to $100 \mathrm{kA}$ in a few seconds, at low densities. Non-inductive ramp-up of $I_{p}$ up to about 2 MA was achieved more recently using LHW alone [20], also at low densities. Thus, there should be little doubt that full plasma current in a tokamak can be consistently produced at low densities without induction.

2. The data base for NBI current drive at high densities and temperatures is also convincing up to MA-levels $(13,14)$ for beam energies up to $-160 \mathrm{kV}$. Pellet injection fueling should be used to prepare the target plasma for adequate densities before NBI. Ample data is also available in this area [45]. 
3. The Alfven-iype instabilities recently observed in beam-dominated plasmas near the stability $\beta$-limits [46] may introduce some added uncertainties in current drive and confinement in such plasmas. This difficulty may be avoidable by operating speed, or at high the $\beta$ limits, with beam energies below the plasma Alfven

ing $\beta$ limits (such as in the ST) [47].

4. The bootstrap current mechanisms are well understood to levels of $I_{\text {bs }} / I_{p}$ up to
$80 \%$ [44].

5. For ST plasmas, current initiation and ramp-up can be carried out first with larger- $A$ plasmas leaning on outboard limiters, as this is permitted in high $q$ designs. The full-bore, low- $A$ divertor plasma can then be produced by equilibrium control before applying pellet and neutral injections. NBI heating and current-drive in the ST are expected to be "classical," as is the case for standard tokamaks [48]. The $A$-dependence of $I_{b s}$ has been calculated to favor low $A$ [49]

\section{SOL and divertor parameters}

This area by far has the highest level of uncertainties, as discussed in Section II in the context of the ITER divertor. This situation suggests the strong need for divertor and SOL physics experimentation in short-duration tokamaks, for HHF and PMI technology development, and for integrated tests and development of innovative divertor solutions under [TER-relevant steady-state conditions $[8,9]$.

This also requires highly flexible designs that can accommodate the uncertainties. The following approaches appear reasonable:

1. The device should be capable of operating over a wide range of $q$ values (sav $5-20$ ) with significant $I_{p}(\geq 0.5 \mathrm{MA})$, to achieve flexibility in several key SOL and divertor parameters (e.g., $\Delta_{Q}, T_{\text {ed, }}, W_{\text {div, }} Q_{1}, L_{t}, L_{\text {xd }}$ etc.).

2. It should accommodate a variety of divertor coil and plate locations to allow fluxtube expansion and contraction, to achieve flexibility in divertor power and particle loads, as demanded by the test divertors.

3. It should allow acress for a wide range of auxiliary heating power $\left(Q_{1}\right)$ and fueling methods, to achieve relatively high values of the disruption limit $n_{x c}$ and high flexibility in the ratio of $n_{e} / n_{x}$ (though a ratio of 3 is assumed in cases I and
$\Pi$ of Tables 3 and 4 ).

Given these capabilities in a highly flexible and modular design, the mission of testing a variety of innovative divertors and developing solutions under TTER-like SOL and 


\section{Conclusion and Discussion}

Based on the broad data base of tokamaks and the emerging data base of ST, we have clarified the basic characteristics of small steady-state tokamaks and STs as ITER divertor simulators for testing and developing integrated divertor solutions within in the next decade. If such a device is installed and put in operation, it will initiate in the U.S. a phase of fusion research that utilizes small tokamaks and STs for divertor technology development.

The basic parameters of such devices $\left(R_{0}-0.5 \rightarrow 1.0 \mathrm{~m}, \mathrm{~A}-1.4 \rightarrow 3, \mathrm{x}_{x}-2.5 \rightarrow 2.1\right.$, $B_{10}-1.0 \rightarrow 2.5 \mathrm{~T}$, and $I_{p} \leq 1 \mathrm{MA}$ ) fits the facilities and expertise of most fusion institutions, and therefore should lead to an exceptionally cost-effective program in this critical area. With thoughtful considerations of flexible and accommodative designs, a variety of integrated divertors can be fully tested in such devices in time to solve one of the critical challenges facing fusion research in the near-term, despite of the remaining uncertainties in data base.

A steady-state ST is shown to be of minimal size and cost, the least demanding of auxiliary systems, and highly flexible and accommodative to uncertainties. A key question for the ST option is whether the ST plasma is basically tokamak-like. It is hopeful that the first-generation experiments presently being designed, under construction, and in operation will settle this question in the next few years.

Finally, the ST option is of interest also because of its potential contribution in fusion nuclear technology development. Finding divertor solutions for ITER asing the ST will also make it possible to design and construct small $\left(R_{0}-0.5-1.0 \mathrm{~m}\right) \mathrm{D}-\mathrm{T}$ fueled, driven STs to produce significant fusion neutron wall loads $\left(-1-2 \mathrm{MW} / \mathrm{m}^{2}\right)$ over significant wall areas $\left(-5 \mathrm{~m}^{2}\right)$ and under steady-state conditions [50]. Such neutron STs will be exceptionally valuable in the development fusion nuclear technologies, such as qualifying the ITER driver blankets and testing their reliability, testing and developing the ITER test blankets, and helping to insure adequate reliability and availability of ITER nuclear operation.

A broadly based conceptual design of such devices will clarify the potential and the requirements of this approach to divertor development.

\section{Acknowledgement}

The author appreciates and enjoys discussions on this subject with $R$. Blanken of OFE; R. Colchin, D. Hillis, J. Galambos, S. Hirshman, B. Nelson, J. Tsai, T. Bigelow, and several others of ORNL; and S. Cohen of PPPL. These discussions have been beneficial to the development of the TST concept. 


\section{References}

[1] R. T. C. Smith et al., "START (Small Tight Aspect Ratio Tokamak)," paper presented at 16th International Symposium of Fusion Technology, September 3-7, 1990, London; A. Sykes et al., "Tight Aspect Ratio Tokamaks," to be presented at 18th European Conference on Controlled Fusion and Plasma Physics, June, 1991, Berlin, FRG.

[2] M. Ono, private communications.

[3] P. K. Browning et al., "The Design and Magnetic Behavior of the SPHEX Spheromak," Proceedings 16th European Conference on Controlled Fusion and Plasma Physics, Vol. 13B, Part II, 787 (1989); P. K. Browning et al., to be presented at 18th European Conference on Controlled Fusion and Plasma Physics, June, 1991, Berlin, FRG; T. Jarboe, private communicaitons.

[4] G. Ludwig, prioate communications; I. C. Nascimento, private communications.

[5] V. Golant, private communications.

[6] Y-K. M. Peng and D. J. Strickler, "Features of Spherical Torus Plasmas," Nucl. Fusion, 26, 769 (1986).

[7] J. A. Holmes et al., "Maximum Beta for a Small-Aspect-Ratio Tokamak," Phys. Fluids B 1, 358 (1989).

[8] V. Alikaev et al. (C. Flanagan, ed.), "Research and Development Needs for ITER Engineering Design," ITER Documentation Series, No. 20 (IAEA, Vienna 1991).

[9] D. E. Baldwin (Chair) et al., "U.S. National Review of the ITER Conceptual Design Activity," (Univ. Texas, March 1991).

[10] P. A. Politzer et al., "Steady-State Tokamak Mission and Program Goals," SteadyState Tokamc: Workshop, October 30-November 1, 1990, San Diego, California.

[11] F. Wagner et al., "Recent Results of H-Mode on ASDEX," LAEA-CN-53/A-4-2, paper presented at 13th IAEA Conference on Plasma Physics and Controlled Nuclear Fusion Research, October 1-6, 1990, Washington DC.

[12] T. S. Taylor et al., "Profile Optimization and High Beta Discharges in DIII-D," IAEA-CN-53/A-3-1-1, ibid; E. A. Lazarus et al., "Stability of High Elongation Plasmas in the DII-D Tokamak," LAEA-CN-53/A-3-1-2, ibid.

[13] G. A. Navratil et al., "Study of High Poloidal Beta Plasmas in TFTR and DIII-D," 
IAEA-CN-53/A-3-3, ibid.

[14] T. C. Simonen et al., "DIII-D Neutral Beam Current Drive Experiments at High Beta Poloidal," in Plasma Physics and Controlled Nuclear Fusion Research, 1988, Vol. I. 669 (LAEA, 1989).

[15] The JET Team (P-H. Rebut et al.), "Recent JET Results and Future Prospects," IAEA-CN-53/A-1-2, paper presented at 13th IAEA Conference on Plasma Physics and Controlled Nuclear Fusion Research, October 1-6, 1990, Washington DC.

[16] D. M. Meade and the TFTR Team, "Recent TFTR Results," IAEA-CN-53/A-1-1, ibid.

[17] Jobes et al., "Formation of a 100-kA Tokamak Discharge in the Princeton Large Torus by Lower Hybrid Waves," Phys. Reo. Lett., 52, 1005 (198A).

[18] K. Toi et al., "Lower Hybrid Current Start-up and ICRF Heating in the JIPP T-IIU Tokamak," p. 523 in Plasme Physics and Controlled Nuclear Fusion Research, 1984, (IAEA, 1985).

[19] R. Motley et al., "Lower Hybrid Current Ramp-up in the PLT Tokamak," p. 473, ibid.

[20] T. Imai et al., "Lower Hybrid Current Drive and Heating Experiments on JT-60," IAEA-CN-53/E-1-3-2, paper presented at 13th IAEA Conference on Plasma Physics and Controlled Nuclear Fusion Research, October 1-6, 1990, Washington DC.

[21] D. N. Hill et al., "Divertor-Plasma Studies on DIII-D," IAEA-CN-53/G-1-3, ibid.

[22] J. Neuhauser et al., "Edge and Divertor Studies on ASDEX," IAEA-CN-53/A-5-2, ibid.

[23] D. E. Post et al., "ITER Physics," ITER Documentation Series, No. 21, Chapters 2 and 3 (IAEA, Vienna), to be published.

[24] M. F. A. Harrison and E. S. Hotston, "Edge Plasma and Surface Conditions in ITER," J. Nucl. Materials, 176\&177, 256 (1990).

[25] J. L. Luxon et al., "Recent Results from DII-D and Their Implications for Next Generation Tokamaks," to be published in Plasma Physics and Controlled Fusion (1990).

[26] ASDEX Team, "The H-Mode of ASDEX," Nucl. Fusion, 29, 1959 (1989). 
[27] K. Borrass, "Disruptive Tokamak Density Limit as Scrape-off Layer/Divertor Phenomenon," to be published in Nuclear Fusion.

[28] K. Borrass, "Scrape-off Layer Based Model for the Disruptive Tokamak Density Limit and Implications for Next-Generation Tokamaks," in Plasma Physics and Controlled Fusion, Vol. III, p. 1393 (1990).

[29] S. A. Cohen et al., "Two-Dimensional Fluid Simulations of the ITER SOL Plasma," J. Nucl. Materials, 176\&177, 908 (1990).

[30] F. Wagner and K. Lackner, in Physics of Plasma-Wall Interactions in Controlled Fusion, ed. D. Post and R. Behrisch (Plenum, New York, 1986); L. De Kock et al., in Plesma Physics and Controlled Nuclear Fusion Research, Vol. II, (IAEA, Vienna
1988).

[31] A. Mahdavi et al., "The DII-D Collaborative Advanced Divertor Program," GAA19547 (General Atomics, San Diego, Calif., 1989).

[32] M. Keilhacker et al., "Modelling Impurity Control by Plasma Flows in the JET Pumped Divertor," IAEA-CN-53/E-5-1, paper presented at 13th IAEA Conference on Plasma Physics and Controlled Nuclear Fusion Research, October 1-6, 1990, Washington DC.

[33] M. Petravic et al., Phys. Reo. Lett., 48, 326 (1982).

[34] G. Fiksel et al., "Experimental Simulation of a Gaseous Plasma Collector," Phys. Fluids B, 2, 837 (1990).

[35] R. E. Nygren and S. A. Cohen (Organizers), "Workshop on Innovative Technologies for Impurity Control," 11-12 January 1990, PPPL.

[36] "Report of a Consultants Meeting on DEMO Requirements," LAEA-TECHDOC-441, (IAEA, Vienna 1987).

[37] N. A. Uckan and the ITER Physics Group, "ITER Design Information Document, Physics," ITER-TN-PH-0-5 (November 1990).

[38] P. C. Stangeby and G. M. MCCracken, "Plasma Coundary Phenomena in Tokamaks," Nucl. Fusion, 30, 1225 (1990).

[39] J. D. Galambos and Y-K. M. Peng, "Ignition and Burn Criteria for D- ${ }^{3}$ He Tokamak and Spherical Torus," Fusion Technology, 19, 31 (1990).

[40] P. Yushmanov et al., "Scaling for Tokamak Energy Confinement," Nucl. Fusion, 25, 
1999 (1990).

[41] J. G. Cordey et al., "A Preliminary Analysis of the ITER Energy Confinement HMode Data Base," IAEA-CN-53/F-3-19, paper presented at 13th IAEA Conference on Plasma Physics and Controlled Nuclear Fusion Research, October 1-6, 1990 , Washington DC.

[42] M. Tumer et al., "Initial Analysis of the START Plasmas," to be presented at 18th European Conference on Controlled Fusion and Plasme Physics, June, 1991, Berlin, FRG.

[43] Fujisawa et al., "Chapter 5: Heating and Current Drive," INTOR Phase II-A, Part 2 report (IAEA, Vienna 1987).

[44] M. Kikuchi et al., "Bootstrap Current During Perpendicular Neutral Injection in JT-60," Nucl. Fusion, 30, 343 (1990).

[45] S. L. Milora et al., "Pellet Injection and Confinement Experiments on JET,"

[46] K. McGuire et al., Phys. Rev. Lett. 50, 891 (1983); W. W. Heidbrink et al., "An Investigation of Beam-Driven Alfvén Instabilities in the DIII-D Tokamak," submitted to $\mathrm{Nucl}$. Fusion.

[47] G. Y. Fu and J. W. Van Dam, "Stability of the Global Alfvén Eigenmode in the Presence of Fusion Alpha Particles in and Ignited Tokamak Plasma," Phys. Fluids B 1, 2404 (1989); C. L. Hedrick, "," to be presented at the International Sherwood Meeting on Fusion Theory, 1991.

[48] M. C. Zarnstorff et al., "Bootstrap Current in TFTR," Phys. Rev. Letters, 60, 1306 (1988).

[49] E. C. Crume, Jr., "Neoclassical Transport Coefficients for Finite-Aspect-Ratio and Bean-Shaped Tokamak Plasmas," Phys. Fluids, 30, 1152 (1987).

[50] Y-K. M. Peng, in "Reversed Field Pinch, Compact Toroids, and Dense Z-Pinch," J. Fus. Energy, 8, 12 (1989). 


\section{Appendix C}

ITER Divertor Simulations in ATF

P. Mioduszewski 


\section{ITER Divertor Simulations in ATF}

The major components of the Advanced Toroidal Facility (ATF) at Oak Ridge National Laboratory (helical windings, vertical field coils, and the helical winding power suppiy) are capable of steady state operation at $B_{0}=1 \mathrm{~T}$. The long range program plan focuses on steady state operation with multi-megawatt plasma heating. The natural divertor configuration provides open field lines at the plasma edge suitable for divertor studies. Possibilities for ITER divertor simulations are twofold: (1) studies of impurity transport on open field lines from the divertor plate to the core plasma, and (2) test of materials and plasma-facing components (PFCs) for high power flux in steady state operation.

\section{Impuriry transport studies:}

The field lines in the edge have a radial component and intercept the vacuum vessel in "divertor stripes". Impurity evolution can be simulated by inserting a gas puff nozzle or e. g. a graphite sample into the divertor stripe. The active connection length which determines the impurity transport into the core, can be varied by choosing the particular location in the diveror stripe. For this purpose, a moveable, $50 \mathrm{~cm}$-diameter graphite plate is installed in one of the sectors which is instrumented for power and particle flow. In addition, moveable top and bottom limiters are installed which are instrumented with gas puff nozzle, Langmuir probes, and thermocouples. Enhanced particle flow in the divertor stipe can be achieved with pellet fueling which is available on ATF. Steady state operation will be particularly useful when combining impurity studies with erosion measurements.

\section{REC test program}

a) PFC tesing with limiters at the last closed flux surface:

ATF can be operated with or without limiters. Presently, it is equipped with a top and bottom rail limiter each, consisting of arrays of instrumented singular graphite tiles. The center tile can be removed through a vacuum lock without venting the machine to change material and/or instrumentation. Relevant plasma eige pa:ameters like densities of $10^{19} \mathrm{~m}^{-3}$ and electron temperatures of $50 \mathrm{eV}$, plus magnetic fields. ensure a relevant environment for materials and 
component tests. With only $200 \mathrm{~kW}$ ECH input power, power densities at the limiters were measured to be $300 \mathrm{~W} / \mathrm{cm}^{2}$; with strong auxiliary heating, power densities in the order of several $\mathrm{kW} / \mathrm{cm}^{2}$ are expected. Because of the removable center tile, the limiters are particularly well suited for studies on erosion/redeposition as well as on impurity transporr.

b) PFC tesaing on a divertor stripe:

The ATF magnetic configuration has a natural helical divertor. The pattem of the diveror suripes on the outer wall is such that it can be enclosed with a localized divertor box which can be accomodated in one of the large horizontal ports. This divernor box can then be instrumented and used for testing of PFCs.

c) Test conditions:

power flux

pulse length

Phase l: $100 \mathrm{~kW}$ (ECH@3rd harmonic).steady state

a) limiters at lase closed flux surface:

$-150 \mathrm{~W} / \mathrm{cm}^{2}$

steady state

Phase II: $3-5 \mathrm{MW}, 30$ s auxiliarv hearing

a) limiters at the last closed flux surface:

up $005 \mathrm{~kW} / \mathrm{cm}^{2}$

$30 \mathrm{~s}$

b) divertor stripes:

$-100 \mathrm{~W} / \mathrm{cm}^{2}$

$30 s$

Phase III: 3-5 MW, steady state (hours)
a) limiters at last closed flux surface:
up to $5 \mathrm{~kW} / \mathrm{cm}^{2}$
steady state
b) divertor stripes:
$-100 \mathrm{~W} / \mathrm{cm}^{2}$
steady state 


\section{Role of Pump iimiters in the ITER Program}

Pump limiters are capable of continit is particle and heat removal [1-5]. The limitation for the exhaust efficiency is given by the maxi-in permi sible heat flux at the leading edge, and has been measured to be around $10 \%$ in most ex:-riments. Sic: exhaust efficiency requirements for ITER are as low as $1 \%$ or less, the leading edge of a pump limiter could probably be recessed far enough to accomodate the heat flux at that lozation. The problem, however, would be the high erosion rates at the limiter tace due to high electron tenicranures. While the plasma conditions in a divertor are determined by high recycling, entailing high densities and low electron temperatures, this highrecycling regime has not been observed at the plasma-facing surface of a limiter. Hence, a pump limiter would be exposed to much higher erosion rates than the target plates of a divertor and this would most likely cause higher impurity contents. It is, therefore, unlikely that pump limiters can make viable components for primary heat and particle exh 'ust in high-power, steady state devices.

Within the ITER R\&D program, however, pump limiters may play a role in studying processes such as recycling, impurity transport, and others. Inside the pump limiter throah processes take place which are similar to those in divertor channels. Particle fluxes of several times $10^{19} \mathrm{~cm}^{-2} \mathrm{~s}^{-1}$ have been measured, temperatures and densities are similar to that of divertor channels. In some experiments, non-linear density build-up in the throat and non-linear pressure rise in the pump limiter plenum has been observed, which is interpreted as a consequence of local recycling. Scrape-off plasmas ourside and inside the pump limiter throats in TEXTOR and Tore Supra, for example, are well instrumented and conditions in the throat can be studied with respect to recycling, impurity generation and transport, erosion etc.

[1] P. Mioduszewski, L. C. Emerson, J. E. Simpkins, A. J. Wootton, et al., J. Nucl. Mater.121 (1984) 285

[2] R. W. Conn, J. Nucl. Mater. 128 \& 129 (1984) 407

[3] The TFR Group, J. Nucl. Mater. 145-147 (1987) 819

[4] D. M. Goebel, R. W. Conn, W. J. Corbett, K. H. Dippel, et al., J. Nucl. Mater. 162-164 (1989) 115

[5] C. C. Klepper, P. Bonnel, J. L. Bruneau, M. Chatelier, et al., 9th International Conference on Plasma-Surface Interactions, Bournemouth, 1990 


\section{Development of Plasma-Facing Components in ATF}

The major components of the Advanced Toroidal Facility (A.TF) at Oak Ridge National Laboratory (helical windings, vertical field coils, and the helical winding power supply) are capable of steady state operation at $B_{0}=1 \mathrm{~T}$.

The long range program plan focuses on steady state operation with multi-megawatt plasma heating. The benefits of such operation are twofold: (1) demonstration that a stellarator can operate steady state at high edge power densities and high beta without deterioration due to plasma-wall interactions such as impurity accumulation or loss of wall pumping, and (2) use of ATF to test materials and plasma-facing components (PFCs) for high power flux, steady state operation.

The PFC development program is envisioned in three phases:

power flux

Phase I: $100 \mathrm{~kW}$ (ECH @ 3rd harmonic), steady state

a) limiters at last closed flux surface:

Phase II: 3-5 MW, 30s auxiliary heating

a) limiters at the last closed flux surface:

b) divertor stripes:

Phase III: $3-5 \mathrm{MW}$, steady state (hours)

\section{Phase 15 : $3-5$ W, 30 auxiliary heating}

$-100 \mathrm{~W} / \mathrm{cm}^{2}$

steady state

pulse length

up to $5 \mathrm{~kW} / \mathrm{cm}^{2}$

30 s

30 s

a) limiters at last closed flux surface:

up to $5 \mathrm{~kW} / \mathrm{cm}^{2}$

steady state

b) divertor stripes:

$-100 \mathrm{~W} / \mathrm{cm}^{2}$

steady state 
1. PFC testing with limiters at the last closed flux surface:

ATF can be operated with or without limiters. Presently, it is equipped with a top and bottom rail limiter each, consisting of arrays of instrumented singular graphite tiles. The center tile is instrumented with Langmuir probes, a thermocouple, and a gas puff nozzle. The center tile can be removed through a vacuum lock without venting the machine to change material and/or instrumentation. Relevant plasma edge parameters like densities of $10^{19} \mathrm{~m}^{-3}$ and electron temperatures of $50 \mathrm{eV}$, plus magnetic fields, ensure a relevant environment for materials and component tests. With only $200 \mathrm{~kW}$ ECH input power, power densities at the limiters were measured to be $300 \mathrm{~W} / \mathrm{cm}^{2}$; with strong auxiliary heating, power densities in the order of several $\mathrm{kW} / \mathrm{cm}^{2}$ are expected. Because of the removable center tile, the limiters are particularly well suited for studies on erosion/redeposition as well as on impurity transpor.

\section{PFC testing on a divertor stripe:}

The ATF magnetic configuration has a natural helical divertor. The pattem of the divertor stripes on the outer wall is such that it can be enclosed with a localized divertor box which can be accomodated in one of the large horizontal ports. This divertor box can then be instrumented and used for testing of PFCs. 
Appendix D

RFTF for PMI and Divertor Studies

P. Mioduszewski 


\section{RFTF for PMI and Divertor Studies}

The RF Test Facility was designed to study and test antenna components in a plasmamagnetic field environment. It has been used to test antenna launchers for DIII-D, TFTR, and Tore Supra, as well as a development antenna for the testing of high power if feedthroughs, capacitors, and Faraday shields. In addition, it has been used to study the physics of rf-plasma-materials interactions, and is currently being used to test the next generation Folded Waveguide launcher.

The RFTF, as shown in Figs. 1 and 2, is composed of a large vacuum chamber set between two superconducting magnets in a magnetic mirror configuration. The enclosed volume between magnets is roughly $1.5 \mathrm{~m}^{3}$ with vacuum pumping provided by means of pumping extensions through the magnet throats to two $2100 \mathrm{~V} / \mathrm{s}$ turbopurops. The large (74 by $163 \mathrm{~cm}$ ) rectangular opening on the front of the vessel provides access for mounting large pieces of hardware inside the vessel as well as for the mounting and insertion of experimental ICRH antennas. An additional 20 ports of various sizes on the other three exposed sides provide ample opportunity for diagnostic access; access through the ends of the pumping extensions is also available.

Energy removal from the vessel is accomplished with a water-cooled liner attached to the vessel walls. Cooling is concentrated where field lines associated with resonant mod-B contours intersect the vessel walls. Figure 3 shows a representative mod-B resonance surface for $28-\mathrm{GHz}, 1200-\mathrm{A}$ operation along with associated field lines. The cooling liner extends through the magnet throats to the pumping tees. Cooling is presently sized to handle $\sim 15-W / \mathrm{cm}^{2}$ power density on the walls in the region of maximum plasma loss. This is based on $1 \mathrm{MW}$ of $\mathrm{cW}$ power delivered to the plasma acting as an antenna load.

The operating maximum field is $\sim 3 \mathrm{~T}$ on axis in the magnet throats, corresponding to a coil current of $1200 \mathrm{~A}$. Separation of the magnets, centerline to centerline, is $112 \mathrm{sm}$, providing a mirror ratio of 4.8 . Figure 3 shows the calculated magnetic field geometry and mod-B contours under maximum field conditions. Small signal field measurements and coloration changes to cooling panel surfaces after plasma and plasma with if operations indicate that the calculated magnetic field patterns are accurate.

The plasma in RFTF is made by an electron cyclotron resonance heating (ECH) discharge with either a $28 \mathrm{GHz}$ gyrotron or a $10.6 \mathrm{GHz}$ klystron. The $28 \mathrm{GHz}$ source is used for full field operation (1200 amperes/coil) and the $10.6 \mathrm{GHz}$ source is used for lower field operation (480 amperes/coil). Both systems are $\mathrm{cw}$ and produce a plasma with an electron density of $1-2 \times 10^{11} \mathrm{~cm}^{-3}$ in the center with an electron temperature of 5-10 eV for a 
power level of $\sim 20 \mathrm{~kW}$. Previous measurements have shown that the density and temperature are fairly constant across the plasma volume. Hydrogen is usually used as the background gas with pressures ranging from $1-4 \times 10^{-4}$ Torr.

There are a number of $\mathrm{cw}$ if sources available to support launcher research and development. The main frequency ranges and powers are as follows:

\begin{tabular}{ll}
\hline Frequency Range $(\mathrm{MHz})$ & CW Power $(\mathrm{kW})$ \\
\hline $2-200$ & 1.5 \\
$3-18$ & 200 \\
$6-20(2)$ & 100 ea.; 500 ea. wimods \\
$2-30$ & 100 \\
$30-60$ & 50 \\
$40-80$ & 1000
\end{tabular}

Plasma potentials and electron temperatures have been measured with if injection into RFTF at $42 \mathrm{MHz}$ and increase dramatically with if power. For example, electron temperatures and plasma potentials without if range from 5-10 eV and 7-10 volts, respectively and increase to $54-60 \mathrm{eV}$ and $180-230$ volts for an if power of $-26 \mathrm{~kW}$.

For the purposes of plasma boundary studies and divertor development, high if power could be used to attain high power fluxes and warm edge plasmas. To date, a single antenna has coupled $260 \mathrm{~kW}$ to the RFTF plasma. By using 4 straps and the right coupling geometry, $\sim 1 \mathrm{MW}$ could be introduced into the plasma with an average steady state power density of $\sim 1 \mathrm{~kW} / \mathrm{cm}^{2}$ on a $\sim 25 \mathrm{~cm}$ diameter target area near the magnet bore. Corresponding particle fluxes would be in the order of $\sim 10^{20} \mathrm{~cm}^{-2} \mathrm{~s}^{-1}$. With this magnitude of $\mathrm{cw}$ power and particle flux and temperatures of $\sim 100$ to $300 \mathrm{eV}$, the facility would be a very flexible test bed for plasma boundary and divertor studies. This would include development and testing of plasma-facing components, as well as divertor plasma studies such as high-recycling, helium pumping, radiative divertor operation, erosion/redeposition, and others. In addition, an experimental program can be developed addressing specific problems pertaining to the interaction of RF antennas with the edge plasma such, as rf-sheath effects, erosion, density control, or RF coupling efficiency. 
ORNL.OWG 85.3095A FEO

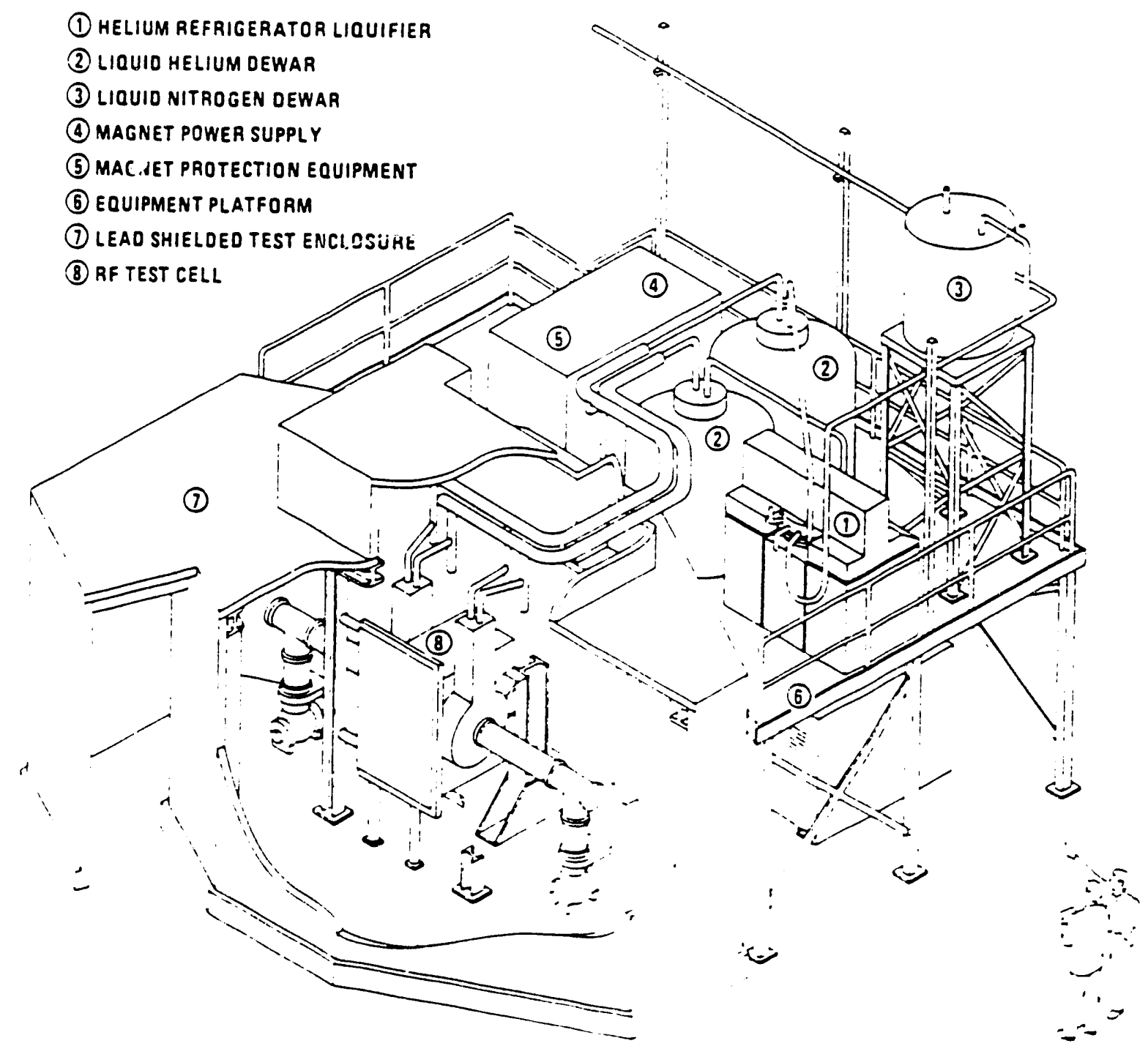



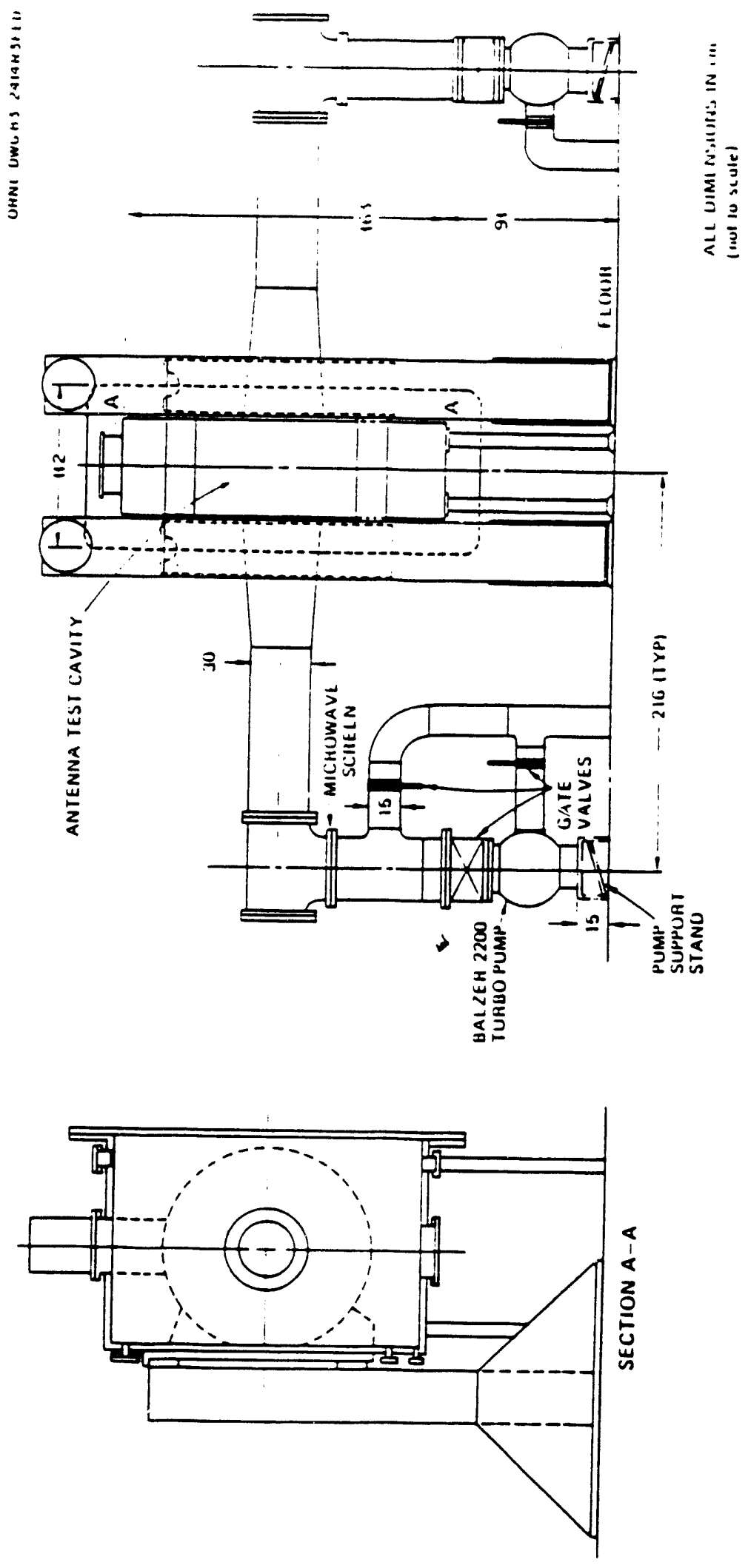


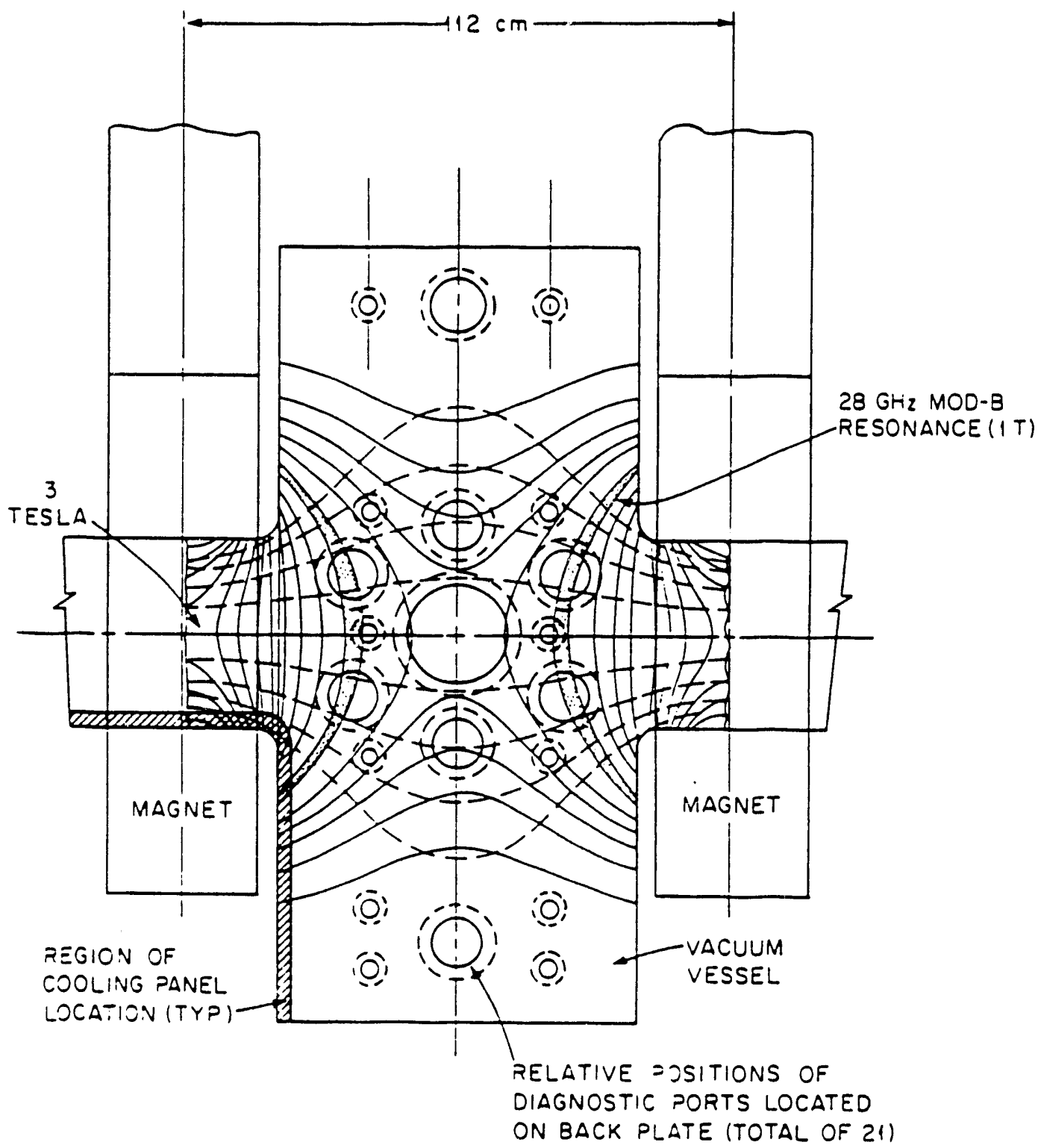


APDENDIX E

\title{
LINEAR PLASMA SIMLLATOR
}

DESIGN ASSESS.MENT, R\&D

\author{
T. F. Yang \\ MIT Plasma Fusion Center, Cambridge, MA 02139
}

(617) $253-8453$

\section{INTRODUCTION}

It was recommended by the ITER design team that a plasma simulator be built as a test facility to study and develop plasma facing components (PFC) and divertor modules and plasma surface interactions (PSI). The recommended device is a 60 -meter-long mirror machine with plasma radius of $20 \mathrm{~cm}$ and plasma density of $1 \times 10^{20} \mathrm{~m}^{-3}$. It would be heated with $10 \mathrm{MW}$ rf power. A target area of $1 \mathrm{~m}^{2}$ is required. Although such a linear device can be designed based on the tandem mirror experiments $[1,2,3,4]$, the information available is not sufficient to ensure that such device can be built which would serve as a meaningful plasma simulator. To ensure that the device, once constructed, will not be bogged down as a physics study machine, a careful design study and a preliminary research and development effort are necessary to sort out and eliminate the uncertainties to the greatest degree. For this reason a technical assessment is given in section 2 and the necessary design and $R \& D$ studies are proposed in section 3.

\section{TECHNICAL ASSESSMENT}

The key physical parameters of the tandem mirror device which are important to the successful construction and operation of the plasma simulator are assessed as follows.

(1) Plasma Density

The plasma density achieved for the TMX- $\mathrm{L}$ tandem mirne device is about $6 \times$ $10^{18} \mathrm{~m}^{-3} \mathrm{l}$. A density in the range of $10^{20} \mathrm{~m}^{-3}$ was established for $2 \times 11 B 5$, a Min- $\mathrm{B}$ 
device in which the plasma was injected with a washer-stack gun and gas injector. The washer-stack gun was a pulsed system which required multimegawat ts of power to operate. A method for acheiving a plasma density of $10^{20} \mathrm{~m}^{-3}$ for the linear device has yet to be found and tested.

\section{(2) Heating Efficiency}

The efficiency of heating the plasma with of power is less than $55 \%$. Therefore it will need at least $20 \mathrm{MW}$ of power in order to deliver $10 \mathrm{MW}$ plasma power to the test module. The heating efficiency depends on the method of injecting the of power and gas feed. Therefore a method to enhance the heating efficiency should be developed. Since we are dealing with such a large amount of power, it is also important to identify the possible power sinks for the power lost so that a protection system can be designed in advance.

\section{(3) Stability}

The MHD stability and microinstability problems for such a long-thin device have to be evaluated carefully and tested. It would be much simpler and less costly if the plasma can be stabilized by streaming plasma and ponderomotive force due to ICRF heating. The system would be very complicated and costly if anchors are needed.

\section{(4) Plasma Flow}

To test PFC, PSI and divertor modules, the plasma should be exhausted to one end with the other end closed to make most efficient use of the power. Such an asymmetric operation has not been attempted in tandem mirror experiments. There is no previous experience of exhausting $10 \mathrm{MW}$ power to one end. A relationship between the plasma exhaustion and confinement can be established as following:

From power balance the plasma temperature can be roughly estimated. The power density of a plasma impinging on a target can be written as

$$
P=n k\left(T_{2}-T_{e}\right) \nu W / \mathrm{m}^{2}
$$


where $\mathcal{V}$ is the thermal velosity for hydrogen plasma

$$
\nu=9.79 \times 10^{3} \sqrt{T_{\imath}+T_{e}} \mathrm{~m} / \mathrm{s}
$$

Assuming $T_{i}=T_{e}$ and $P=10.111 \% / \mathrm{m}^{2}$, then

$$
T_{1}=0.5 \times\left(\frac{P}{1.566 \times 10^{5}}\right)^{2 / 3}=7.988 \mathrm{eV}
$$

which is a low value. The temperature should be in the $50 \mathrm{eV}$ to $200 \mathrm{eV}$ range implying that either the density or size of the device can be reduced. To simulate a wide range of plasma conditions both the density and temperature should be variable over a large range of values at a given power level. The axial confinement time can be determined as following.

The plasma volume is

$$
V_{p}=\pi a^{2} L=7.54 \mathrm{~m}^{3}
$$

The total energy content is

$$
E=V_{p} n k\left(T_{2}+T_{e}\right)=1927.3 \mathrm{~J}
$$

The axial confinement time can be estimated as

$$
\tau_{! !}=E / P=0.1927 \mathrm{~ms}
$$

This is a reasonable value. From this we can obtain the particle throughput to the exhaust

$$
Q=V_{p} n / \tau_{i i}=3.9 \times 10^{24} s^{-1}
$$

or

$$
Q=1.2 \times 10^{5} \text { torr }-l / s
$$


To ensure that the plasma will impinge on the target at full power density $\left(10 \mathrm{MW} / \mathrm{m}^{2}\right)$. the plasma conditions ( $T_{1}, T_{e}$ and density) on the target have to be maintained at the same level as in the scrape-off laver. Therefore the recycle rate at the target has to be kept very low, or the plasma will be cooled down and its density will increase, such that the test conditions will be inadvertently changed. To maintain the test conditions. the vacuum space has to be at a pressure less than $10^{-3}$ torr. For such a pressure the required pumping speed is at least

$$
S=1.2 \times 10^{8} \mathrm{l} / \mathrm{s}
$$

which is much too large and requires a large-scale gettering pump. The system could only be operated for one second with a long pump-down time in between pulses.

\section{(5) Fueling, Heating and Exhausting}

The major effort of tandem mirror experiments was to improve the axial confinement time so that the end losses could be kept as low as possible. The fueling was just sufficient to make up for the end loss. The experiments were carried out at pulse lengths typically a few tens of ms. The steady-state operation of a mirror device with continuous flow of plasma at a high power level has not been demonstrated. Steady-state heating, fueling and exhausting has to be tested. A fueling method has tobe developed such as a washer-stack gun and/or gas injection ionized by microwave power. A multimegawatt washer-stack gun has to be build and operated at steady state to be useful.

The continuous heating of a plasma at the $20 \mathrm{MW}$ level has not been studied previously. Apparently, the injection of rf power with multiple antennae is necessary in order to keep the density of the power flowing through the each antenna at a reasonable value so that the antennae will not be damaged. It was found that ICRF beach heating is the most effective way of heating the plasma in a mirror machine[7,8]. For ICRF beach heating the wave is launched at the high field region near the mirror end of the central cell and the wave propagates toward beach, the resonance region near the midplane, where the dumping and absorption of the wave take place. The location of the antenna is very important. Therefore the injection of rf power with multiple-antenna system has to be studied. 
(6) Magnets

The pressure of the plasma in the central cell is

$$
p=n k\left(T_{1}-T_{e}\right)=25.5 .6 \mathrm{~J}, \mathrm{~m}^{3}
$$

Choosing $\beta=0.5$ the magnetic field in the central cell can be determined as follow

$$
B_{c}=\sqrt{2 \mu_{o} p_{i} / \beta}=3.584 \times 10^{-2} \mathrm{~T}
$$

Picking a mirrcr ratio, $\mathrm{R}=10$, we have a mirror field $B_{m}=0.1792 \mathrm{~T}$. This magnetic field strength is very low. This means that the ICRF frequency is a few hundreds of $\mathrm{kHz}$ which requires a very large tuning capacitance. The better choice may be to pick $B_{c}$ instead of beta. Let us choose $B_{c}=0.2 \mathrm{~T}$ and $B_{m}=2.0 \mathrm{~T}$, we then have

$$
3=1.6 . \%
$$

These are very reasonable values. The beta value or the pressure can be at least doubled indicating that the size of the device can be greatiy reduced. The magnetic field intensity at the $2 \mathrm{~T}$ level should not pose any engineering difficulty. However, a choice has to be made whether to build the coil with superconductors or with water-cooled copper based on the trade off of power consumption for steady-state operation versus capital cost.

\section{DESIGN STUDY, RESEARCH AND DEVELOPMENT}

The assessment given above addresses the key issues for a linear plasma simulation device and indicates the importance of carrying out a design study to determine the feasibility of such a device. The research and development work should also be undertaken as soon as possible to find solutions to these issues so that new information can be factored into the design in a timely fashion. 
The research and development work could be carried out on the C.MPPX ( Compact Mirror Plasma Propulsion Experiment ) facility at MIT. This is a very compact axisymmetric tandem mirror device which was built as a space plasma propulsion experiment. The key parameters are listed in Table 1. Figure 1 show the facility and Figure 2 shows a lavout of the device, and the heating and diagnostics. The loffe coils have been designed and can be added whenever needed for stability. Because of its compactness the operation is much simpler than the large device and is versatile and low cost.

\section{Table 1}

\section{Designed System Parameters}

$\begin{array}{ll}\text { Overall length } & 3.2 \mathrm{~m} \\ \text { Central cell length } & 1.15 \mathrm{~m} \\ \text { Central cell radius } & 0.36 \mathrm{~m} \\ \text { Central cell field }\left(B_{\mathrm{c}}\right) & 2.4 \mathrm{kG} \\ \text { Maximum field }\left(B_{\text {max }}\right) & 20.0 \mathrm{kG} \\ \text { Plasma density (variable) } & 10^{19} \mathrm{~m}^{-3} \\ \text { Plasma temperature } & .01-1.0 \mathrm{keV} \\ \text { Plasma Heating Power: } & \\ \text { • ECRH } & 2.0 \mathrm{~kW} \\ \text { - ICRH } & 800 \mathrm{~kW}\end{array}$

Currently the research work is concentrated on understanding the ICRF beach heating phenomenon both theoretically and experimentally. Theoretically, a computer code $\mathrm{BEACH}$ has been developed to study the wave propagation in the inhomogeneous magnetic field of the mirror machine. Experimentally, the waves are launched from antenna 1 in the south end cell and from antenna 2 at the north end of the central cell at ICRF frequencies at the midplanes of each cell respectively. The beach effect has been confirmed both theoretically and experimentally.

Presently the gas is fed into the south end of the central cell and is ionized by microwave radiation. The diagnostics currently operational are Langmuir probe, B-dot probe, microwave interferometer, $H_{\alpha}$ detector and dye laser interferometer. A retarding field grid 
energy analyzer:9! and charge exchange analyzer will be added later. The antennae are dual half loop type. The plasma can be exhausted into the large vacuum tank to test large modules if needed.

There is a total of $800 \mathrm{~kW}$ of ICRF power with the frequency tunable from $2 \mathrm{MHz}$ to $30 \mathrm{MHz}$. With $50 \%$ power transfering efficiency, the target area can be as large as $20 \mathrm{~cm} \times 20 \mathrm{~cm}$ for a power density of $10 \mathrm{MW} / \mathrm{m}^{2}$. It is an ideal facility in which to perform the R\&D necessary to design and construct the linear plasma simulator. It is also an excellent facility for PFC, PSI and divertor study before the plasma simulator is built. The special retarding field grid energy analyer developed at MIT can measure the very localized electron temperature and ion temperature and sheath potential on the material surface. The surface properties can be closely related to the plasma properties which permits us to gain a better understanding of the PSI phenomena. A new probe is also under development to measure density as well as plasma temperature. According to the discussion given above, the R\&D work needed is as follows.

(1) To develop an efficient method to increase the plasma density.

(2) To gain full understanding of rf wave propagation and absorption so as to find a method to enhance the heating efficiency.

(3) To study the multiple-antenna system for efficient injection of a large quantity of rf power into the plasma.

(4) To investigate plasma stabilization methods such as streaming plasma, ponderomotive force due to ICRF heating, magnetic field modification and line tying.

(5) To study methods of exhausting plasma through one end and its impact on the heating of the plasma.

(6) To study auxiliary heating and fueling, such as neutral beam injection.

(7) To study the effect of field strength on plasma conditions and stability.

(b) To study long pulse operation. 
(9) To study high speed pumping system.

(10) To establish a wide range of plasma parameters, such as that the temperature can be varied from $10 \mathrm{eV}$ to $400 \mathrm{eV}$, at constant power.

\section{REFERE.NCES}

1: T.C. Simonen, S.L. Allen, D.E.Baldwin. T.A. Casper, J.F.Clauser, et al. , "Thermal barrier confinement experiments in the T.MX-U Tandem Mirror," in Proc. Plas. Phys. and Contr. Nucl. Fus. Research, Vol. 2, London (1985) 255

2! N. Hershkowitz, R A. Bruen, D.A.Brouchous, J.D. Callen, C. Chan, J.R. Conrad, et.al.,"Plasma Potential Control and .MHD Stability ExI eriments in the Phaedrus Tandem Mirror," in Proc. Plas. Phys. and Contr. Nucl. Fus. Research, Vol.2, London (1985) 265

3. T. Cho, M. Ichimura, M. Inutake, K. Ishii, A. Itakura, I. Katanuma, T. Kawabe, Y. Kiwamoto, A. Mase,et.al., "Potential Formation in Axisymmetrized Tandem Mirror Gamma 10,"in Proc. Plas. Phys. and Contr. Nucl. Fus. Research, Vol.2, London (1985) 275

[4] R.S. Post, M. Gerver, J. Kesner, J.H. Irby, B.G. Lane, M.E. Mauel, B.D. McVey, A. Ram, E. Sevillano, et al. "TARA and CONSTANCE B Mirror Confinement Experiments and Theory," in Proc. Plas. Phys. and Contl. Nucl. Fus. Research, Vol.2, London (1985) 285

(5) F.H. Coensgen, J.F.Clauser, D.L. Correll, W.F. Cummins, C. Gormezano, B.G. Logan, A.W. Molvik, et al. "2XIIB plasma confinement experiments" in Proc. Plas. Phys. and Contr. Nucl. Fus. Research, Vol.2, London (1985) 135

6. J.E. Osher, Rev. Sci. Instrum. Vol.53, .Vo.11.(1982)1685

[7' V. Hershkowitz, R. Majeski, J. Ferron. R. Breun, P. Brooker, d. Brouchous, "Experimental results from Phaedrus-b" Intermational School of Plasma Physics, Edited by S. Ortolani and E Sindoni, Larenna .Sept(1987)855 
8i T.F. Yang, S. Peng, F. R. Chang-Diaz, "The Propagation of RF liave in A Tander .Mirror Plasma Propulsion Device." in Proc. AIAA/DGLR/JS.ASS 21st Intl. Elect. Propl. Conf. , Orlando.FL.July (1990).

9: T.F. Yang, A.S. Wan, J. Megusar, and G.S. Luan "Measurement of Sheath Potential and .Metal Surface Phenomena at the Alcator C Plasma Edge," J. Vucl. Mater. 172(1990)220 


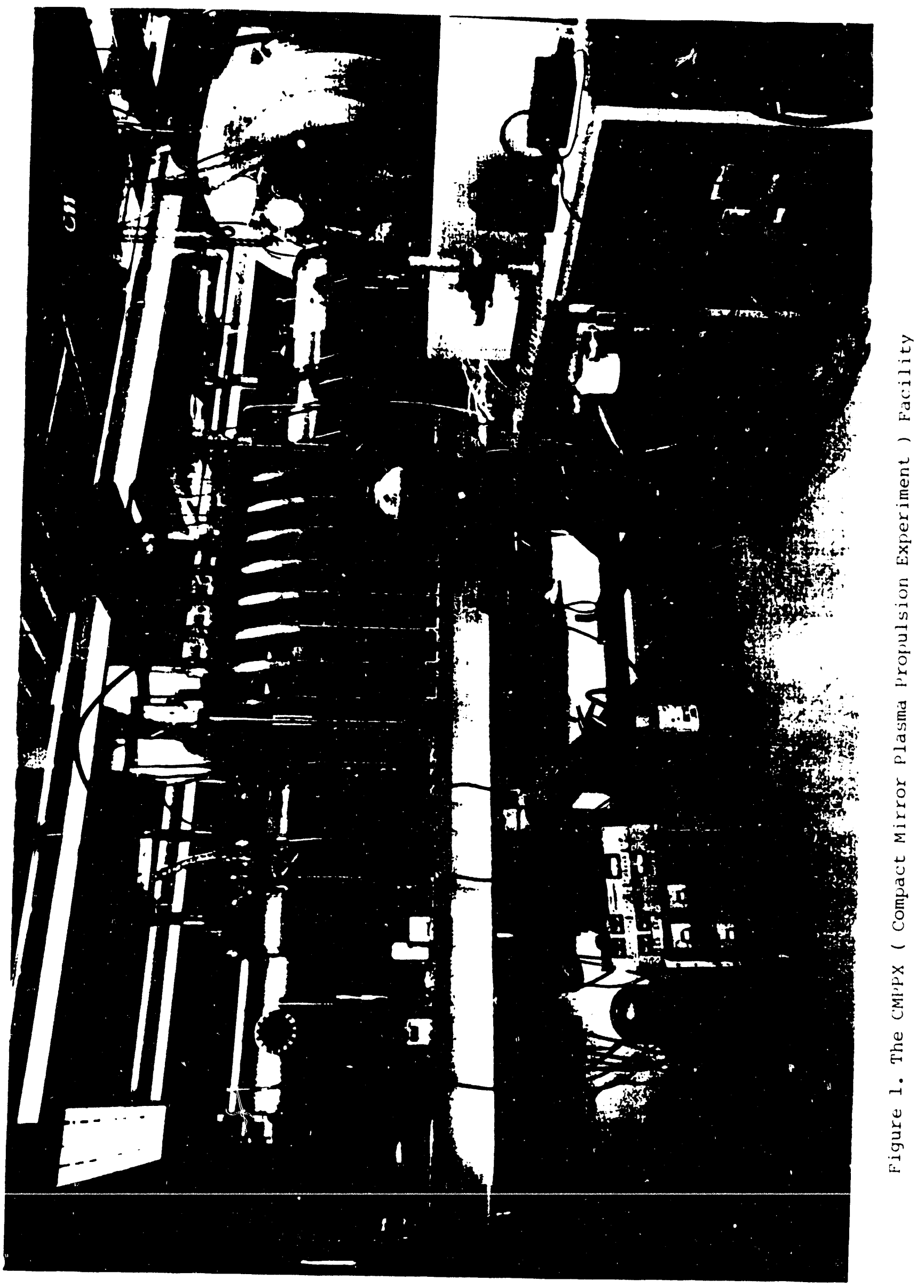




\title{
THE DEVELOPMENT OF A GASEOIS DIVERTOR FOR ITER
}

\author{
T. F lang \\ .IIT Plasma Fusion Center. Cambridge. 11 A 02139
}

$(617) 253-8453$

\section{CONCEPT}

A novel gaseous divertor concept is described consisting of gas chamber and pumping at high pressure or by reionizing the neutrals. The concept results in substantial reductions of the plasma temperature and heat flux at the target and the pumping requirement. Fluid model simulations of the scrape-off region of the Aries Reactor design by feeding the gas at the target at a flux of $1 \times 10^{23} \mathrm{~m}^{-2} / \mathrm{s}$ at $0.5 \mathrm{eV}$ has shown that the electron and ion temperatures can be cooled to $20 \mathrm{eV}$. The heat flux to the target can be reduced from $80 \mathrm{MW} / \mathrm{m}^{2}$ to $6 \mathrm{MW} / \mathrm{m}^{2}$. The plasma temperature and heat flux at the divertor target are monotonically decreasing functions of the neutral incident flux. Interestingly the temperature and the heat flux also decrease with decreasing neutral gas initial flowing speed removing the need of gas jets. The backflow problem can be minimized by including a baffle plate to form a gaseous chamber. Monte-Carlo simulations using test particles have showed that the throat of the gaseous chamber can be practically plugged by the incident plasma to prevent backflow of neutrals into plasnıd core. The pumping can be facilitated by either operating the divertor chamber at high pressure on the order of 30 Torr or reionizing the neutrals traveling to a weak toroidal field region. The concept should be model independent and equally applicable to ITER. A test program using CMPPX facility is discussed. 


\section{INTRODUCTION}

Future tokamak reactors are likely to be operated at high 3 or high field with very high central temperature and density. The resulting electron and ion temperatures at the plasma edge. $T_{\text {edge }}$ could be as high as $1000 \mathrm{el}$ with corresponding plasma densities in the $5 \times 10^{: 9} \mathrm{~m}^{-3}$ range 1 The erosion rate on the divertor target would be as high as 1 $m$ per year. The heat flux will be tens of $11 \mathrm{~W}^{\prime} \mathrm{m}^{2}$. Such excessive erosion and high heat loads cannot be relieved of by appropriate choice of material and/or design method alone. An active control method is needed to reduce the temperature and heat flux impinging on the divertor. Besides erosion and high heat flux problem there are other important issues which have to be addressed: impurity and helium removal, activation, vacuum pumping and maintenance. These issues have to be resolved in an integrated fashion.

The gaseous divertor is one of several proposed solutions. The novel gaseous divertor concept described here offers the possibility of an integrated solution to the issues mentioned above. Preliminary modeling of the concept has been performed. Because of the lack of computational tools there had not been significant development in this area up to now, but the availability of B- 2 code 2 has now made it possible to study the plasma-gas interaction and transport in the scrape-off laver.

The divertor concept was modeled based on the Aries Reactor design. However, the concept is model independent and is equally applicable to ITER [3]. The fluid model simulation in the scrape-off laver was carried out using the B-2 code. The boundary conditions at the interface between the plasma core and the edge region are determined by the transport calculation of the plasma core.

The effect of the gas feeding rate and injection speed on the electron temperature, the ion temperature and heat flux at the target is studied in section 2. Methods of minimizing the backflow problem is described in section 3. The Monte-Carlo simulation using test particles is used for this analysis.

The pumping of the divertor will be become very simple if the divertor chamber can be 
operated at high pressure, preferably in the 30 Torr range. which balanced the pressure of the plasma in the scrape-off layer. At this pressure the pumping speed required is very low and the large through-put from the plasma to the vacuum system can be easily handled by mechanical pumps. Additional improvement ideas on the gaseous divertor, such as the reionization pumping and the rolling rod target concept, are discussed in section 4 . A testing program on the C.MPPX facility at .MIT is proposed and discussed in section 5 .

\section{FLUID MODELING}

The fluid modeling was carried out using B-2 code 2 ; using the the Aries-I reactor parameters 1 The results are preliminary because further code improvements are necessary to include many physics and atomic reactions and to model accurately the geometry of the target, the chamber and the pumping ducts. Nevertheless, the relevant effects of neutral gas puffing on the cooling of the plasma at the divertor target can be analyzed using this model.

The Aries-I reactor is a 1000 WWe reactor with a plasma radius of $6.5 \mathrm{~m}$, a minor radius of $1.4 \mathrm{~m}$ and a neutron wall loading of about $2.8 \mathrm{MW} / \mathrm{m}^{2}$. Aries- $\mathrm{I}$ is a high field reactor with $B_{o}=13 \mathrm{~T}$. The major parameters are listed in Table 1. The plasma configuration is shown in Figure 1 in which the region of simulaticn in the scrape-off layer is outlined. The expanded plot of the simulation layer is shown in Figure 2. The B-2 simulation was carried out by maintaining constant boundary conditions as indicated in Figure 2 so that the properties of the core plasma were not changed. The boundary conditions at the interface between the core plasma and the edge region modeled in this study were determined by the transport calculations if the plasma core of the ARIES-I reactor. 
Table 1

Aries-I .Major Parameters

$\begin{array}{ll}\text { Major plasma radius } & 6.52 \mathrm{~m} \\ \text { Mlinor plasma radius } & 1.45 \mathrm{~m} \\ \text { Plasma aspect ratio } & 4.5 \\ \text { Plasma elongation } & 1.6 \\ \text { Toroidal field (on axis) } & 13 \mathrm{t} \\ \text { Plasma beta } & 2 \% \\ \text { Average electron density } & 1.6 \times 10^{20} \mathrm{~m}^{-3} \\ \text { Average electron temperature } & 20 \mathrm{keV} \\ n \tau_{e} & 1.8 \times 10^{20} \mathrm{~m}^{-3} \mathrm{~s} \\ \text { Fusion power } & 1991 \mathrm{MW}^{-1}\end{array}$

In the case of no gas feeding, the sensitivity of the plasma properties at the divertor target on the scrape-off layer width and target location has been studied. Empirical diffusion coefficients $D$ and thermal conductivities $\chi_{e}$ and $\chi_{i}$ were used. The plasma properties at the target were found not to be sensitive to changes of the transport parameters. The electron temperature was determined to be a slow decreasing function of the width of the scape-off layer. The temperature decreases by $25 \%$ when the width is doubled. This is expected because the target area near the separatrix was increased by roughly $25 \%$. The overall target area was nearly doubled. Therefore it is not practical to reduce the electron temperature and heat flux by simply increasing the width of the scrape-off layer.

Figures 3 and 4 show the temperature and energy flux profiles along the divertor plate for electrons (dashed curve) and ions (solid curve) for $T_{\text {edge }}=6{ }^{6} 0 \mathrm{eV}$ for the case of no gas feeding. The electron and ion temperatures are peaked near the separatrix. The peak electron temperature is $170 \mathrm{eV}$ with a corresponding peak ion temperature of only $20 \mathrm{eV}$. The electron energy flux is $80 \mathrm{MW} / \mathrm{m}^{2}$ and ion energy flux is $20 \mathrm{MW} / \mathrm{m}^{2}$. Handling such an enormous heat load and high electron temperature is out of the question. Some form of active control to remove the heat from the plasma before impinging on the target is needed. 
A commonly suggested method is radiation cooling by seeding the scrape-off layer with impurities and or using a gas target. For simulating the gaseous divertor case, the B-2 code has been modified in order to feed the gas at the target and to incorporate pumping at the outer boundary.

Figures 5,6 and $T$ present the results of simulations using the modified B-2 code. Figure $j$ shows the electron temperature profiles on the divertor target for $T_{\text {edge }}=600$ and $400 \mathrm{eV}$. Our reference case assumed $T_{\text {edge }}=400 \mathrm{eV}$. Comparing curve 1 in Figure 5 witı the dashed curve in Figure 3 for $600 \mathrm{eV}$ plasma surface iemperature the peak $T_{e}$ on the target was reduced from $170 \mathrm{eV}$ to $110 \mathrm{eV}$ with gas puffing at temperature of $1 \mathrm{eV}$ and at peak flux of $1 \times 10^{23} \mathrm{~m}^{-2} \mathrm{~s}^{-1}$. Figures 2 and 3 show that for $T_{\text {edge }}=400 \mathrm{eV}$, the peak plasma temperature on the target drops dramatically from $80 \mathrm{eV}$ to $18 \mathrm{eV}$ with gas feed at $1 \mathrm{eV}$ and peak flux of $1 \times 10^{23} \mathrm{~m}^{-2} \mathrm{~s}^{-1}$. The dependence on the plasma temperature and heat Hux on the gas feed is large. The temperature at the target further dropped to $5 \mathrm{eV}$ when the gas temperature was reduced to $0.5 \mathrm{el}$ as shown by curve 4 .

Therefore, contrary to the early thinking it was found in this study that the gas should be fed at very low velocity, equivalent to a temperature of the order of $1000 \mathrm{~K}$, which is a strong indication of the use of a gaseous chamber

Similarly, curves 2, 3 and 4 in Figure 6 show the energy flux profiles on the target without gas feed, with gas feed at $1.0 \mathrm{eV}$ and $0.5 \mathrm{eV}$ respectively for $T_{\text {edge }}=400 \mathrm{eV}$. The peak heat flux drop sed from $35 \mathrm{MW} / \mathrm{m}^{2}$ to $4.5 \mathrm{MW} / \mathrm{m}^{2}$, almost by one order of magnitude. Furthermore the spread of high heat region was reduced by a factor of 2 from $50 \mathrm{~cm}$ down to $25 \mathrm{~cm}$. Figure 7 shows that the peak temperature is a fast decreasing function of gas puffing flux. The gas injection speed can be further reduced. This means that it is not necessary for the gas to flow at high speed (i.e., in gas jets) and a chamber with high neutral density is sufficient.

A qualitative physical explanation for such a cooling effect described above can be given as follows. The mean free path for impact ionization of neutrals with electron is 


$$
\lambda_{e o}=\frac{v_{e}}{n_{o}\langle\sigma v\rangle}
$$

where $v_{e}$ is electron thermal velocity and $n_{0}$ is neutral density. There is a broad peak of reaction rate $\langle\sigma v\rangle$ in the energy range from $200 \mathrm{eV}$ to $2,000 \mathrm{eV}$. 4 . The averaged reaction rate in that range is $2 \times 10^{-14} \mathrm{~m}^{3} / \mathrm{s}$. For $T_{e}=400 \mathrm{eV}$ and $n_{0}=1 \times 10^{23} \mathrm{~m}^{-3}$ at a pressure of 33 Torr in a gas chamber(see section 3 ) the electron thermal velocity is

$$
\begin{aligned}
v_{e} & =4.19 \times 10^{15} \sqrt{400} \\
& \simeq 8.4 \times 10^{6} \mathrm{~m} / \mathrm{s}
\end{aligned}
$$

and the mean free path is approximately

$$
\begin{aligned}
\lambda_{\text {eo }} & \simeq 8.4 \times 10^{6} /\left(10^{23} \times 2 \times 10^{-14}\right) \\
& =4.2 \times 10^{-3} \mathrm{~m}
\end{aligned}
$$

which is very short. The mean free path will be even shorter when the temperature drops. With each ionizing reaction the electrons will lose at least $13.6 \mathrm{eV}$ of energy. In additional there is large amount of energy lost by excitation reaction with molecular and atomic hydrogen. Taking into account of line radiation from excited states of neutral hydrogen the empirical ionization energy is 4 :

$$
\begin{aligned}
E_{\text {ionization }}\left(\mathrm{eV}^{\prime}\right)= & 17.5+\left(5 .+\frac{37.5}{T_{e}[\mathrm{eV}\rfloor}\right) \\
& \times \log _{10}\left(\bar{n}_{\mathrm{e}_{1}} \frac{10^{21}}{\mathrm{~m}^{3 !}+10^{17}}\right)
\end{aligned}
$$

Therefore the ionization energy can be higher than $20 \mathrm{eV}$. Moreover additional electrons and ions are created after each impact ionization which will increase the number of reactions, such as charge exchange, electron and ion impact ionization and recombination. Such cascading effects causes the electron tempcrature to drop drastically. The recombination rate is also very high. The energ! will be radiated during the recombination. The energy carried by the fast neutrals will be deposited througout the divertor chamber, and nort just in the divertor target, decreasing the peaking of the heat flux at the target. 
From the pressure balance point of view the gas pressure at room temperature is comparable to the incoming plasma pressure in the scrape-off laver. The peak pressure on the separatrix is

$$
P=n k\left(T_{1}-T_{e}\right)=50 T \text { orr }
$$

The average pressure is about 35 Torr. Therefore the backflow of the neutral can be blocked by the plasma without a corresponding burning out of the neutral gas of the chamber if the chamber pressure is controlled.

Figures 5 and 6 indicate that the region of heat flux above $1 . \mathrm{MW} / \mathrm{m}^{2}$ is only $10 \mathrm{~cm}$ wide, confined within the shaded strip of the scrape-off layer shown in Figure 8. Therefore it is safe to place a baffle plate in the region outside this hot strip, as shown in Figure 8. The baffle plate forms a gaseous chamber with the inclined target and back plate as shown by the expanded plot in the middle of the figure. In the process, a divertor throat is formed which further assures that the backflow of neutral from the gaseous chamber to the core plasma is minimal. The effectiveness of the plasma plugging of the gaseous chamber is analyzed in the next section.

\section{MONTE-CARLO MODELING}

The fluid code B-2 is applicable only to a simulation region where the the coordinate system is orthogonal as shown by Figure 2. In Figure 2 the inner boundary is the separatrix and the outer boundary is a flux surface defined by limiters. The flux surface and radial coordinates are orthogonal. Therefore the divertor target or any material surface has to be normal to the flux surfaces, i.e., it has to lie on the radial grid at boundary. The choice of this coordinate system limits the shape and size of the divertor plates. There is no option for internal boundary like the baffle. In the gaseous chamber the divertor target is intersecting the flux surface at an angle. Therefore the B-2 code is not applicable for simulating the entire region including the gaseons chamber. 
The study of the gaseous chamber has been carried out using a Monte-Carlo code. The drawback of the Monte-Carlo code is that to carry out a true simulation a prohibitive large number of particles is required. Therefore only test particles have been used. The advantages are that it is not constrained by boundary conditions and coordinate system limitations, and that pumping and physical processes can be easily incorporated.

Preliminary results of the simulation are shown in Figure 9. Both outer and inner divertors are included in the simulation. The outer target is inclined with respect to the flux surface. There are two baffle plates on the outboard side. The lower baffle plate and the target form a throat which is plugged by the plasma to restrict the back flow of neutrals into the main plasma. In the inner divertor chamber the target is nearly vertical and there is no lower baffle plate. The upper baffle plate is against the magnet or shield. Such an arrangement will keep the height of the divertor very low so that the size of the TF coil can be kept minimal. This design allow's the particles from the inboard chamber to reach the outboard chamber to be pumped out.

In Figure 9 the solid curves are the ion orbit and the dashed random tracks are neutrals. Figure 9a shows the high neutral build-up inside the chamber without pumping. There were very few backflow neutrals into the scrape-off laver. The plasma volume for Aries is $V_{p}=441 \mathrm{~m}^{3}$ and the average electron density is $n_{e}=1.6 \times 10^{20} \mathrm{~m}^{-3}$. The particle confinement time is assumed $\tau_{p} \approx 4 \sec$ (approximately four times $\tau_{e}$ ). The gas throughput is

$$
\begin{aligned}
Q & =\frac{n_{r} l_{p}}{\tau_{p} \times 32.4 \times 10^{19} T o r r-\ell / \mathrm{sec}} \\
& \simeq 5.44 \cdot 11^{2} \text { Tor }-\ell / \mathrm{s}
\end{aligned}
$$

If it is assumed that the chamber can he uperated at a pressure $p=10^{-3}$ Torr, then the total pumping speed is $5.44 \times 10^{5} \mathrm{G}$. The $1 \mathrm{~h}$ timistic specific pumping speed of a cropump is approximately $40,000 \mathrm{l}$ : $\mathrm{sec}^{2} \mathrm{~m}^{2}$. then the required area for pumping is 
without taking into account of the conductance of the pumping duct. The area requirement will be reduced to $68 \mathrm{~m}^{2}$ if $\tau_{p}$ is doubled. However. this gain can easily be wiped out with higher vacuum requirements and the loss of conductance due to a long pumping duct. Therefore the area required for pumping is excessive.

The use of a gaseous chamber may permit higher operating pressure. If $p=33$ Torr is allowed, then the system can be pumped by mechanical pumps. For a mechanical pump operated at pressure above 0.1 torr the pumping speed reaches a plateau. A Helch DIOO-SEAL $1397 \mathrm{~b}$ has a pumping speed of $400 \ell \mathrm{s}$ with a port of $4.5 \mathrm{~cm}$ in diameter. The pumping speed required at 33 Torr is only $16 \ell / \mathrm{s}$ which can be easily handled by a mechanical pump just mentioned. Several mechanical pumps can be placed around the tokamak to closely regulate the chamber pressure. The discussion here illustrates the tremendous advantage of using high pressure gas chamber. The true parameters have to determined with more detailed and precise numerical simulation and experimental test.

\section{Innovative pumping concepts applicable to the gaseous divertor}

In this section a novel pumping scheme is described. The neuirals are free to travel across the magnetic field. When they come to the sptce of very weak toroidal field at large major radius, the neutrals can be reionized. The ions will travel along the poloidal field vertically and leave the tokamak to a remote location. With the choice of ionization method the impurity and helium separation can be made at the exit of the divertor chamber. The reionization pumping method is illustrated by Figures $9 \mathrm{~b}$ and $9 \mathrm{c}$ in which upward drifting of the ions is shown by parallel solid curves, orbits of the reionized frarticles. The neutral density is reduced when the number of the ionized particles are increased. A detailed numerical study and experimental test are needed in order to devilop such an idea.

The target can be made of rods of $2 \mathrm{~cm}$ in diancler. If the rod can be rotated at 1 revolution per sec. the heat flux will become $2.11 \mathrm{~W} / \mathrm{m}^{2}$ or less. The cooling of the rods with gas is possible. As is illustrated by Figure 10 such rods are mounted on railings and

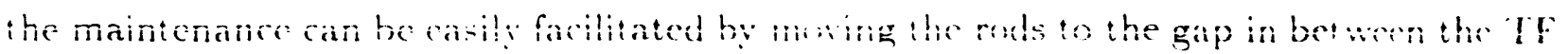


coils to be extracted. The low heat flux and erosion rate allow the use of low activation materials such as metal ceramic and graphite.

\section{Testing Program}

The gaseous livertor concept can be tested and developed using the compact mirror plasma propulsion experimental (C.MPPX) facility at .IIT. The characteristics of such facility has been presented in the write-up of linear plasma simulator. Figure 11 shows the Hux line at the end if the IIIT C.MPPX device which resembles the divertor region where the plasma is hot on the axis and is cold at the edge. Figure 12 is the expanded exhaust end of figure 11 and the implementation of gas chamber resembling that of Figure 9 . The target intersects the hot plasma core with conditions similar to that in scrape-off layer in tukamak. The test can be carried out in the following stages:

\section{(1) Baseline Test}

Establish the baseline information by intercepting the plasma with a target as shown by figure 12 without gas chamber. The target can be perpendicular or at a inclination $w$ tre field line. One can carry out the following experiments considered are follows:

(1) Measure the heat Hux and temperature on the target.

(2) Measure plasma density, temperature and neutral density near the target.

(3) Examine the surface damage.

(1) Pump with the mechanical system ard analyze the Gas with an RGA (Residual Gas Analyzer) to determine the gas content. Study the helium and impurity transport by injecting them into the central cell of the mirror device.

\section{(II) Cias Target Studv}

Install the gas chamber as shown by figure 12. Make the same measurements as stage(l) and use only the arechanical pump. In addition to the experiments listed in stage

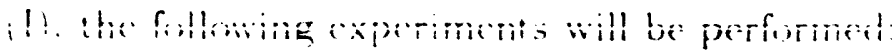


(1) Study the effect of gas feed to the plasma and target.

(2) Study the backflow.

(3) Study the backfow by varying the throat size and length.

(1) Study the helium removal by feeding the helium to the main plasma.

(5) Study the effect on heat Hux by changing target inclination.

(6) Compare the material surface properties with those from stage (I)

(i) Study the effect of the pumping speed on the pressure build-up and vice versa.

(8) Study the effect of pressure build-up in the gas chamber on the plasma and vice versa.

(9) Examine the pressure balance between the incoming plasma and the gas chamber.

(III) Ion Pumping Study.

Reionize the neutrals in the region shown in figure 13. Make the same measurement as stage (1). The following additional studies will be performed:

(1) Measure the ions flowing out along the field lines.

(2) Study the ion pumping speed with various ionization methods, for example, EC RH breakdown and resonance heating, thermionic and high voltage break. down, or a combination of these methods.

(3) Study the preferential helium removal method.

(4) Study the prefercntial impurity removal method.

(i) - lud! the hack thw.

(6) Study the alternative gas chamber as hhwn in figure 14.

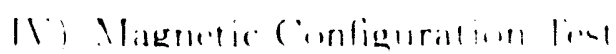


Finally one can carry out the magnetic configuration test by creating a null point and separatrix as shown by figure 15 (This is only a sketch but such a system has been designed for the Wisconsin Tandem Mirror Reactor by Yang 1 as neutron plug and direct energy convertor). This configuration is very close to the poloidal divertor in a tokamak except toroidal field. The same experiment as stage (III) will be carried out.

\section{(1) . Material Test}

In conjunction with the gaseous divertor experiments discussed above. one can test many materials for the target. Tungsten, and Aluminium oxide(ceramic material) should be tested. From our past experiment in Alcator $\mathrm{C}$ we begin to understand how the Tung. sten and Molybdenum start to melt and how the redeposit taki..g place 5,6 . Aluminium would be an excellent target material because of the low activation. The aluminium oxide can be woven into fabric which might be shaped into different configuration.

(1) . Weasurement of Reaction Crosi-section

The reaction cross-sections in the low temperature range are crucial to numerical modeling. The data for energy below 21) el are scarce and should be fully established.

11I) Permeation Study

('urrently the measurement of permeation rate of hydrogen or helium through metals was carried out using monoenergetic beams at the energy much higher than the temperature in the scrape-off laver. The permeation rate might be different if the metals are in the plasma. The permeation rate for many species in the plasma for various conditions shuild be carried out.

(1II) Civals

The guals can be summarized as bellew:

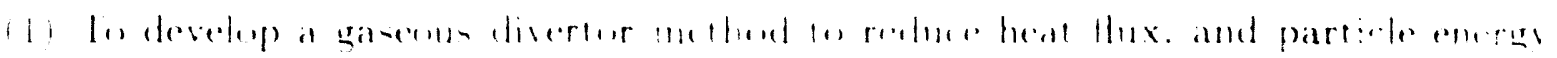

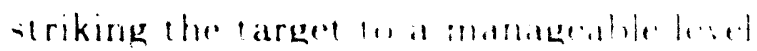

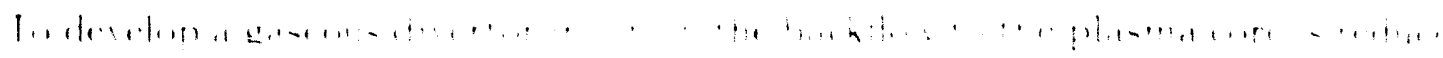


to a tolerable level.

(2) To develop the high pressure pumping scheme

(3) To develop a helium removal scheme.

1) Lis develop a ion pumping scheme.

(5) To develop many material candidates and processing schemes for the divertur target. The effort will include the luw activation materials.

\section{REFERENCES}

1 I F NAJAMBADI. R II CONN and IRIES TEAM. "Arips Tokamak Fusion Re.

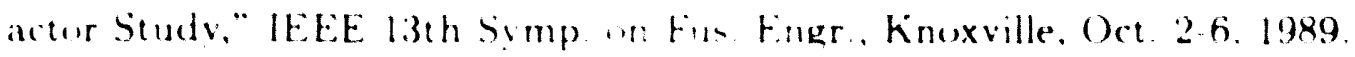

2 B. J.BRAAMS. "A Multi-Fluid code for smulation of the Edge Plasma in Tokamaks". VET Report Vr. 68. EIR.Fl XII-41) 37 68. (198T)

3 E. Salpietro.'Overview of the ITEK project, presented at the 9 th Top. Meeting un the Tech. of Fus. Energy. (hicate.. Sept.1!99())

1 P. J. GIERSZEWSKl, "Plasma Veutral (ias Transport in Divertors and Limiters". Thesis Dissertation.PFC RR-4.3 24!(9).3). (1983).

5 B. Batiger et al. MITAMIRR.1. 11 merslly of Misconsin landem Mirror Reactur Design, LWFD.M-400(1980)

(6 T.F. Yang, A.S. Wan. J. Megunir and Ci.S Luan" Measurement of Sheath Potential

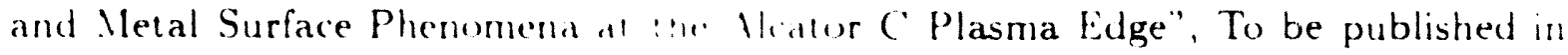

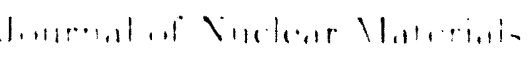

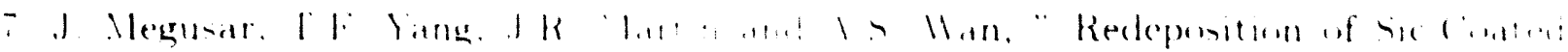

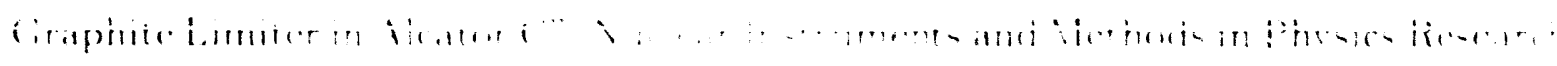
$3210,-1011$ 
8' A.S. Wan, T.F. Yarg, B. Lipschultz, and R. Labombard, "Janus. a Bidirectional. Multifunctional Plasma Diagnostic", Review of Sciertific Instruments, 157..No.8.(1986)15+2.

9 K. Okuno, 'Permeation Behavior of Deuterium Implanted into 304 SS' presented at the 9th Top. Meeting on the Tech. of Fus. Energy, Chicago,Sept(1990) 


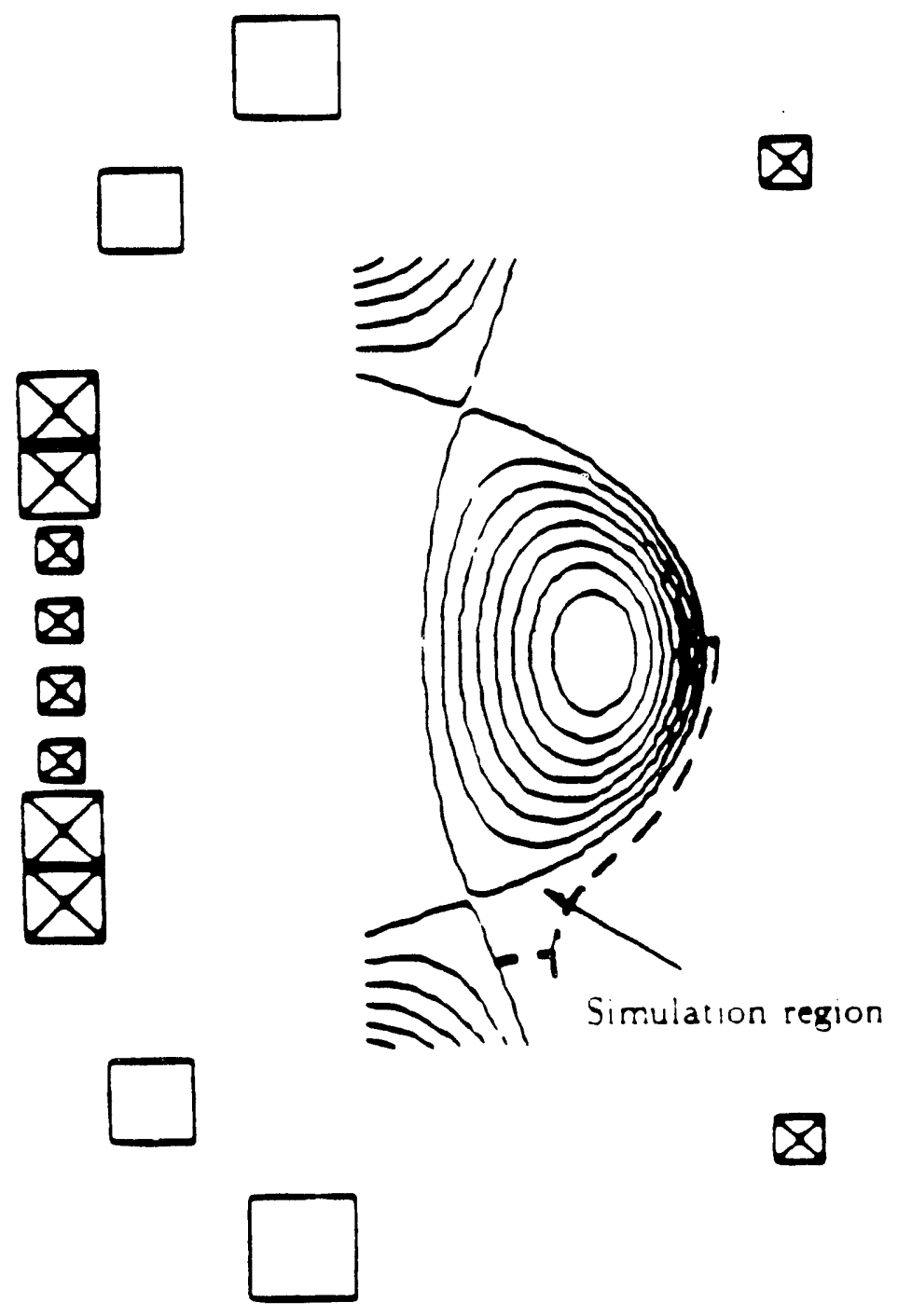

Foure! tresel congguadin 


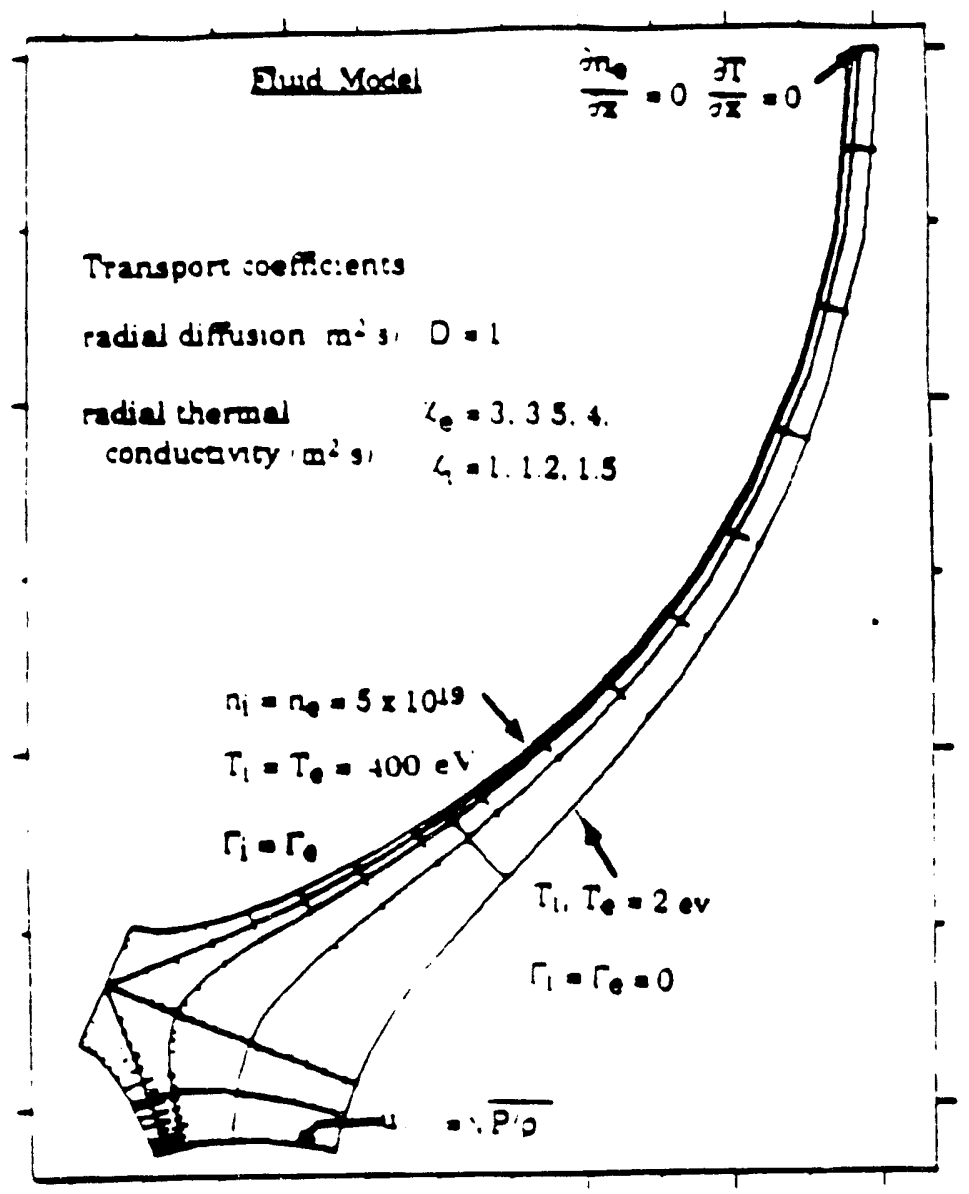

Figure 2. Expanded simuialiun rcglun with reierence hisundary conditions. 


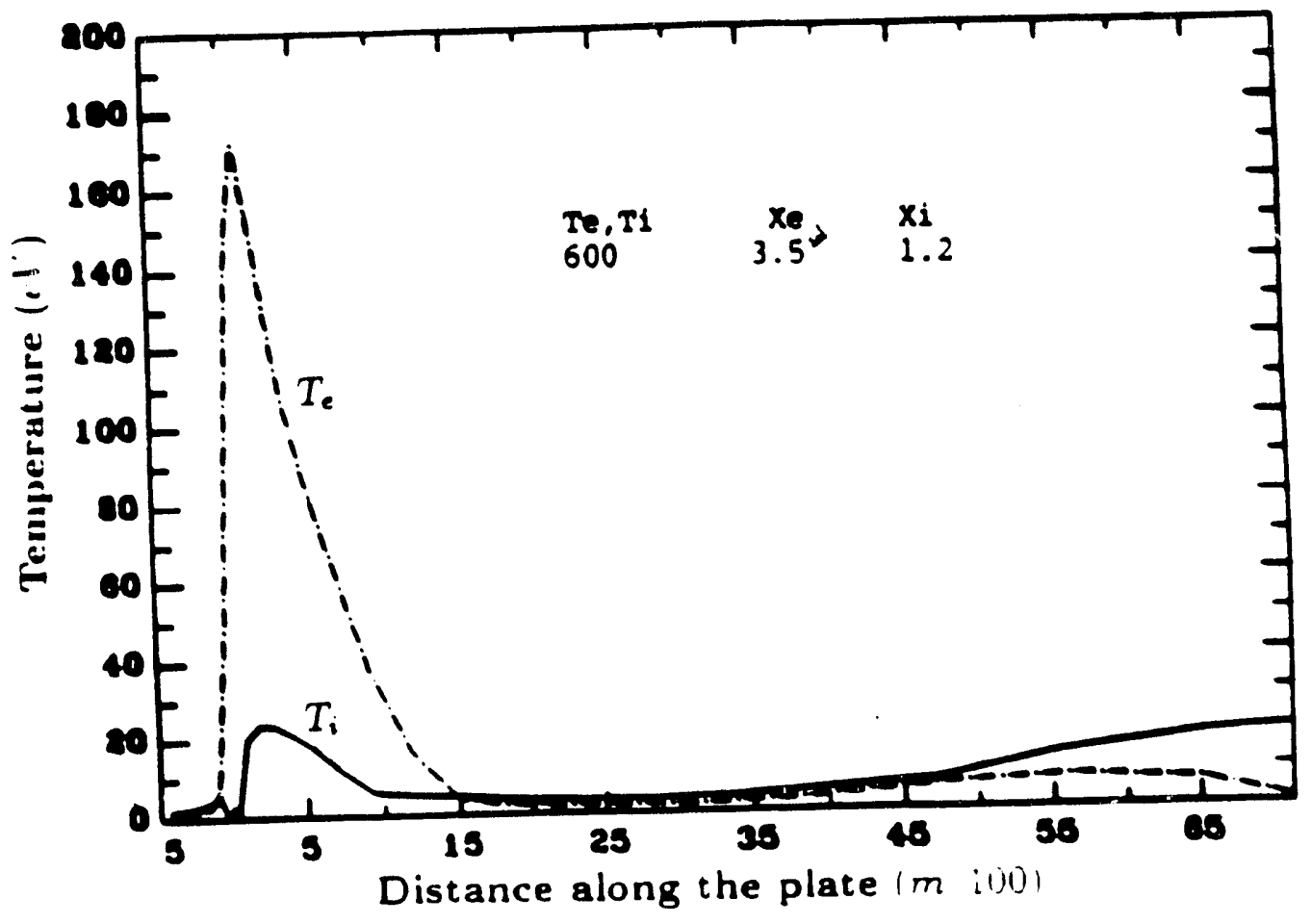

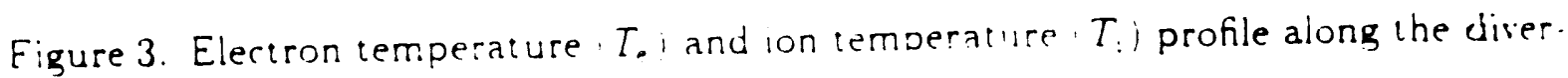
ior target plate without gas feed. 


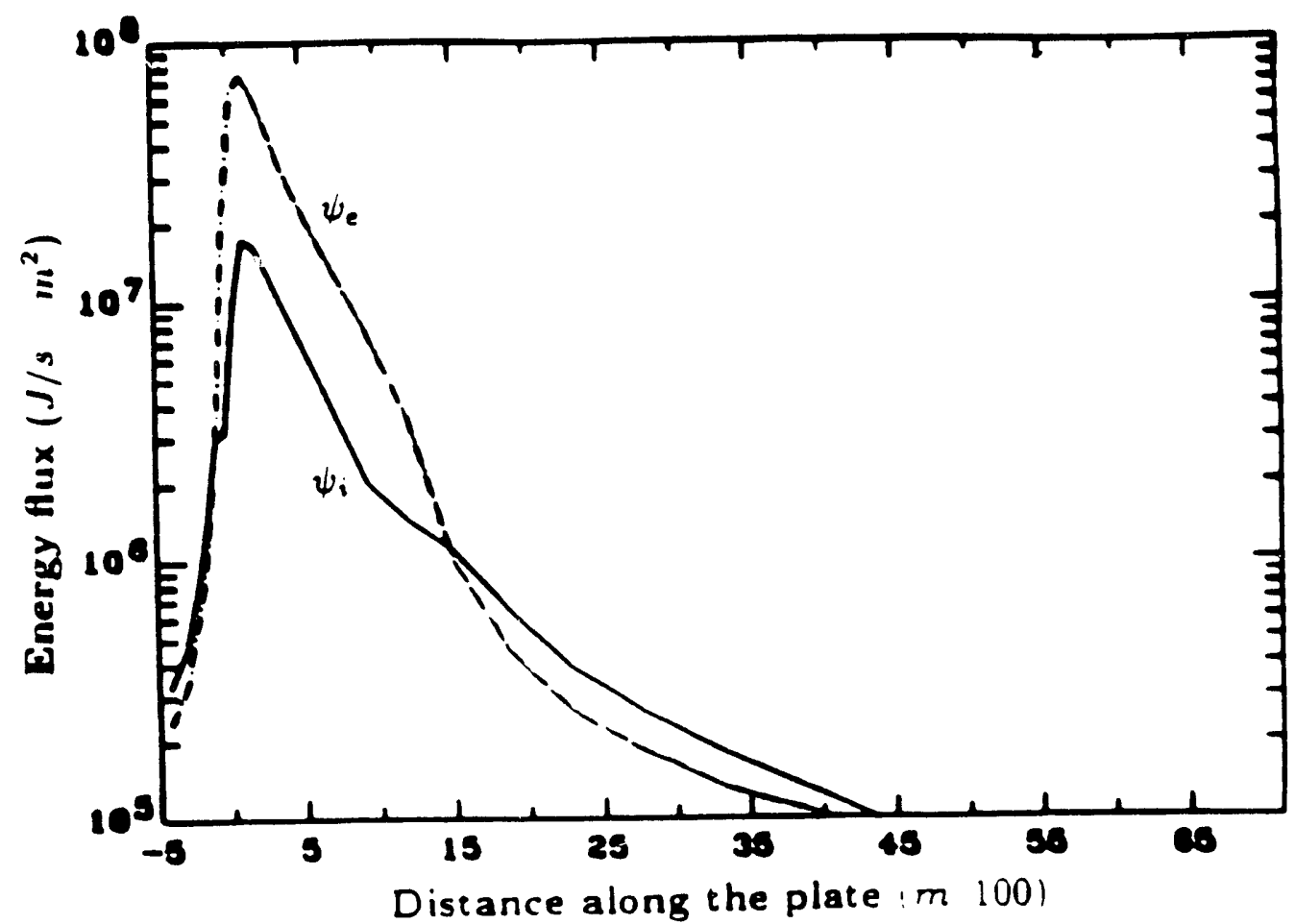

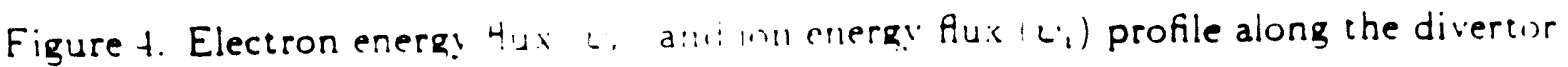
target plate without gas feed. 


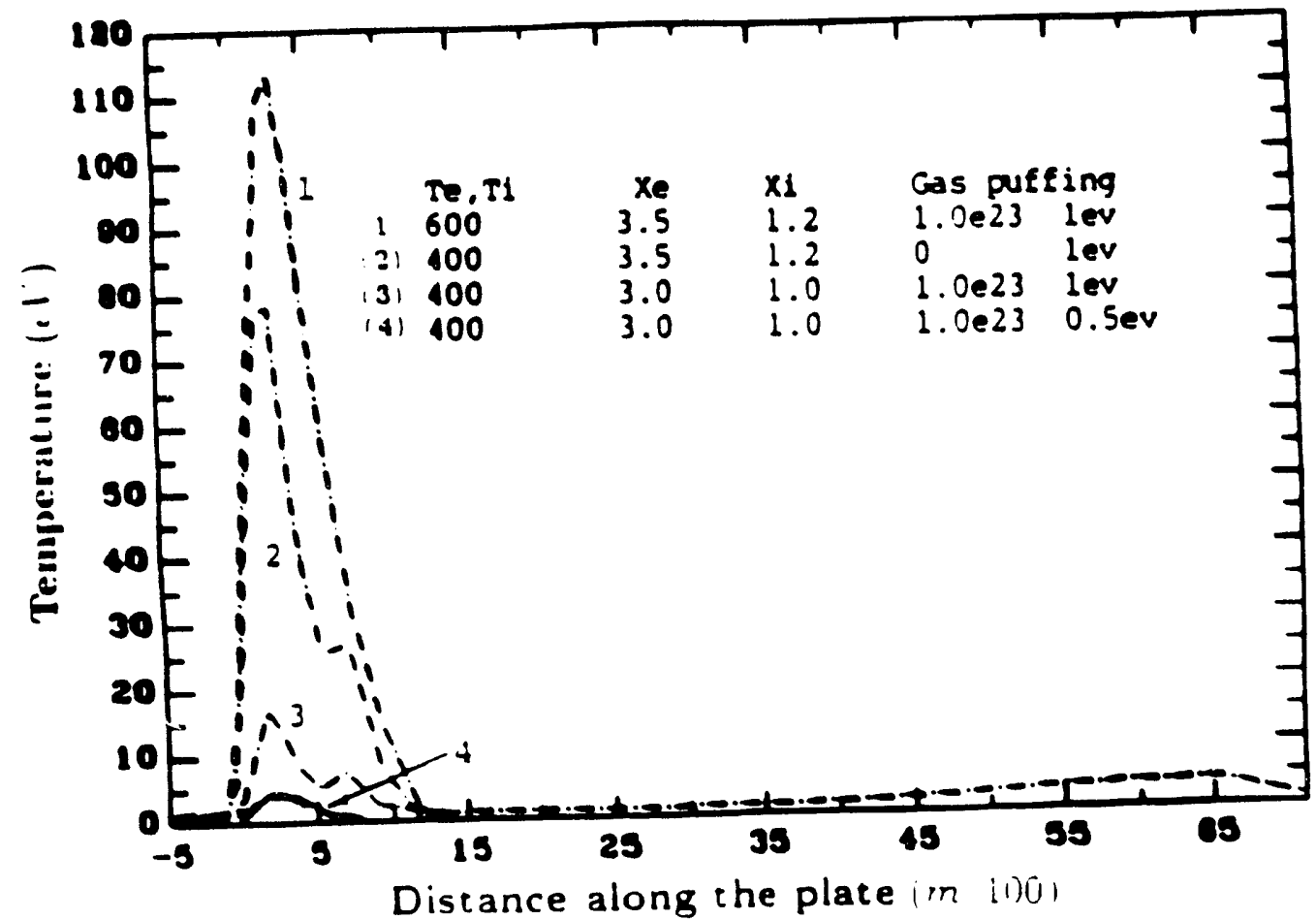

Figure 5. Electron temperature $\left(T_{e}\right)$ profile along the divertor target plate with gas feed. 


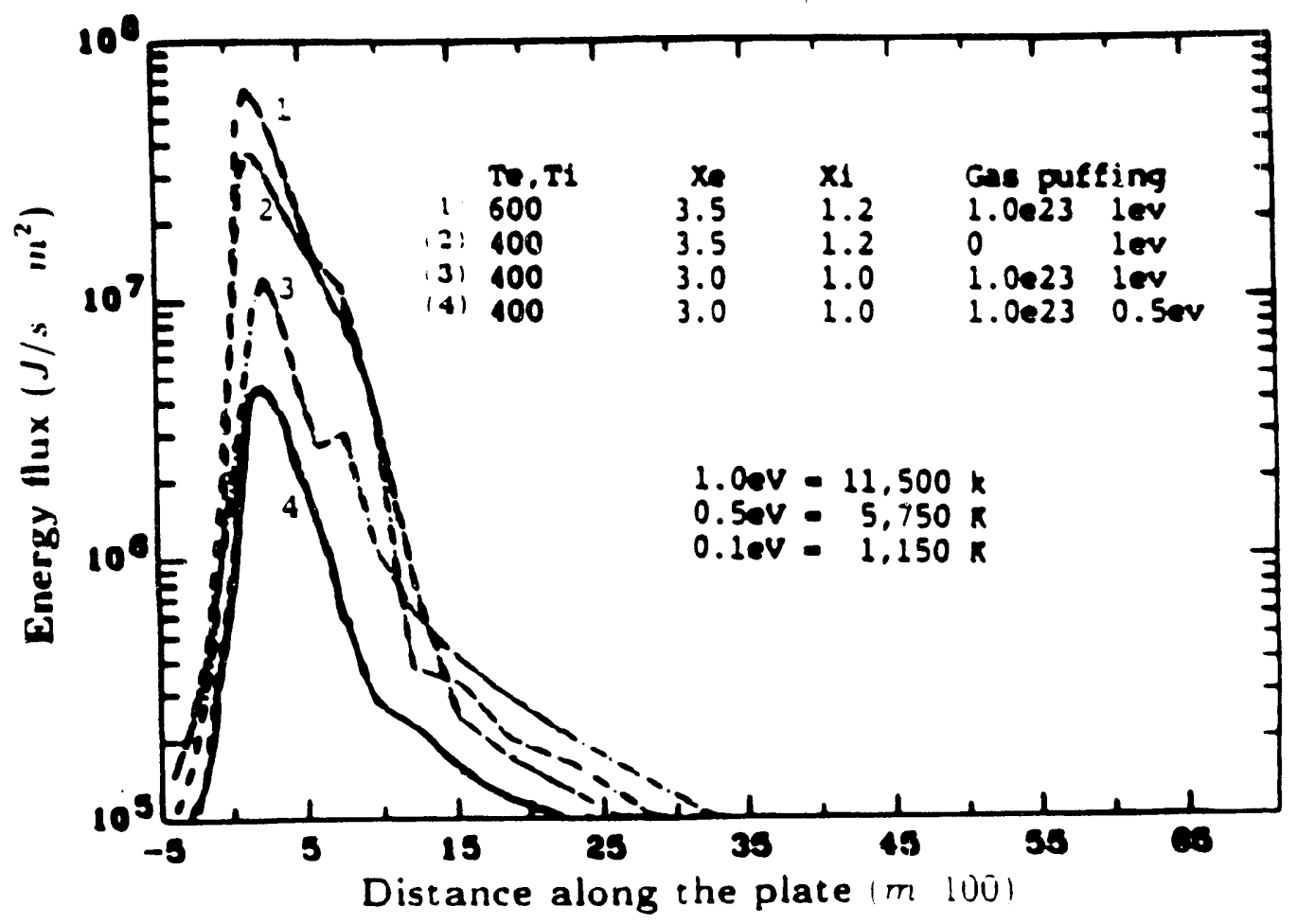

Figure 6. Electron energy flux $\left(\psi_{e}\right)$ profile along the divertor target plate with gas feed. 


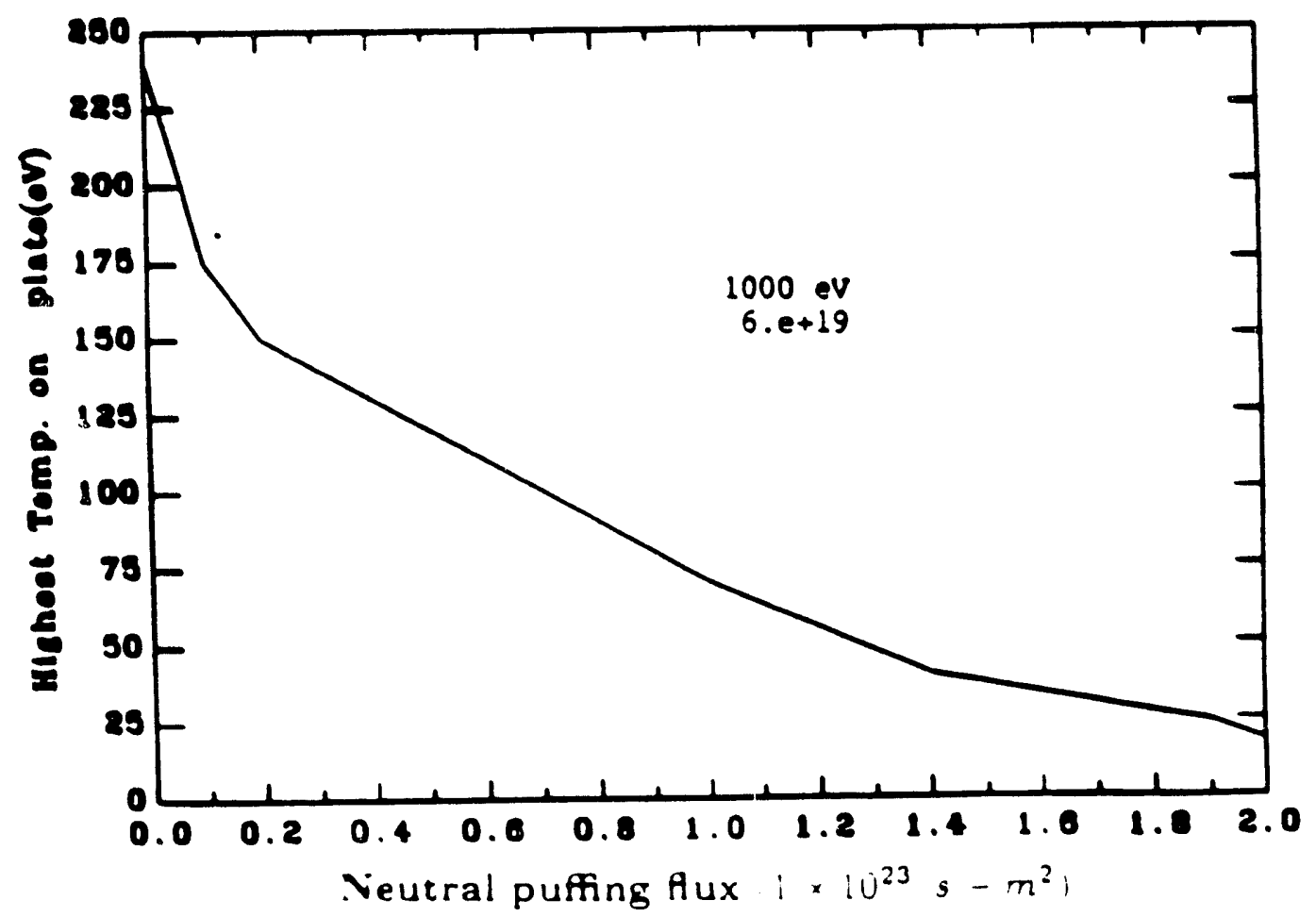

Figure $i$. Electron temperature. $T_{t}$, as function of gas puffing flux. 


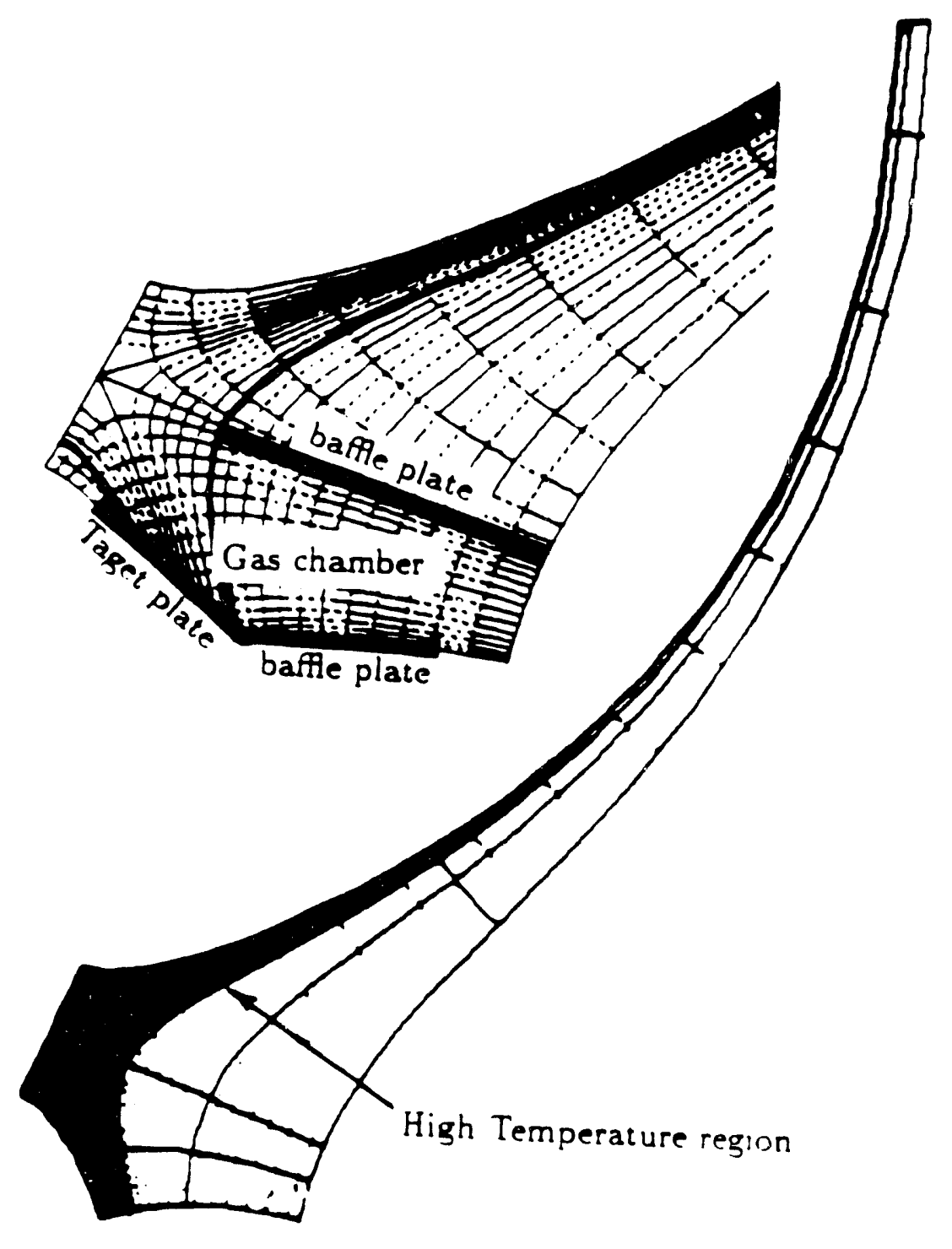

Figure $:$ The hot plasma region in the scrape-of iaver (shaded area) in the lower figure The upper figure shows the gas chamber formed hi he target plate. and two baffe plates. 

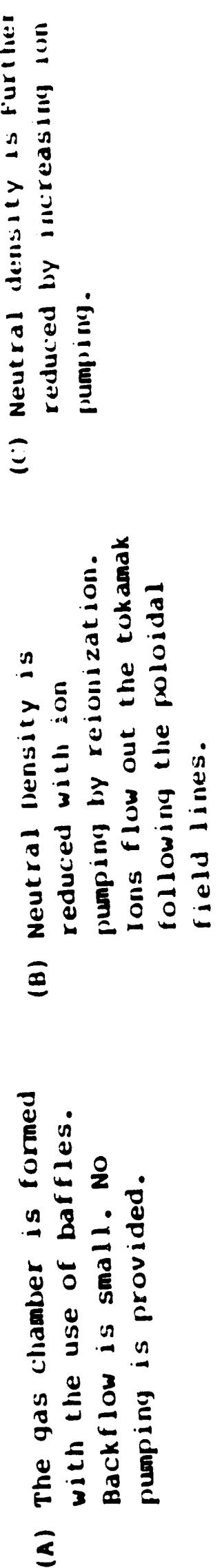
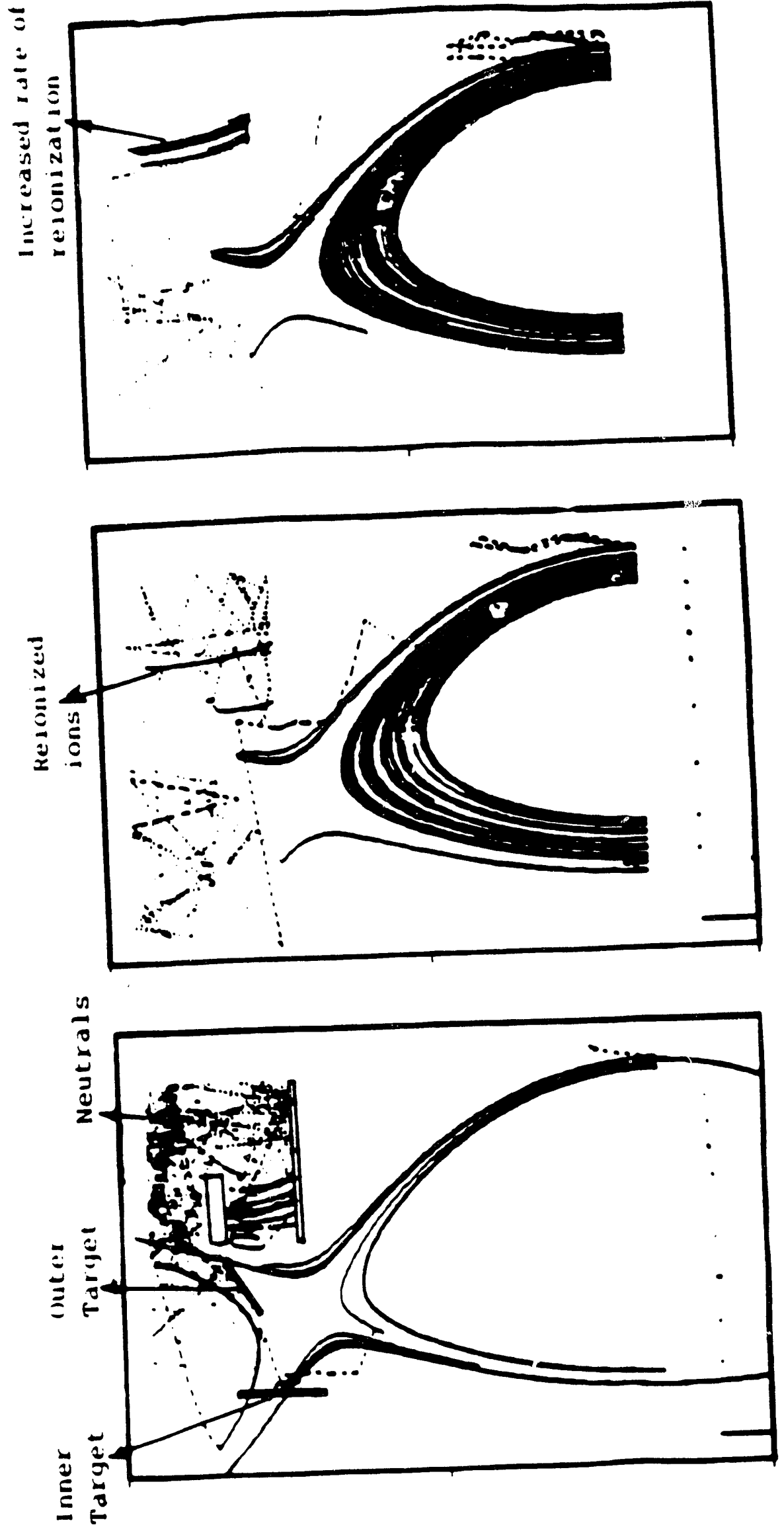


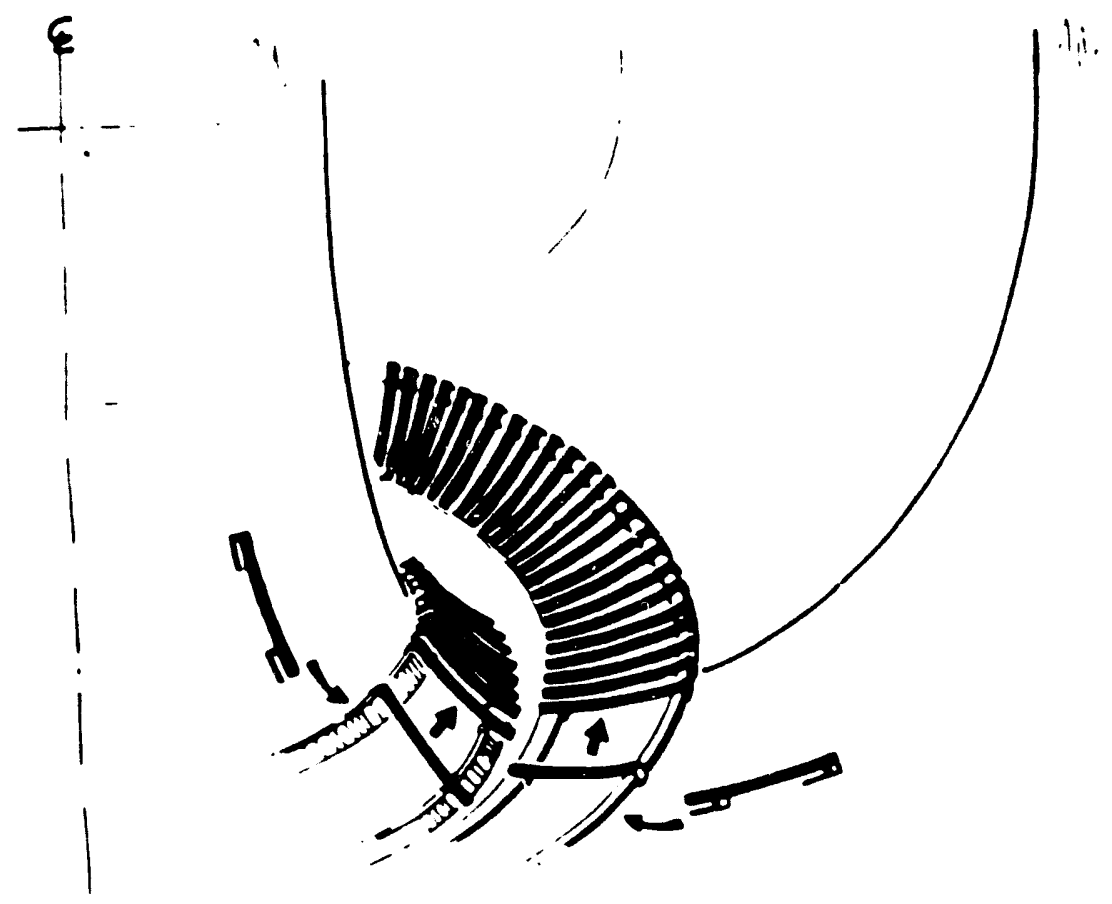

Figure 10 . A cassette or rolling rode design of the divertor targets.

23 


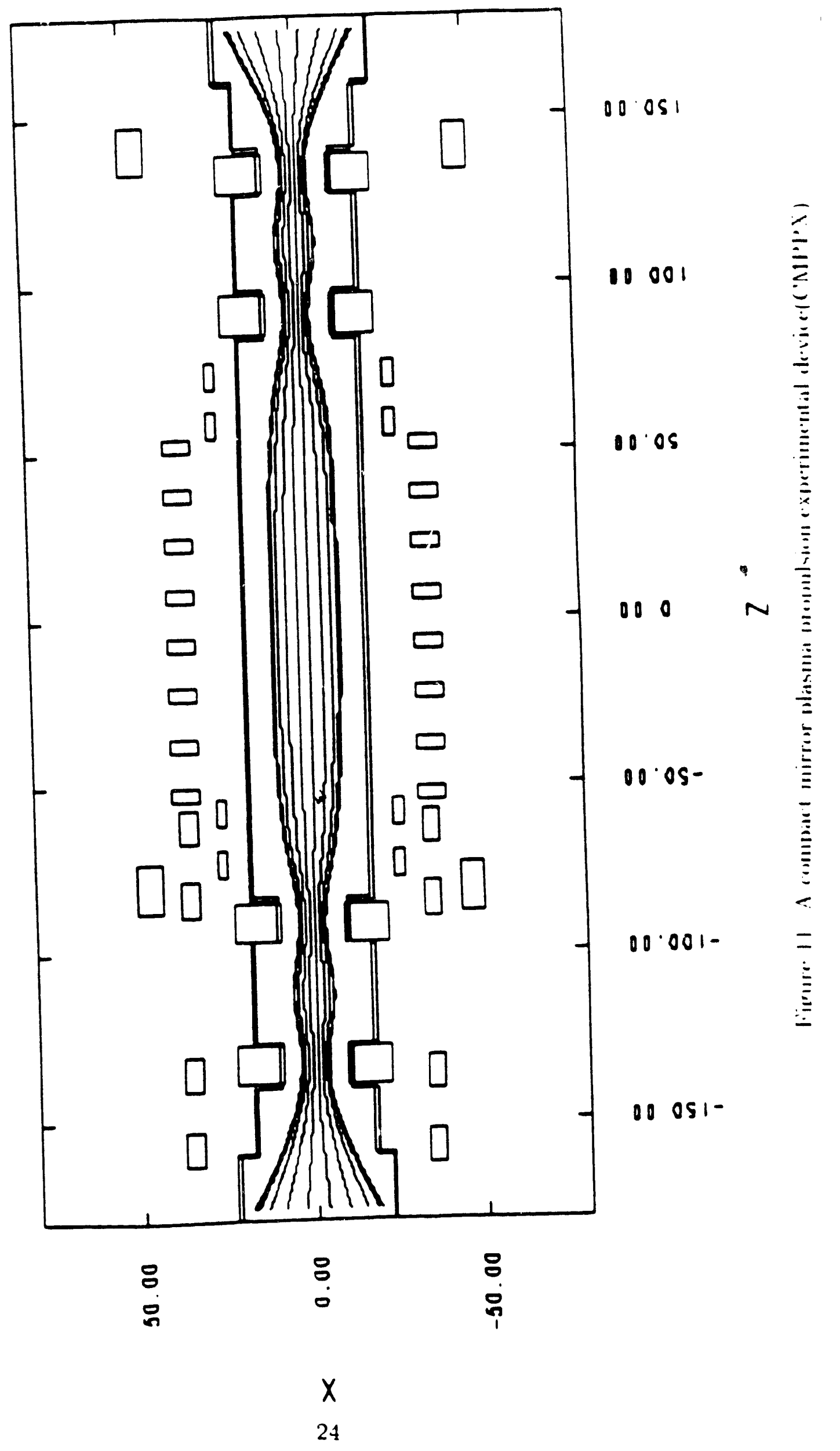




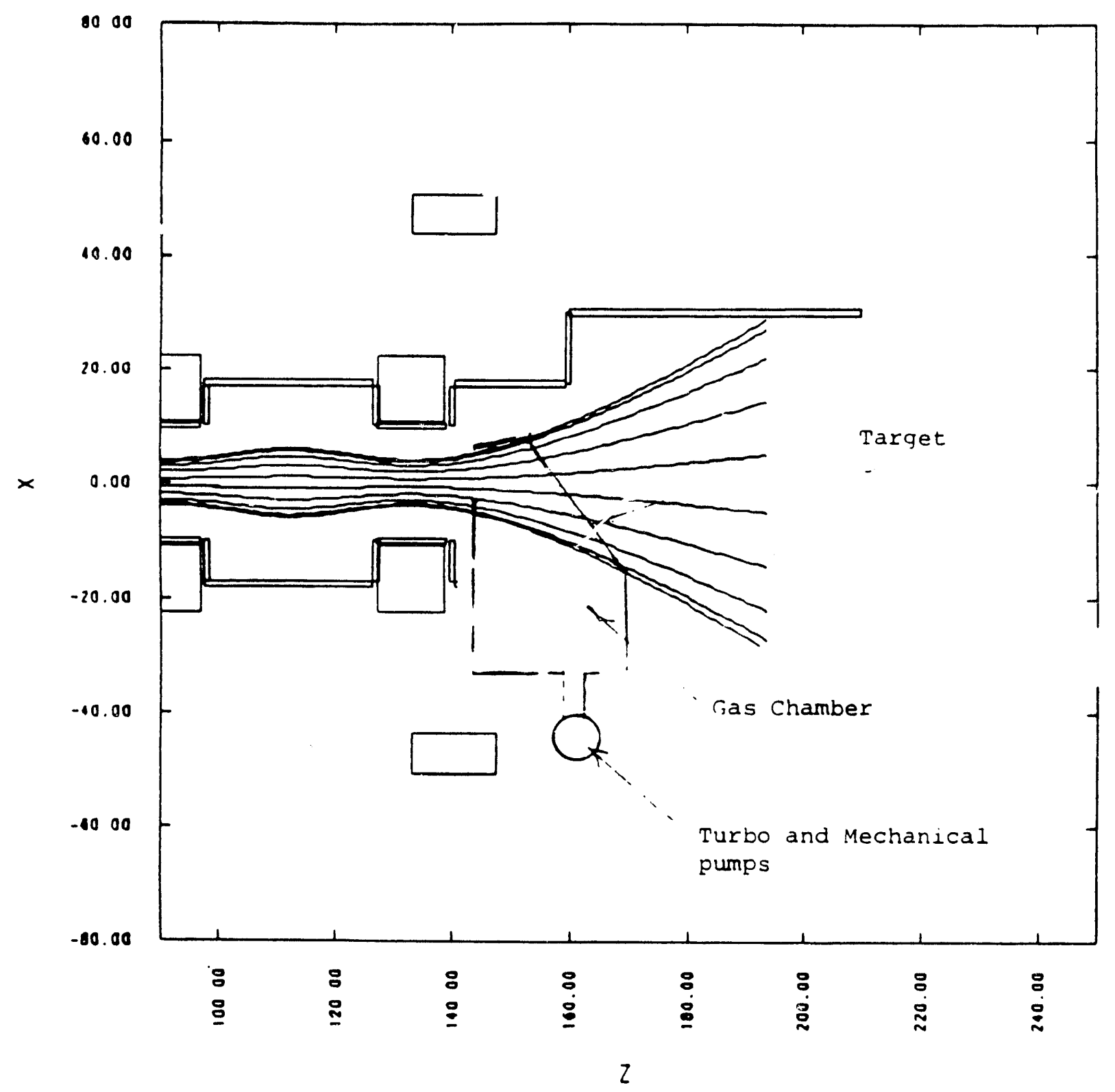

Figure 12. A gas chamber set-up 


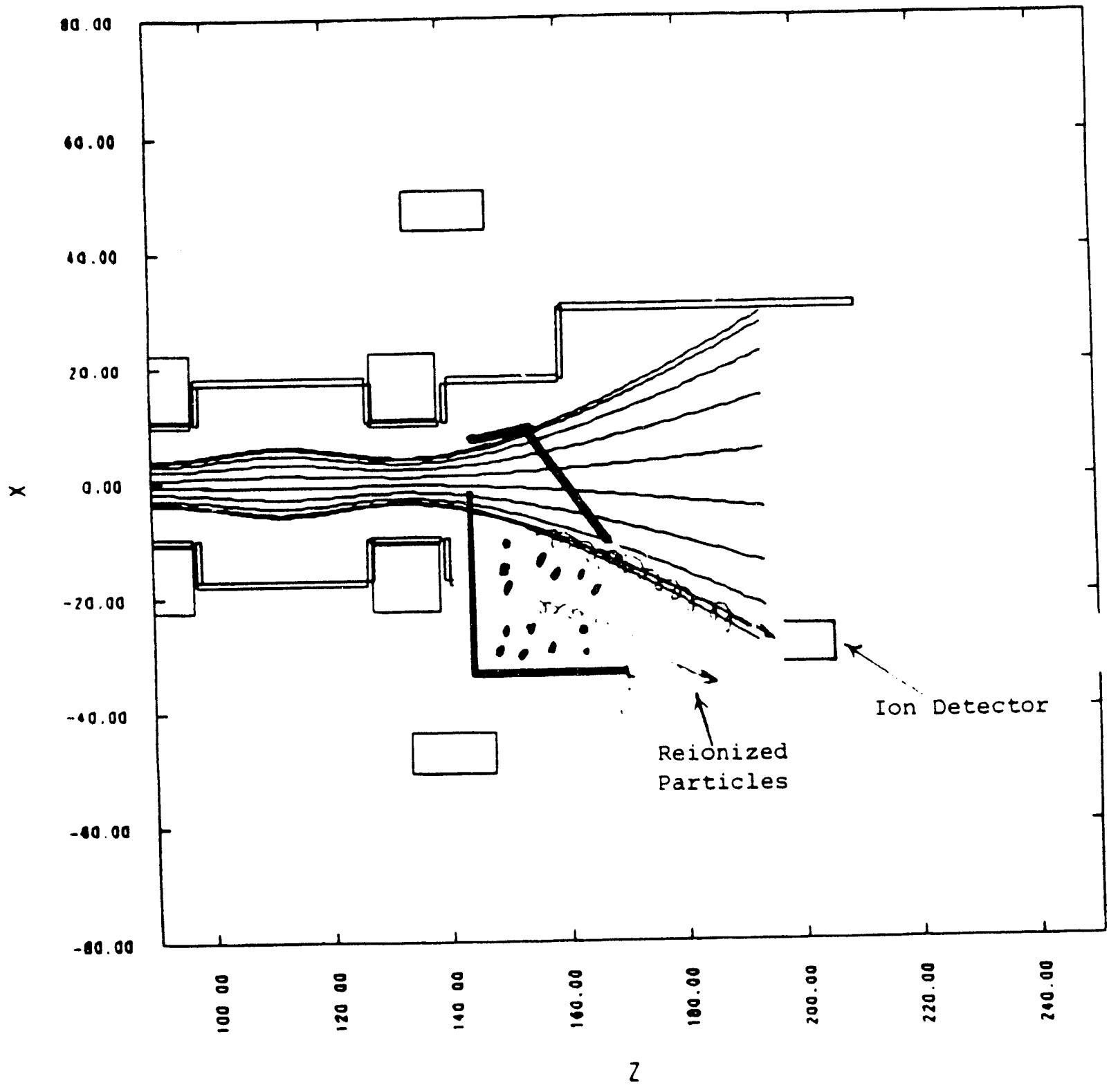

Figure 13. A gas chamber set-up for reionization experiment 


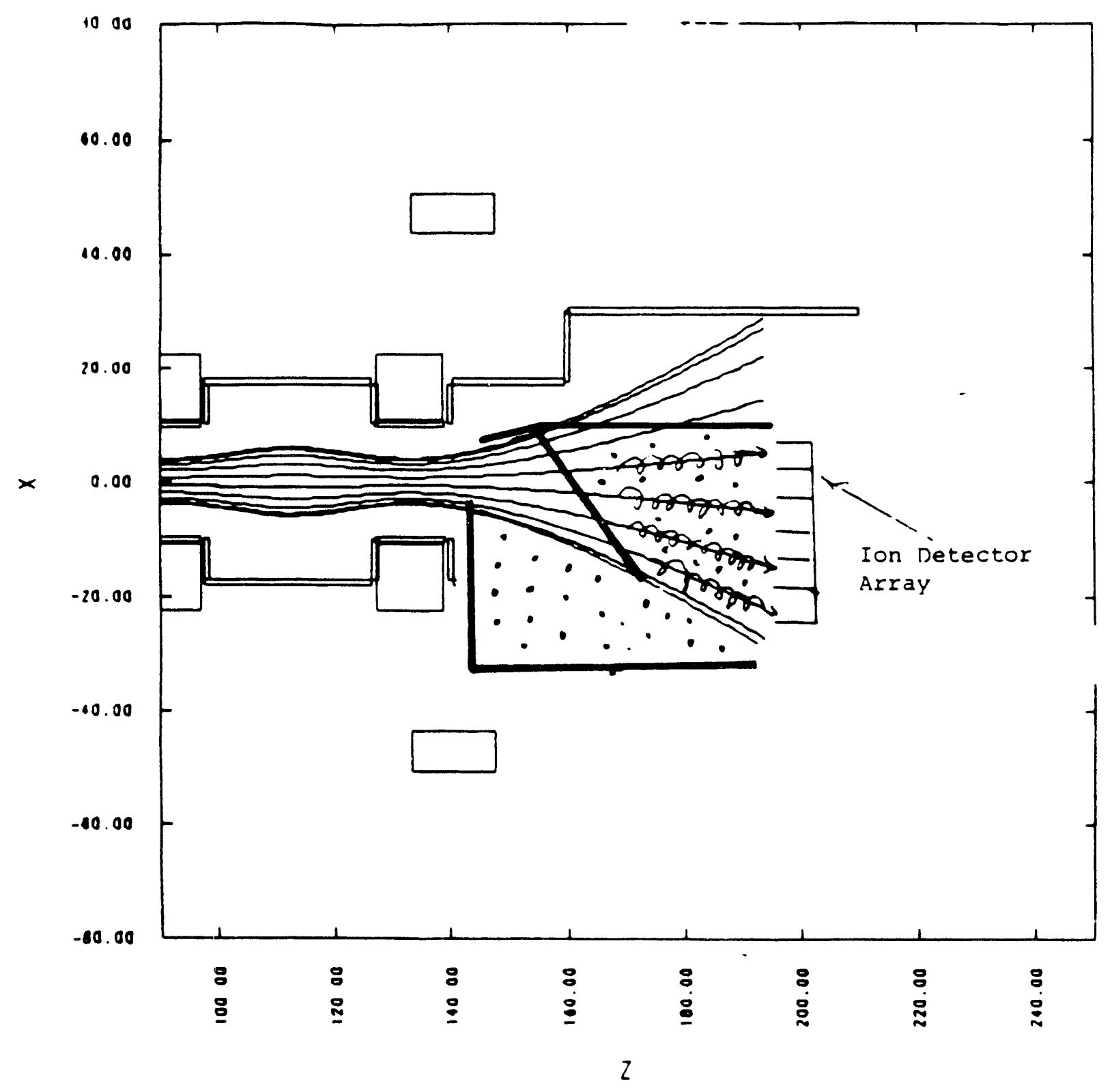

Figure 14. Alternative gas chamber set-up for reionization experient 


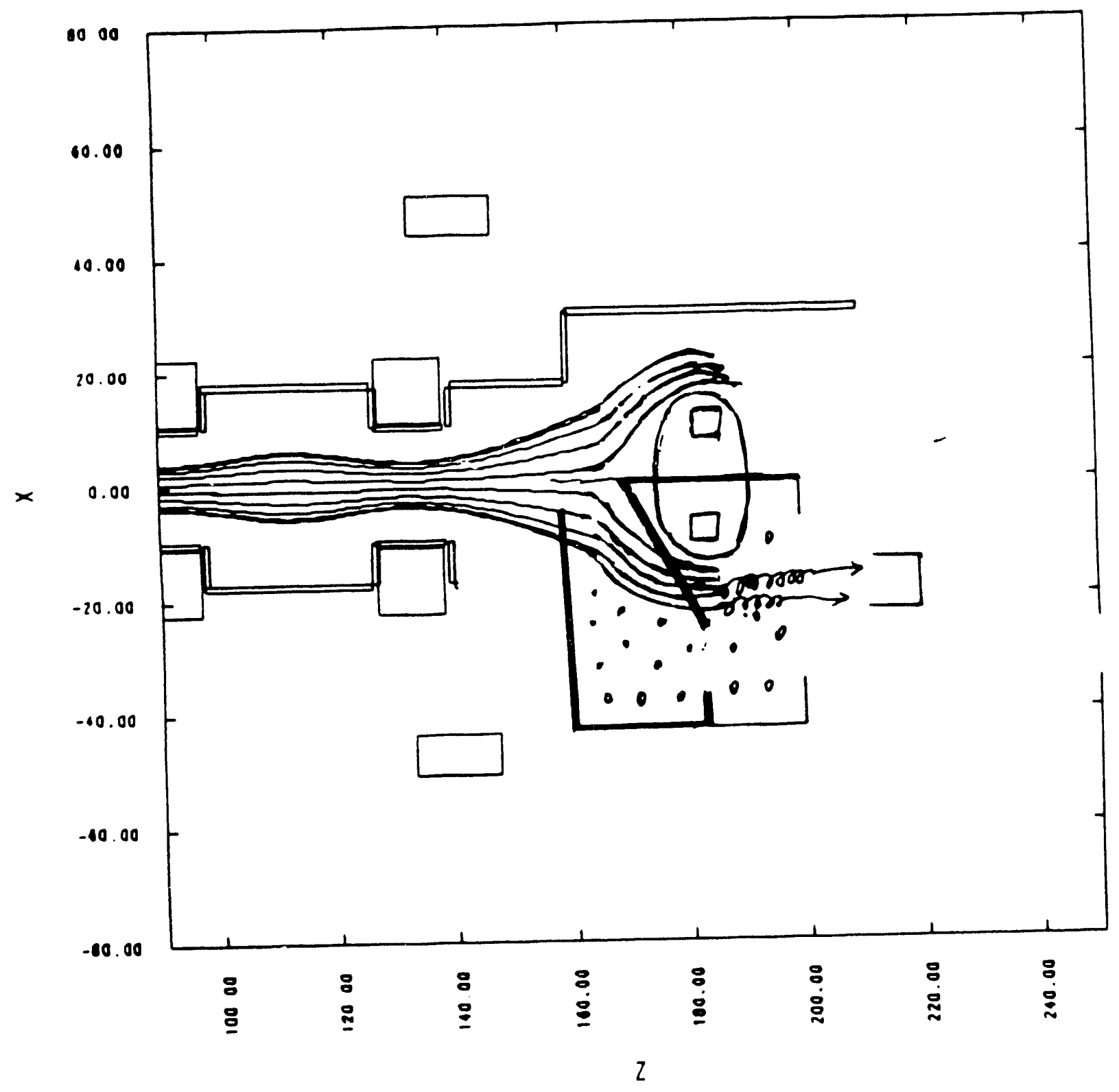

Figure 15. Test of gas chamber in the configuration with magnetic separatrix 
Dr F Paoloni. Univ of Wollongong. AUSTRALIA

Prof MH Brennan. Univ of Sydney, AUSTRALIA

Plasma Research Lab. Australian Nai. Univ. AUSTRALIA

Prof IR Jones. Flinders Univ. AUSTRALIA

Prof F Cap. Inst. for Theoretical Physics. AUSTRIA

Prof M Heindler. Insotut fur Theoretischie Physik. AUSTRIA

Prot M Goossens. Astronomiseh Insvtuut. BELGIUM

Ecole Royale Militare. Lab. de Phy Plasmas, BELGIUM

Commission-European. DG XII-Fusion Prog.. BELGIUM

Prof R. Bouaque. Rijksuniversitert Gent. BELGIUM

Dr. PH. Sakanaka. Instituto Fisica. BRAZIL

Instituto De Pesquisas Espaciais-INPE. BRAZIL

Documents Otfice. Atomic Energy of Canada Lid. CANADA

Dr. M.P Bachynski. MPB Technologies. Inc., CANADA

Dr. H.M. Skarsgard. Univ of Saskatchewan. CANADA

Prot J Terchmann. Univ of Montreal. CANADA

Prof. S.R. Sreonivasan. Univ of Calgary. CANADA

Prof. TW. Johnston. INRS-Energie. CANADA

Dr. A. Bolton. Centre canadien de tusion magnéuque. CANADA

Dr. C R. James., Univ. of Alberta. CANADA

Dr. P Lukac, Komenskeho Universzita. CZECHOSLOVAKIA

The Librarian, Culham Laboratory. ENGLAND

Library, R61. Ruthertord Appleton Laboratory, ENGLAND

Mrs. S.A. Hutchinson, JET Lbrary, ENGLAND

P. Măhonen. Univ. of Helsınki, FINLAND

C Mourtet. Lab. de Physique des Milieux lonisés, france

J. Radet, CEN/CADARACHE - Bat 506, FRANCE

Ms. C. Rinnı. Univ. of loannina. GREECE

Dr. T. Mual, Academy Bibliographic Ser., HONG KONG

Prepnnt Library, Hungarian Academy of Sci. HUNGARY

Dr B. Das Gupta, Saha Inst. of Nudear Physics. INDIA

Dr. P Kaw, Inst. for Plasma Research, INDIA

Dr. P. Rosenau, Israel Inst. of Tochnology. ISRAEL Libranan. Intemational Center for Theo Physics, ITALY

Miss C. De Palo, Associazione EURATOM-ENEA, ITALY

Dr. G. Grosso, Istituto di Fisica del Plasma, ITALY

Dr. H. Yamato, Toshiba Res \& Devel Center. JAPAN

Prof. I. Kawakami, Atomic Energy Res.Inst. JAPAN

Prof. K. Nishikawa, Hiroshima Univ., JAPAN
Director. Japan Atomic Energy Research Inst. JAPAN

Prot S Itoh. Kyushu Univ. JAPAN

Data and Planning Center. Nagoya Univ, JAPAN

Prof S Tanaka, Kyolo Univ, JAPAN

Library, Kyoto Univ. JAPAN

Prof N. Inoue. Univ of Tokyo. JAPAN

S Mon, Technical AdVsगr, JAERI. JAPAN

O Mitara. Kumamoto Inst. of Technology. JAPAN

$H$ Jeong. Korea Advanced Energy Research Inst. KOREA

Prot D.I. Choi. The Korea Adv. Inst. of Sa \& Tech. KOREA

Prof. B.S. Liley, Univ of Waikato. NEW ZEALAND

Inst. of Plasma Physics. PEOPLE'S REPUBLIC OF CHINA

Libranan, Inst. of Physics, PEOPLE'S REPUBLIC OF CHINA

Library, Tsinghua Univ. PEOPLE'S REPUBLIC OF CHINA

Z. L. S.W. Inst Phystes. PEOPLE'S REPUBLIC OF CHINA

Prof J.A.C. Cabra, Insotuto Supenor Teconico. PORTUGAL

Dr O. Petrus, Al. I CuzA Univ. ROMANIA

Or. J. Villiers. Fusion Studies, AEC, S AFRICA

Prof. M.A. Hellberg, Univ. of Natal, S. AFRICA

C.IE.M.A.T. Fusion Division Library, SPAIN

Dr. L. Stenflo, Univ. of UMEA. SWEDEN

Libray, Royal Inst. of Technology, SWEDEN

Prot H. Withelmson, Chalmers Univ. of Tech., SWEDEN

Centre Phys. Des Plasmas, Ecole Polytech. SWITZERLAND

Bibliothook. Inst. Voor Plasma-Fysica. THE NETHERLANDS

M. Durgut. Vico Charman, Middle East Toch. Univ. TURKEY

Dr D.D. Ryutov, Sibenan Branch of Academy of Scl. USSR

Dr. G.A. Eliseev, Kurchatov Inst. USSA

Libranan. The Ukr.SSR Academy of Sciences. USSR

Dr. L.M. Kovrizhnykh, Inst. of General Physics, USSR

Kemtorschungsanlage GmbH, Zenvalbibliothok, W. GERMANY

Bioliothek. Inst. Fïr Plasmaforschung, W. GERMANY

Prof. K. Schindler, Ruhr-Universitat Bochum, W. GERMANY

Dr F Wagner, (ASDEX), Max-Planck-Institut, W. GERMANY

Libranan, Max-Planck-Insutut, W. GERMANY

Prof. R.K. Janev, Inst. of Physics, YUGOSLAVIA 

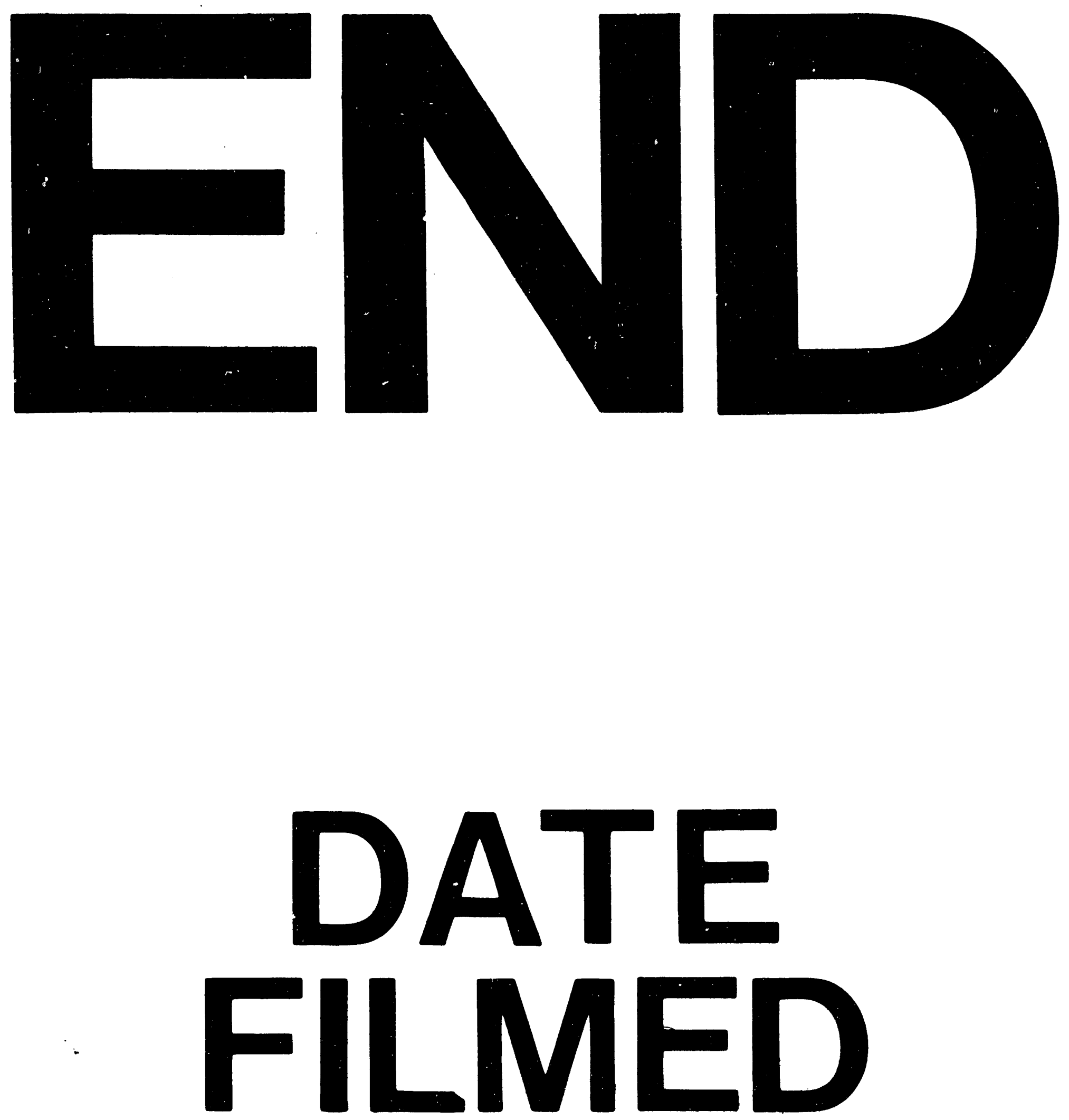

1

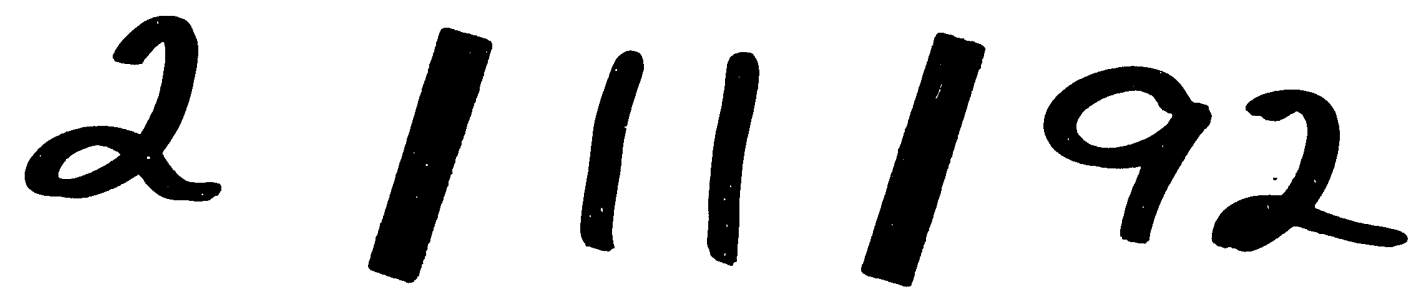


